\title{
IV. Rekrutierung, Ausbildung und Einsatz der neuen Juristen: Die akademische Juristen- ausbildung und die Volksrichterausbildung (1945-1947/48)
}

Das größte Problem des Justizwesens in der SBZ war insbesondere unmittelbar nach 1945 der dramatische Personalmangel. Einer Aufstellung vom 4. Januar 1947 zufolge waren von den insgesamt 16267 vor dem Zusammenbruch in der Justiz Beschäftigten - darunter 2467 Richter und Staatsanwälte - aufgrund der Entnazifizierung 10457 entlassen worden ${ }^{1}$. Zwar wird die Zahl der entlassenen Richter und Staatsanwälte nicht genannt; von den 2467 hatten indes 1968 der NSDAP oder ihren Gliederungen angehört. Aufgrund der strengen Entnazifizierungsvorschriften kann davon ausgegangen werden, daß trotz der Versuche einiger Landesjustizverwaltungen, „belastete“ Volljuristen weiterhin $z u$ beschäftigen, die große Masse dieser 1968 Personen aus dem Justizdienst ausscheiden mußte. $\mathrm{Zu}$ den durch die Entnazifizierung bedingten Personalverlusten kamen Entlassungen aufgrund krimineller und disziplinarischer Vergehen hinzu: Zwischen dem 1. Januar 1946 und dem 10. August 1947 ereigneten sich in der SBZ immerhin 47 derartiger Fälle bei den Richtern und Staatsanwälten ${ }^{2}$. Außerdem wanderten von Anfang 1946 bis November 194748 Richter und Staatsanwälte nach Berlin oder in die westlichen Zonen $\mathrm{ab}^{3}$.

Die von SMAD und SED verfolgte Zielsetzung, gleichzeitig mit der Entnazifizierung den kommunistischen Führungsanspruch durchzusetzen, ließ sich aufgrund des Mangels an geeignetem Personal in der Justiz anfangs nicht umsetzen. Es ging in den Wirren der unmittelbaren Nachkriegszeit zunächst darum, die Funktionsfähigkeit des Justizwesens durch die Einstellung möglichst qualifizierter, nicht belasteter Personen aufrechtzuerhalten. Dazu wurden bereits im Dritten Reich pensionierte oder vorzeitig entlassene Justizjuristen reaktiviert, was indes zu einer Überalterung der Richterschaft führte ${ }^{4}$. Zudem setzten sowjetische Kommandanten im Zuge der Besetzung deutsche "Antifaschisten“ - in der Regel

1 Anlagen zum Schreiben der DJV an die SMAD-Rechtsabteilung, 4. 1. 1947, BAB, DP1 VA Nr. 821, Bl. 17-19.

2 Entsprechende Berichte forderte die DJV am 5./6. 8. 1947 aufgrund einer Weisung Jakupows an, BAB, DP1 VA Nr. 822, Bl. 29, 35-66.

3 Vgl. DJV an SMAD-Rechtsabteilung, 16. 4. 1947, BAB, DP1 VA Nr. 821, Bl. 60f.; Verzeichnis der Richter und Staatsanwälte, die aus der russischen Zone nach Berlin oder den westlichen Zonen abgewandert sind, BAB, DP1 VA Nr. 143, Bl. 1-6 (darunter auch drei wegen angeblicher krimineller Machenschaften).

4 Siehe dazu insbesondere die Aufzeichnungen Benjamins vom November 1945 und April/Mai 1946 in: Wentker, Volksrichter, Dok. 6, S. 106, Dok. 14, 127. 
Kommunisten - als Richter und Staatsanwälte ein, ungeachtet der Tatsache, daß diese nicht die Befähigung zum Richteramt besaßen 5 . Auch als mit der Gründung der Landesverwaltungen die Justiz in geordnetere Verhältnisse zurückkehrte, wurde aufgrund des Personalmangels an dieser Einrichtung festgehalten. Insgesamt waren Anfang Juli 1946 in der SBZ insgesamt 112 Richter und Staatsanwälte "ohne Vorbildung“ tätig: 54 in der Provinz Sachsen, 28 in Brandenburg, 25 Mecklenburg, vier in Sachsen und einer in Thüringen. Unter ihnen befanden sich freilich 48 Personen, die aus dem mittleren Justizdienst oder aus der Polizei stammten oder bei einem Anwalt tätig gewesen waren und somit zumindest begrenzte Rechtskenntnisse aufwiesen ${ }^{6}$. Eine weitere Maßnahme der Landesverwaltungen zur Behebung der personellen Engpässe bestand in der Heranziehung von Rechtsanwälten zum „richterlichen Ehrendienst“. Auch hier sind regionale Unterschiede zu verzeichnen: Anfang April 1947 waren in Sachsen 100 und in Sachsen-Anhalt 51 Rechtsanwälte als Richter und Staatsanwälte tätig, in den anderen Ländern kein einziger ${ }^{7}$. Ein gutes Jahr später, Anfang Mai 1948, gab es insgesamt 250 Rechtsanwälte „im Ehrendienst“, davon 156 in Sachsen, 54 in Sachsen-Anhalt, 33 in Thüringen und sieben in Brandenburg. ${ }^{8}$. Allerdings erhob die DJV bald Einwände gegen diesen Einsatz von Rechtsanwälten, da Anwälte manchmal in ein und derselben Sache als Staatsanwalt oder Richter und als Verteidiger tätig wurden und da diese selbst als "politisch belastet" galten, "politisch belastete“ Hilfsarbeiter aus ihren Büros mit richterlichen Aufgaben betrauten oder diese in ihrer Abwesenheit mit ihrer Vertretung beauftragten ${ }^{9}$. Die Zahl der Rechtsanwälte im Ehrendienst ging zwar im Verlauf der folgenden Jahre zurück; sie lag im März 1950 jedoch immer noch bei 197 . Offiziell beendet wurde deren Tätigkeit als Richter erst Mitte 1949 in Brandenburg, am 30. Juni in Thüringen, am 31. Dezember 1950 in Sachsen-Anhalt und am 31. März 1951 in Sachsen ${ }^{10}$. Schließlich wurden auch Referendare zur Wahrnehmung richterlicher Geschäfte herangezogen: Am 1. März 1947 waren es in Brandenburg und Mecklenburg jeweils drei, in Sachsen-Anhalt zwei, in Sachsen acht und in Thüringen sieben - insgesamt 23 -, die als Richter oder Staatsanwalt fungierten ${ }^{11}$. Der Leiter der Ausbildungsabteilung in der DJV, Hartwig, gab in diesem Zusammenhang zu bedenken, „daß bei längerer Dauer [des Einsatzes] die Ausbildung der Referendare leidet“. Benjamin

5 Vgl. Benjamin u. a., Zur Geschichte der Rechtspflege 1945-1949, S. 42-48, sowie die Erinnerungsberichte von Max Berger, Karl Grünberg, Erich Rochler (in: SAPMO, SgY 30 56, 1116, 773), Alfred Lindert und Erich Skribelka (in: DP1 VA Nr. 6656).

6 Vermerk Winkelmanns, 9. 7. 1946, BAB, DP1 SE Nr. 3474, Bl. 3f. Zum Problem der zahlreichen brandenburgischen Richter im Soforteinsatz vgl. Pohl, Justiz in Brandenburg (Manuskript), S. $27 \mathrm{f}$.

7 Anfrage der DJV vom 15.4. 1947 und Antworten der Landesjustizministerien, BAB, DP1 VA Nr. 811, Bl. 1, 5, 7-9, 11.

8 Vgl. die Aufstellungen der einzelnen Landesjustizministerien vom 5. bzw. 11. 5. 1948, BAB, DP1 VA Nr. 7324. Zur politischen Zusammensetzung siehe Lorenz, Rechtsanwaltschaft in der DDR, S. 66 .

9 Siehe Vermerk Hartwigs, 9. 4. 1948, und Chef der DJV an Landesregierungen/Justizministerium, 28. 4. 1948, BAB, DP1 VA Nr. 811, Bl. 69, 71; Justizaufbau, o.D. [Januar 1948], BAB, DP1 VA Nr. 3, Bl. 140.

$10 \mathrm{Vgl}$. Lorenz, Rechtsanwaltschaft in der DDR, S. 67.

1 DJV an Landesregierungen/Justizministerium, 25.1. 1947, mit der Anfrage, ,in welchem Umfange Referendare mit der Wahrnehmung richterlicher Geschäfte betraut werden“, und die $\mathrm{Zu}$ sammenstellung über die Beantwortung dieser Verfügung, BAB, DP1 VA Nr. 6533. 
stimmte ihm zwar zu, bat aber „zur Zeit von weiteren Schritten abzusehen mit Rücksicht auf den großen Mangel an Richtern und Staatsanwälten"12. Mit all diesen aus der Not geborenen Maßnahmen konnte genügend qualifiziertes Personal jedoch nur in geringem Umfang bereitgestellt werden; sie waren zudem mit zu vielen Nachteilen verbunden, um die Personalknappheit möglichst rasch und effizient beheben zu können.

\section{Die akademische Juristenausbildung}

\section{Reformkonzeptionen für das juristische Studium und das Referendariat (1945/46)}

Vor diesem Hintergrund blieb den Verantwortlichen in der SBZ letztlich nichts anderes übrig, als neue Juristen möglichst rasch auszubilden, um die vakanten Posten besetzen zu können. Dabei setzten zunächst noch alle beteiligten Kräfte auf die herkömmliche deutsche Juristenausbildung. Auch das KPD-Sekretariat dachte hier offensichtlich nicht in revolutionären Bahnen und plädierte lediglich dafür, befähigten Volksschülern den Zugang zur Universität zu ermöglichen und das juristische Studium sowie das Referendariat auf jeweils zwei Jahre zu verkür$z^{2 e n}{ }^{13}$. Die für die Hochschulen verantwortliche Deutsche Zentralverwaltung für Volksbildung (DVV) kooperierte in dieser Frage zunächst eng mit der DJV. So beauftragte sie Vizepräsident Kleikamp im Herbst 1945 mit der Ausarbeitung eines Musterstudienplanes ${ }^{14}$. Die Beratung darüber zeigte, daß Kleikamp und der Jenaer Jurist Richard Lange insbesondere über die Bedeutung der geistes- und gesellschaftswissenschaftlichen Fächer sowie des Praxisbezugs übereinstimmten, der unter anderem durch eine obligatorische "Zwischenpraxis" während des Studiums hergestellt werden sollte ${ }^{15}$. Auch der Leiter der Ausbildungsabteilung in der DJV, Wende, dachte ähnlich. In einer im Auftrag Schiffers angefertigten Ausarbeitung vom Oktober bildete die Ausbildung der Juristen ein zentrales Element, da Vertrauen in die Rechtspflege wesentlich von der Qualität der Richter, Staatsanwälte und Rechtsanwälte abhing. Wende plädierte darin für eine „ausreichende[.] geschichtliche[.] Grundlegung des Studiums“ sowie „eine ausreichende Kenntnis der sozialen Funktion des Rechts" sowie für Ferienpraktika an den Gerichten und Arbeitsgemeinschaften unter der Leitung von pädagogisch begabten Praktikern. Das Schwergewicht im dreijährigen Referendariat wollte er auf die Amtsgerichtsstationen legen, da hier der Anfänger „den leichtesten Überblick

12 Vermerk Hartwigs, 7. 6. 1947, BAB, DP1 VA Nr. 997, Hervorhebung im Original.

13 Zur Frage der Justizreform, 5. 10. 1945, SAPMO, NY 4182/1118, Bl. 63 f. Protokoll der Sekretariatssitzung vom 8. 10. 1945 in: Dokumente zur Geschichte der kommunistischen Bewegung, Bd. 1, S. 104.

14 Dies geht aus einem Vermerk Kleikamps für Melsheimer vom 27. 5. 1946, BAB, DP1 SE Nr. 3478, hervor.

15 An der Beratung, zu der Robert Rompe von der DVV eingeladen hatte, nahmen außerdem Theodor Brugsch (DVV), Rosenthal-Pelldram, Friedrich Zucker (Rektor der Universität Jena) und ein weiterer Proefessor aus Jena teil: siehe Vermerk Kleikamps betr. Studienplan für juristische Fakultäten, 19. 10. 1945, BAB, DP1 VA Nr. 888. Der Studienplan Kleikamps war in den einschlägigen Akten nicht auffindbar. 
über die staatliche Rechtspflege" erhalte, in engen Kontakt mit Wirtschaft und Gesellschaft komme und ihm hier auch die Wirkung richterlicher Arbeit am deutlichsten erfahrbar würde ${ }^{16}$. Kleikamp und Wende gingen also beide von der Konzeption Schiffers aus, in der die Ausbildung der Juristen zwar reformbedürftig war, nicht aber grundsätzlich zur Disposition gestellt werden sollte.

Der stellvertretende Leiter der SMAD-Rechtsabteilung, Professor Mankowski, billigte den Studienplan Kleikamps ${ }^{17}$ und erteilte den beiden Vizepräsidenten der DJV die Weisung, sich um diese Fragen weiterhin zu kümmern ${ }^{18}$. Auch die SMAD-Rechtsabteilung strebte also vorerst keine grundsätzliche Änderung des juristischen Studiums in der SBZ an und war zudem bereit, der DJV eine herausgehobene Rolle in allen Beratungen über die „Ausarbeitung der Lehrprogramme, Lehrpläne und Lehrbücher für die juristischen Fakultäten der Universitäten "19 zuzugestehen. Trotz dieser für Kleikamp und Wende erfreulichen Rückendekkung durch Karlshorst ging es bei der Umsetzung ihrer Reformvorhaben kaum voran. Eine seit Oktober 1945 zu diesem Zweck geplante Konferenz der Dekane der juristischen Fakultäten kam nicht zustande ${ }^{20}$. Außerdem hatte Kleikamp den Eindruck, daß seit Dezember 1945 „das Schwergewicht für die Lenkung des Universitätsunterrichts ganz auf die Zentralverwaltung für Volksbildung “ überging. Ein Indiz dafür war, daß Oberstleutnant Lyssjak die abschließende Gestaltung des von Kleikamp entworfenen Mustervorlesungsplans nach einer Reihe von Besprechungen in der DVV dem Dekan der juristischen Fakultät von Berlin, Eduard Kohlrausch, überließ. Die SMAD-Rechtsabteilung, so Kleikamp im Rückblick, schalte die DJV nur noch bei Bedarf ein, etwa wenn es bei den Vorlesungsplänen der juristischen Fakultäten um schwierige Spezialfragen ging; „zu den politisch grundsätzlichen Fragen des Universitätswesens" werde die DJV jedoch nicht mehr hinzugezogen ${ }^{21}$. Dieser Kurswechsel innerhalb der SMAD ist wahrscheinlich darauf zurückzuführen, daß sich im Kompetenzgerangel die dortige Volksbildungs- gegenüber der Rechtsabteilung 22 durchgesetzt hatte; jedenfalls kamen die Reformvorhaben bezüglich des juristischen Studiums vorerst zum Stillstand.

Demgegenüber waren die Bemühungen der DJV um die Bestätigung der neuen Assessorprüfungsordnung von relativ raschem Erfolg gekrönt. Schiffer drängte unter Verweis auf den bestehenden Richtermangel und das wachsende Bedürfnis unter den Referendaren, ihre Assessorprüfung abzulegen, Ende Dezember 1945 die SMAD-Rechtsabteilung, dem von der DJV eingereichten Entwurf möglichst umgehend zuzustimmen ${ }^{23}$. Die schließlich am 27. Januar 1946 bestätigte „Ordnung der Assessorprüfung für Referendare“ ${ }^{24}$ vom 16. Januar 1946 hielt an der

16 Ausarbeitung Wendes für Schiffer, 24. 10. 1945, BAB, DP1 VA Nr. 7312.

17 Kleikamp an Wende, 9. 11. 1945, BAB, DP1 VA Nr. 888.

18 Vermerk Kleikamps für Melsheimer, 27. 5. 1946, BAB, DP1 SE Nr. 3478.

19 So das Vorläufige Statut der DJV, in: Amos, Justizverwaltung, S. 219.

20 Vgl. die Ausarbeitung Wendes für Schiffer, 24. 10. 1945, DP1 VA Nr. 7312.

21 Vermerk Kleikamps für Melsheimer, 27. 5. 1946, BAB, DP1 SE Nr. 3478.

22 Von solchen Auseinandersetzungen berichtet Nikitin, Sowjetische Militäradministration und die Justiz (Manuskript), S. 10. Die von der DVV überlieferten Akten sind äußerst fragmentarisch und geben dazu keinerlei Aufschluß.

23 Chef der DJV an SMAD-Rechtsabteilung, 29. 12. 1945, BAB, DP1 SE Nr. 461.

24 In: BAB, DP1 VA Nr. 7854. 
dreijährigen Ausbildungsdauer für Referendare fest ${ }^{25}$ und orientierte sich auch sonst in ihren Bestimmungen am GVG. Der allgemeinen unitarischen Tendenz und dem preußischen Vorbild entsprechend, wurde bei der DJV ein Justizprüfungsamt für Referendare eingerichtet, das für die gesamte SBZ zuständig war ${ }^{26}$. Die Reformvorstellungen Schiffers, Wendes und Kleikamps fanden in der Prüfungsordnung ihren sichtbaren Ausdruck. Denn der Referendar sollte nicht nur fachliche Kenntnisse vorweisen, sondern auch zu erkennen geben, „daß er die Bedeutung der sozialen, wirtschaftlichen und gesellschaftlichen Fragen der Gegenwart selbständig so zu beurteilen vermag, wie es den neuen Aufgaben des deutschen Richters entspricht" ( $(4)$. Dazu sollte die vierte Klausur „einen für das Recht wesentlichen Gegenstand aus dem sozialen, wirtschaftlichen oder gesellschaftlichen Leben behandeln" ( $\$ 7$, Absatz 3, Satz 2).

Schiffer wollte mit seiner Assessorprüfungsordnung auch den Bestrebungen einzelner Länder zuvorkommen, eigene Vorschriften zu erlassen und das zweite Examen selbst abzunehmen ${ }^{27}$. Die sächsische Justizabteilung akzeptierte zwar die Prüfungsordnung vom 16. Januar 1946, wollte mit der Prüfung aber ein in Sachsen gebildetes Prüfungsamt betrauen ${ }^{28}$. Mit sowjetischer Rückendeckung wies Schiffer diese Vorstellung zurück und setzte sich damit durch ${ }^{29}$. Sehr viel langwieriger erwies sich die Auseinandersetzung mit Thüringen. Präsident Paul erhob im Januar bei der SMAD Bedenken gegen die Assessorprüfungsordnung; ohne deren Antwort abzuwarten, führte das Oberlandesgericht in Gera im April Assessorprüfungen in eigener Regie durch ${ }^{30}$. Heftige Proteste Wendes veranlaßten Oberlandesgerichtspräsident Barth, angesichts der „Zweifelhaftigkeit der Situation“ von weiteren Zulassungen zum Assessorexamen abzusehen ${ }^{31}$. Paul beharrte jedoch auf der Zuständigkeit des eigenen Landes, so daß am 1. Juli 1946 fünf Referendare in Thüringen ihr zweites Examen ablegten ${ }^{32}$. Erst nach einem erneuten Protest der DJV und weiteren Beratungen zwischen Külz und Paul ${ }^{33}$ lenkte schließlich die thüringische Justizverwaltung am 14. November 1946 ein $^{34}$. Somit waren - trotz Unterstützung durch die SMAD-Rechtsabteilung und Bekräftigung des DJV-Standpunktes auf einer Länderkonferenz am 16. August 1946 durch

25 Auf Antrag konnte das Referendariat auf zwei Jahre verkürzt werden, wenn die „Fähigkeiten und Leistungen den Durchschnitt wesentlich überragen“ oder wenn der Bewerber vor 1945 wegen politischer Einstellung oder Rasse nur zwei Jahre im Referendardienst verbracht hatte: vgl. Verordnung zur Assessorprüfung betr. Referendare mit abgekürzter Ausbildung, in: BAB, DP1 VA Nr. 7480 .

26 Die am 29. 5. 1946 ernannten Mitglieder des Justizprüfungsamtes setzten sich aus Angestellten der DJV, Mitgliedern des Berliner Justizdienstes, Universitätsprofessoren und auswärtigen Mitgliedern zusammen. Präsident des Prüfungsamtes war Wende: BAB, DP1 VA Nr. 1030.

27 Chef der DJV an SMAD-Rechtsabteilung, 29. 12. 1945, BAB, DP1 SE Nr. 461.

28 Landesverwaltung Sachsen/Abt. Justiz an DJV, 29. 5. 1946, ebenda.

29 Chef der DJV an Landesverwaltung Sachsen/Abt. Justiz, 2.7. 1946; Chef der DJV an SMADRechtsabteilung, 2. 7. 1946; SMAD-Rechtsabteilung an Chef der DJV, 31. 7. 1946; eine Abschrift dieses Schreibens ging am 7. 8. 1946 an alle Landesverwaltungen, ebenda.

30 Vermerk Wendes, 13. 4. 1946, ebenda.

31 Barth an DJV, 10. 4. 1946, ebenda.

32 Barth an DJV, 18. 9. 1946, ebenda.

33 Chef der DJV an Landesamt für Justiz, Thüringen, 28. 9. 1946; Landesamt für Justiz, Thüringen, an DJV, 11.10.1946, ebenda.

34 Landesamt für Justiz, Thüringen, an DJV, 14. 11. 1946, ebenda. 
Melsheimer ${ }^{35}$ - zehn Monate vergangen, bis sich ihre Assessorprüfungsordnung allgemein durchgesetzt hatte.

Im Unterschied zur Assessorprüfungsordnung war die Referendarprüfungsordnung nicht von der DJV allein ausgearbeitet, sondern im Entwurf am 6. Dezember 1945 mit den Dekanen der fünf juristischen Fakultäten und der DVV beraten worden ${ }^{36}$. Nach weiteren, DJV-intern vorgenommenen Änderungen unterbreitete Schiffer die neue Prüfungsordnung am 12. April 1946 der SMAD-Rechtsabteilung zur Bestätigung ${ }^{37}$, die aber erst acht Monate später erfolgte. Die „Ordnung der Referendarprüfung und der Ausbildung der Gerichtsreferendare" vom 16. Dezember 1946 war zudem umgearbeitet worden ${ }^{38}$. Eine der zentralen Abweichungen der eingereichten ${ }^{39}$ von der bestätigten Fassung betraf die Ernennung zum Gerichtsreferendar: War ursprünglich nur das Bestehen der Referendarprüfung als Voraussetzung genannt worden, so schloß die Version vom Dezember 1946 NSDAP-Mitglieder und „aktive Mitglieder und Leiter faschistischer Organisationen“, Personen, die „unmittelbar an der Strafpraxis und Politik“ des Hitlerregimes teilgenommen hatten, Kriegsverbrecher und Vorbestrafte ausdrücklich von der Ernennung aus $(\mathbb{S} 1)$. Außerdem wurden nicht, wie von der DJV vorgesehen, die Oberlandesgerichte, sondern die Landesjustizverwaltungen mit der Aufsicht über die Referendarprüfung und die Durchführung des Referendariats betraut $^{40}$. Der Reformansatz der DJV hatte sich unter anderem in $\$ 1$ der eingereichten Fassung niedergeschlagen: „In der Prüfung soll festgestellt werden, ob der Bewerber nach seiner allgemeinen Bildung, seinem fachlichen Wissen und seinem Verständnis für die sozialen und wirtschaftlichen Fragen der Gegenwart für den Vorbereitungsdienst als Referendar geeignet ist." Dieser Passus erhielt in dem von Karlshorst bestätigten Wortlaut eine spezifizierte Form: „Zweck der Referendarprüfung ist, festzustellen, inwieweit der Bewerber um die Anstellung als Gerichtsreferendar auf dem Gebiet des Rechts vorbereitet ist, die sich aus den demokratischen Reformen ergebenden sozialen und wirtschaftlichen Aufgaben versteht und hiernach für die Ausübung der Rechtsprechung tauglich erscheint." Diese Formulierung konnte zwar in einem marxistischen Sinne ausgelegt werden, war jedoch ebenfalls mit dem Reformansatz Schiffers vereinbar. Der Verbindung von Studium und juristischer Praxis - eine weitere Reformforderung der DJV - hatte man dadurch Rechnung getragen, daß ein zweimonatiges Praktikum bei einem Amtsgericht vorgeschrieben wurde $(\$ 9)$. Im Hinblick auf die Prüfungsfächer, die alle-

35 Protokoll über die Konferenz mit den Vertretern der Justizabteilungen der Landes- und Provinzialregierungen am 16. 8. 1946, BAB, DP1 VA Nr. 22, Bl. 47.

36 Im Nachtrag vom 10.12. 1945 zu seinem ersten Entwurf der Referendarprüfungsordnung (8.11. 1945) bezieht sich Wende auf die „Besprechung mit den Dekanen von fünf juristischen Fakultäten am 6. d. Mts. in der Zentrale für Volksbildung", BAB, DP1 VA Nr. 1000; vgl. auch Aktennotiz Abendroths, 20. 3. 1947, ebenda.

37 Chef der DJV an SMAD-Rechtsabteilung, 12.4. 1946, ebenda.

38 Ordnung der Referendarprüfung und der Ausbildung der Gerichtsreferendare und Aktennotiz Abendroths, 20. 3. 1947, ebenda.

39 Diese Fassung der Prüfungsordnung wurde am 5. 4. 1946 von Wende abgezeichnet, ebenda.

40 Auf der Länderkonferenz vom 12. 8. 1946 hatten alle Ländervertreter dafür plädiert, die Ausbildung der Referendare den Justizabteilungen zu übertragen: siehe Protokoll über die Konferenz mit den Vertretern der Justizabteilungen der Landes- und Provinzialregierungen am 16. 8. 1946, BAB, DP1 VA Nr. 22, Bl. 47. 
samt dem gängigen juristischen Kanon entstammten, und die Aufteilung der Referendarzeit folgte die bestätigte Prüfungsordnung dem von der DJV eingereichten Entwurf. Die sich aus der Assessor- und Referendarprüfungsordnung ergebende traditionelle juristische Ausbildungsordnung war daher zwar in reformerischer Absicht ergänzt $t^{41}$, in ihren Grundzügen freilich unverändert gelassen wor$\operatorname{den}^{42}$.

\section{Der Versuch eines Reformkurses (1946-1947/48)}

Erst am 12. Februar 1947, als auf einer Tagung der Dekane der juristischen Fakultäten in Halle ein Studienplanentwurf der DVV beraten wurde, kam eine entsprechende Diskussion wieder in Gang. DJV-Vizepräsident Melsheimer bemängelte am DVV-Entwurf vom 12. September $1946^{43}$, den er als "reichlich unmodern“ bezeichnete, das Fehlen von volkswirtschaftlichen Vorlesungen ebenso wie Sondervorlesungen zu neueren Gesetzesproblemen wie dem „Recht der Bodenreform und der Bauern“, zur „Gesetzgebung des Kontrollrats“, zur „neue[n] deutsche[n] Verfassungsentwicklung “ und zum „Kreis- und Gemeinderecht“" ${ }^{\text {"4. }}$. Der Leiter der DVV-Hochschulabteilung Rompe machte sich die Einwände Melsheimers zu eigen und regte die Überarbeitung des Studienplans in Zusammenarbeit mit der DJV an ${ }^{45}$. Kontakte zwischen beiden Zentralverwaltungen in dieser Angelegenheit, bei denen die DJV durch Wolfgang Abendroth ${ }^{46}$ vertreten wurde, sind jedoch erst für Juli überliefert. Nach einer ersten Sitzung am 15. Juli ${ }^{47}$, wurde drei Tage später Einvernehmen darüber hergestellt, daß die Lehrpläne um Pflichtvorlesungen zu Volkswirtschaftslehre und Volkswirtschaftspolitik ergänzt werden müßten. Zusätzlich sollten die fakultativen Vorlesungen über Freiwillige Gerichtsbarkeit und Grundzüge des Kirchenrechts verpflichtend gemacht und eine Darstellung des Besatzungsrechts, des Rechts der staatseigenen Betriebe und des Rechts der Bodenreform in den Lehrplan einbezogen werden. Auch über die Vorlesungen zur Einführung in die Rechtswissenschaft, zur Rechtsphilosophie und Rechtssoziologie wurde diskutiert und immerhin „erwogen“, den dialektischen und historischen Materialismus in die beiden Pflichtvorlesungen als obligatorisch einzubeziehen ${ }^{48}$. Am 23. Juli wurde bei einer erneuten Zusammenkunft ein auf dieser Grundlage beruhender Studienplan gebilligt, der fünf Tage später seine end-

41 Daraus ergab sich als konkrete Schlußfolgerung eine Ergänzung der Prüfungsfächer um die Grundzüge der Volkswirtschaft: siehe Chef der DJV an Landesregierungen/Justizministerium, 25. 8. 1947, BAB, DP1 VA Nr. 1000 .

$42 \mathrm{Vgl}$. Abendroth, Ausbildungs- und Prüfungsordnungen, S. 140.

43 Lehrplan der Juristischen Fakultät, 12. 9. 1946, BAB, DR2 Nr. 179, Bl. 21.

44 Bericht über die Rechtswissenschaftliche Tagung in Halle am 12. 2. 1947, SAPMO, NY 4182/1120, Bl. 29-32, hier 31.

45 Rompe an DJV, 27. 2. 1947, ebenda, Bl. 28. Dieser wollte auch Vorlesungen über Finanzwissenschaft und das Recht der UdSSR.

46 Abendroth hatte seit Dezember 1946 für das Justizministerium in Potsdam und in der Hochschulabteilung der DVV gearbeitet, Lebenslauf Abendroth, BAB, DP1 VA Nr. 1025, Bl. 39; seit dem 1.7. 1947 war er in der DJV als Oberjustizrat der Abteilung VI zugeteilt, Verfügung Schiffers, 1. 7. 1947, BAB, DP1 SE Nr. 3596, Bl. 1002.

47 Vermerk Abendroths über die Sitzung in der DVV, 15. 7. 1947, BAB, DP1 VA Nr. 1000.

48 Notiz betreffend juristische Studienpläne und Referendar-Prüfungsordnung, 21. 7. 1947, ebenda. 
gültige Fassung erhielt ${ }^{49}$. Am 23. September schließlich einigten sich auch die Dekane der fünf juristischen Fakultäten auf diesen Lehrplan, der, wie die Teilnehmer betonten, den Studenten nicht vorschrieb, wann sie welche Veranstaltungen zu belegen hatten, diese aber in verpflichtende und fakultative aufteilte ${ }^{50}$. Der traditionelle Fächerkanon wurde insbesondere nach entsprechenden Forderungen Melsheimers um aktuelle Stoffe wie Bodenreformrecht und Besatzungsrecht erweitert, deren Beherrschung für einen Justizjuristen unabdingbar war. Die Aufnahme von Volkswirtschaftslehre und Volkswirtschaftspolitik in die Vorlesungen erfüllte hingegen eine der Reformforderungen Schiffers, der Recht und Wirtschaft enger aufeinander bezogen sehen wollte. Auf eine Erweiterung des Lehrplans im Sinne der SED deutete hin, daß im Rahmen der Einführung in die Rechtsphilosophie auch der dialektische, und in Philosophiegeschichte der historische Materialismus mit behandelt werden mußte. Zudem war die Anregung Rompes aufgegriffen worden, als fakultative Vorlesung eine „Einführung in das sowjetische Rechtssystem" zu geben. Dabei handelte es sich jedoch um nicht mehr als einige rote Farbtupfer in einem im großen und ganzen noch sehr traditionell gehaltenen Studienplan.

Von zentraler Bedeutung für die Reformvorhaben der DJV waren auch ihre Aufsichtsrechte und Kontrollmöglichkeiten über die juristischen Fakultäten. Trotz der sowjetischen Tendenz, das Jura-Studium primär zu einer Angelegenheit der DVV zu machen, wollte zumindest die SMAD-Rechtsabteilung die DJV „in verstärktem Maße" mit der Aufsicht über die universitäre Juristenausbildung befassen. Oberstleutnant Lyssjak nannte in diesem Zusammenhang Universitätsbesuche durch DJV-Angehörige, die Nachprüfung der Vorlesungsverzeichnisse und die Orientierung über Zusammensetzung und Einstellung der Studentenschaft sowie über Lehrstuhlbesetzungen und die Persönlichkeiten der Professoren ${ }^{51}$. In seinem Bestreben, den Einfluß der DJV auf die Universitäten auszuweiten, ließ Kleikamp daraufhin sofort Kontakt zur DVV aufnehmen ${ }^{52}$. Die reagierte positiv auf den Wunsch der DJV, zum Zweck der Aufsicht „eine unmittelbare Fühlung mit den juristischen Fakultäten herzustellen“, und versprach, die Justizverwaltung durch Mitteilung der vorliegenden Personallisten, Lehrpläne und Vorlesungsverzeichnisse zu unterstützen ${ }^{53}$. Eine entsprechende Rundverfügung der DJV vom 4. Juli 1946 an die Präsidenten der Länder und Provinzen und an die Dekane der rechts- und staatswissenschaftlichen Fakultäten stieß indes nicht überall auf Zustimmung ${ }^{54}$. Der Dekan in Jena, Arwed Blomeyer, bat, von Vorlesungsbesuchen abzusehen, da damit „der Anschein einer Überwachung geweckt werden [könnte]“. Und er fügte hinzu: „Zu den demokratischen Errungenschaf-

49 Vermerk Hartwigs, 23. 7. 1947, ebenda; Lehrplan der Juristischen Fakultät, 28. 7. 1947, DR2 Nr. 4688, Bl. 21.

so Abendroth, Konferenz, S. 362 (dort auch der Studienplan).

51 Aktenvermerk Kleikamps über Unterredung mit Lyssjak am 16. 5. 1946, 16. 5. 1946, BAB, DP1 SE Nr. 3478.

52 Vermerk Kleikamps für Melsheimer, 27. 5. 1946, BAB, DP1 SE Nr. 3478; Wende an Kleikamp, 17. 5. 1946, über eine Unterredung mit Rompe, ebenda.

53 DJV an DVV, 31. 5. 1946; DVV, Abt. f. Hochschulen u. Wissenschaft, an DJV, 18. 6. 1946, ebenda.

54 DJV an Präsidenten der Landes- und Provinzialverwaltungen, 4. 7. 1947; DJV an Dekane der Rechts- und Staatswissenschaftlichen Fakultäten in der sowjetischen Besatzungszone, 4.7. 1947, ebenda. 
ten, die mit der Befreiung von der Naziherrschaft erreicht worden sind, gehört auch die Wiedergewinnung der akademischen Freiheit." ${ }^{55}$ Hindernisse gegen ein umfassendes Kontrollrecht der DJV waren daher auch auf das Bedürfnis der Universitäten nach der Erhaltung ihrer wiedergewonnenen Autonomie zurückzuführen. Die DJV nahm dennoch ihr Aufsichtsrecht wahr, wenngleich sie sich vor entsprechenden Besuchen der Zustimmung der Fakultät und der Hochschulabteilung des zuständigen Volksbildungsministeriums versicherte ${ }^{56}$.

Wenn die DJV ihre Reformvorhaben vorantreiben wollte, mußte sich ihr Einfluß an den juristischen Fakultäten auch auf die Zusammensetzung des Lehrkörpers erstrecken. Kaum eine Disziplin mußte nach 1945 einen ähnlich hohen Verlust an Hochschullehrern verkraften wie die Rechtswissenschaft. Aufgrund von Entnazifizierung, "Westflucht“, Tod und Gefangenschaft waren von 117 Professoren und Dozenten, die im Wintersemester 1944/45 an den juristischen Fakultäten der Universitäten Rostock, Greifswald, Berlin, Halle, Leipzig und Jena gelehrt hatten, im Sommersemester 1947 nur noch neun Ordinarien und ein Emeritus übriggeblieben ${ }^{57}$. Kleikamp versuchte vergeblich, bei den 1946 anstehenden Neuberufungen der Berliner Fakultät mitzuwirken. Sowohl sein Protest gegen die Professoren Hermann Dersch (Arbeitsrecht) und Walter Erbe als auch seine Anregungen, „dem Lehrkörper frisches Blut aus der Praxis zuzuführen“, waren erfolg$\operatorname{los}^{58}$. Dennoch hielt Schiffer „die Herstellung engerer Beziehungen zwischen den juristischen Fakultäten und der Justizverwaltung " für eine zentrale Aufgabe bei der Reform des Jura-Studiums, um den Bezug zur Praxis zu intensivieren. Dazu regte Hartwig im Februar 1947 an, einerseits Professoren zu Richtern zu bestellen und andererseits an den Fakultäten Lehraufträge an Praktiker zu erteilen ${ }^{59}$. Auch die Volksbildungsverwaltungen der Länder griffen angesichts der Personalnot an den Fakultäten auf dieses Mittel zurück, so daß zunächst keine weiteren Anregungen der DJV erfolgten. Erst am 5. Januar 1948 ergriff DJV-Vizepräsident Melsheimer in dieser Sache erneut die Initiative. Er wollte damit nicht primär dem mangelnden Praxisbezug des juristischen Studiums abhelfen, sondern vor allem für "die nach dem Zusammenbruch des Dritten Reiches entstandenen Rechtsgebiete“ (wie Recht der Bodenreform, Besatzungsrecht usw.) Lehrkräfte gewinnen ${ }^{60}$. Am 29. Januar wurde eine entsprechende Rundverfügung an die Landesjustizministerien versandt ${ }^{61}$, und die SMAD-Rechtsabteilung begrüßte die Anregung der DJV62. Auch bei der DVV und bei den Ländervertretern stieß das Anliegen auf Zustimmung ${ }^{63}$, so daß die DJV am 22. März in einer erneuten Rundverfügung die

55 Dekan der Rechts- und Wirtschaftswissenschaftlichen Fakultät an Chef der DJV, 22. 8. 1946, ebenda.

56 Siehe den Bericht Hartwigs und Abendroths über den Besuch der Leipziger Juristen-Fakultät am 15. und 16. 7. 1947, 18. 7. 1947, BAB, DP1 SE Nr. 3553.

57 Vgl. Jessen, Kämpfer der Arbeiterklasse, S. 77. Zur Entnazifizierung der Hochschullehrerschaft insgesamt Müller/Müller, Festung Wissenschaft, S. 62 f.; Jessen, Professoren, S. 226.

58 Vermerk Kleikamps für Melsheimer, 27. 5. 1946, BAB, DP1 SE Nr. 3478.

59 Hartwig an Benjamin, 6. 2. 1947, BAB DP1 SE Nr. 3559.

60 Vermerk Hartwigs betr. Unterricht an den juristischen Fakultäten, 7.1. 1948, BAB, DP1 SE Nr. 3551.

61 DJV an Landesregierungen/Justizministerium, 29. 1. 1948, ebenda.

62 Vermerk Langes über eine Mitteilung Jakupows vom 16. 2. 1948, 16. 2. 1948, ebenda.

63 Chef der DJV an DVV, 25. 2. 1948, Disposition des Referats von Abendroth zum Referat über die 
Landesjustizministerien $\mathrm{zu}$ ersten konkreten Schritten in dieser Angelegenheit aufforderte ${ }^{64}$. Nach den erforderlichen Besprechungen zwischen Justizministerium, Volksbildungsministerium und den juristischen Fakultäten wurden daraufhin Praktiker aus der Verwaltung, aus den Gerichten und aus der Anwaltschaft zum Wintersemester 1948/49 zum Unterricht an den juristischen Fakultäten hinzugezogen ${ }^{65}$. Die Namen, die der DJV mitgeteilt wurden, stießen dort freilich nicht immer auf Zustimmung. Benjamin bemängelte an den Vorschlägen aus Dresden, daß die Kräfte zu alt, durch NSDAP-Mitgliedschaft oder -Anwartschaft belastet, konservativ-reaktionär seien oder einfach nicht als „Vertreter fortschrittlicher Rechtswissenschaft“ gelten könnten. „Mir scheint“, so faßte sie ihre Kritik zusammen, „daß vom Justizministerium des Landes Sachsen wie auch von dem Volksbildungsministerium der Zweck, der mit dem Einsatz von Praktikern verfolgt wird, nämlich durch den Einsatz fortschrittlicher Praktiker die Universitäten in ihrer noch nicht überwiegend fortschrittlichen Lehre und Haltung aufzulokkern, nicht voll erkannt worden ist. "66 Im Windschatten der Reformbestrebungen Schiffers verfolgten die Kommunisten in der DJV sehr viel weitergehende Ziele. Ihre Reformvorstellungen hinsichtlich des juristischen Hochschulstudiums liefen langfristig auf eine völlige Neuordnung der Inhalte sowie eine linientreue Hochschullehrerschaft hinaus; da kurzfristig ein Austausch der Professorenschaft mangels kommunistischer Juristen mit der erforderlichen Qualifikation nicht erreichbar war, mußten wenigstens die hinzugezogenen Praktiker den politischen und ideologischen Anforderungen genügen. Dies dürfte bei den im Wintersemester 1948/49 tätigen Praktikern wohl kaum durchgehend der Fall gewesen sein ${ }^{67}$.

Die Referendarprüfungsordnung blieb 1947 und 1948 im wesentlichen unverändert. Mittels Rundverfügung vom 25. August 1947 wurde die Anzahl der Prüfungsfächer - der Reformperspektive Schiffers entsprechend - auf „Fragen der allgemeinen Bildung" und "Grundzüge der Rechtsgeschichte" erweitert. Der Prüfling sollte zudem zeigen, „daß er Verständnis für die soziale, wirtschaftliche und politische Bedeutung der Rechtsnormen gewonnen" habe - eine Forderung, aus der jedoch lediglich abgeleitet wurde, daß auch „die Grundzüge der Volkswirtschaft" geprüft werden sollten ${ }^{68}$. Auf den ersten Blick erscheint eine weitere, den Landesjustizministerien am 24. Mai 1948 mitgeteilte Ergänzung der Referendarprüfungsordnung eher nebensächlich: Das für Jura-Studenten vorgeschriebene Praktikum durfte nun erst nach dem vierten Semester absolviert werden ${ }^{69}$. Diese

Heranziehung von Praktikern zum Unterricht an den juristischen Fakultäten, ebenda. Das Protokoll der Länderkonferenz vom 12. 3. 1948, BAB, DP1 VA Nr. 6958, ist unvollständig, nicht aber der Bericht aus der DVdI vom 16. 3. 1948, BStU, MfS AS 230/66, Bd. 1, Bl. 49-55, hier $54 \mathrm{f}$. Die Zustimmung der Ländervertreter geht aus der Rundverfügung vom 22. 3. 1948 hervor.

${ }_{64}$ Chef der DJV an Landesregierungen/Justizministerium, 22. 3. 1948, BAB, DP1 SE Nr. 3551.

65 Mit Rundverfügung vom 27. 5. 1948 hatte die DJV um Namen und Fachgebiete der ins Auge gefaßten und bereits tätigen Praktiker gebeten; eine erste Liste mit Namen wurde in der DJV am 9.7. 1948 zusammengestellt, ebenda.

66 Benjamin an Abteilung VI, 17. 9. 1948, ebenda; sie bezog sich auf eine am 9. 9. 1948 übermittelte Liste des Justizministeriums in Dresden, ebenda.

67 Vgl. die am 22. 9. 1948 der SMAD-Rechtsabteilung übermittelte Liste aller Praktiker des Wintersemesters $1948 / 49$, ebenda.

68 Chef der DJV an Landesregierungen/Justizministerium, 25. 8. 1947, BAB, DP1 VA Nr. 1000.

69 Chef der DJV an Landesregierungen/Justizministerium, 24. 5. 1948, ebenda. 
Bestimmung ist in zweierlei Hinsicht bemerkenswert: Zum einen kann sie auf eine direkte Anordnung Jakupows zurückgeführt werden, und zum anderen entsprach diese Regelung der Praxis in der Sowjetunion ${ }^{70}$. Die SMAD-Rechtsabteilung gab somit ihre bisherige Zurückhaltung hinsichtlich der Gestaltung des Jurastudiums auf und scheute sich nicht, in Einzelfällen eine Annäherung an sowjetische Verhältnisse anzustreben. Vor diesem Hintergrund wurde die Realisierung des Reformkurses der DJV zumindest erschwert.

Ganz anders verhielt sich die SMAD-Rechtsabteilung noch 1946 im Hinblick auf die Referendarausbildung. Nikolajew schlug Schiffer am 17. Mai vor, angesichts des Richtermangels die dreijährige Referendarausbildung "wenigstens für die Referendare, die besondere Begabung an den Tag gelegt haben", zu verkürzen, akzeptierte aber dessen Zurückweisung seiner Anregung ${ }^{71}$. Auch das Vorhaben des thüringischen Justizministers vom August 1947, dem Landtag ein Gesetz „zur vorübergehenden Abkürzung der juristischen Ausbildung " vorzulegen, konnte Schiffer unter Verweis auf die von der SMAD bestätigte Referendarprüfungsordnung vom 16. Dezember 1946 verhindern 72 . Das Beharren Schiffers auf dem dreijährigen Referendariat zeigt zudem, daß er trotz seiner geänderten Auffassung hinsichtlich der Volksrichterausbildung die traditionelle Referendarausbildung erhalten wollte, um neben dem Volksrichter auch noch auf den "gelehrten" Richter zurückgreifen zu können. Daß für die DJV bei der Referendarausbildung die Qualitätssicherung und nicht deren Politisierung im Vordergrund stand, verdeutlichte Abendroth, als er im Anschluß an ein Treffen mit Referendaren aus Brandenburg deren zu häufigen Einsatz als Richter kraft Auftrags, deren unzureichende Ausbildung im öffentlichen Recht und das Fehlen „einer praktisch schulenden Zeitschrift" beklagte ${ }^{73}$.

Auch an der Assessorprüfung, die von dem bei der DJV gebildeten Justizprüfungsamt abgenommen wurde, änderte sich im Vergleich zu den Prüfungen vor 1945 zunächst nichts. Ja, Wende berichtete sogar, daß er 1946 bei den Prüfungen statt der von der Prüfungsordnung vorgesehenen Klausur über ein soziologisches Thema „im allgemeinen“ eine zweite strafrechtliche Klausur habe schreiben lassen. Außerdem habe bis Ende 1946 das vom Reichsjustizprüfungsamt übernommene Material „für Hausarbeiten, Klausuren und Vorträge gereicht" ${ }^{\text {"74. In einer }}$ Ausarbeitung vom Dezember 1947 über die Erfahrungen des Justizprüfungsamtes mit den Assessorprüfungen sprach Hartwig einleitend von dem „bewährte[n] überkommene[n] System der zweiten juristischen Staatsprüfung “. Die Beibehaltung des Referendariats rechtfertigte er damit, daß die Einführung der Volksrichter in die Praxis „einen genügenden Stamm von Volljuristen“ erfordere; zudem werde die Rechtsprechung der Oberlandesgerichte „auch weiterhin überwiegend

70 Vermerk Hartwigs über eine Unterredung mit Jakupow am 9. 4. 1948, 13. 5. 1948, BAB, DP1 VA Nr. 997. Hartwig fügte eine Abschrift einer Notiz über das Rechtsstudium in der Sowjetunion aus der DRZ 3 (1948), S. 137, bei.

71 Aktenvermerk über die Rücksprache Schiffers mit Karassjow am 17. 5. 1946, BAB, DP1 VA Nr. 11, Bl. 40.

72 MfJ Thüringen an DJV, 14. 8. 1947; Chef der DJV an MfJ Thüringen, 23. 8. 1947, BAB, DP1 VA Nr. 997.

73 Vermerk Abendroths für Hartwig, 3. 7. 1947, ebenda.

74 Vermerk o.D. [Ende 1946], BAB, DP1 VA Nr. 7854. 
in der Hand voll ausgebildeter Juristen liegen müssen“. Hartwigs Kritik an den Prüflingen und dem juristischen Vorbereitungsdienst war durchweg sachlicher und nicht ideologisch-politischer Natur. Er bemängelte unter anderem den zu milden Maßstab, der an die Leistungen der Referendare im Vorbereitungsdienst angelegt werde, falsche Vorstellungen von den Prüfungsanforderungen, mangelnde Allgemeinbildung, Fehler in den Hausarbeiten und die fehlende Klausurtechnik der Kandidaten ${ }^{75}$. Eine Rundverfügung der DJV vom 12. Januar 1948 zur Referendarausbildung erweiterte diese Beanstandungen um zwei Punkte. Zum einen kritisierte sie den mit Urteilen des Reichsgerichts getriebenen „Präjudizienkult" in den Rechtsgutachten der Examenskandidaten, da die "frühere höchstrichterliche Judikatur [...] daraufhin überprüft werden [müsse], ob sie unter den heutigen Bedingungen aufrechterhalten werden“ könne. Man wollte also keineswegs nahtlos an die Rechtsprechung des Reichsgerichts anknüpfen. Zum anderen gehe es nicht an, daß den Referendaren die nach 1945 begründeten Rechtsgebiete wie Planungsrecht, Agrarrecht und das Recht der volkseigenen Betriebe noch weitgehend unbekannt seien: „Die Entfremdung zwischen Volk und Recht“, so die Begründung, „kann nur beseitigt werden, wenn der Jurist sich in stärkstem Maße von rechtssoziologischen Erwägungen leiten läßt und wenn seine gesamte Tätigkeit vom Geiste des neuen Landesverfassungsrechts und der Gesetze, die nach dem Zusammenbruch des Dritten Reiches zur Demokratisierung des politischen, gesellschaftlichen und wirtschaftlichen Lebens geschaffen wurden, durchdrungen ist. "76 Das Plädoyer für die Aufnahme der neuen Gegenstände in die Ausbildung ist zwar durchaus plausibel; die Begründung hingegen ist von einer eigentümlichen Ambivalenz. Sie läßt sich vordergründig den Reformbestrebungen Schiffers zuordnen; mit den hier vermittelten Maßstäben für die richterliche Tätigkeit war jedoch einer Ideologisierung und Politisierung der Richterausbildung ein weites Einfallstor geöffnet.

\section{Anzabl und Eignung des akademischen Juristennachwuchses (1946-1948)}

Die zentrale Aufgabe der akademischen Juristenausbildung in der unmittelbaren Nachkriegszeit bestand darin, genügend unbelastete und qualifizierte Nachwuchskräfte für den Justizdienst hervorzubringen, um die allgemeine Personalnot zu beheben. Die Anzahl der Jura-Studenten war jedoch im Vergleich zur Vorkriegszeit dramatisch zurückgegangen: Wurden im Wintersemester 1935/36 an den Universitäten in Berlin, Halle, Jena, Leipzig und Rostock noch 2353 Studenten registriert, waren es im Sommersemester 1946 lediglich 883. In den Westzonen waren demgegenüber 8838 Studenten an 15 juristischen Fakultäten eingeschrieben: Die Zahlen hatten sich im Vergleich zum Wintersemester 1935/36 (4490 Studenten) fast verdoppelt ${ }^{77}$. Die niedrigen Studentenzahlen in der SBZ sind einmal

75 Otto Hartwig, Zur Assessorprüfung. Aus den Erfahrungen des Justizprüfungsamtes der Sowjetischen Besatzungszone, o.D., BAB, DP1 VA Nr. 997.

$76 \mathrm{DJV}$ an Landesregierungen/Justizministerium, 12. 1. 1948, BAB, DP1 VA Nr. 10, Bl. 116-121, Zitate $119,120$.

77 Die Zahl der juristischen Lehrkräfte und Studenten an den deutschen Universitäten, in: DRZ 2 (1947), S. 30. 
auf die im Vergleich zu den Westzonen strikteren Zulassungsvorschriften zurückzuführen ${ }^{78}$, denen zufolge ehemalige Mitglieder der NSDAP und ihrer Gliederungen, Führer und Führerinnen der HJ und des BDM, SA- und SS-Mitglieder, aktive Wehrmachts- und Polizeioffiziere und andere vom Studium grundsätzlich ausgeschlossen wurden; Ausnahmen konnten bei nachgewiesener aktiver Betätigung gegen den Nationalsozialismus, bei politisch bedingtem Ausschluß aus der NSDAP oder bei Inhaftierung aufgrund politischer Vergehen gemacht werden ${ }^{79}$. Des weiteren wurde die Anzahl der Jura-Studenten für jede Fakultät - wohl von der SMAD in Zusammenarbeit mit der DVV - festgelegt. Dabei trug man, wie die Rechts- und Staatswissenschaftlichen Fakultät Halle der DJV mitteilte, „der Aufnahmefähigkeit der Fakultäten nicht ausreichend Rechnung", so daß Schiffer am 16. Juli 1946 die DVV bat, „daß die Fakultäten bis auf weiteres so viel Nachwuchs ausbilden, als mit ihrer Leistungsfähigkeit irgend vereinbar" sei ${ }^{80}$. Am 6. August 1946 teilte Oberstleutnant Lyssjak auch der DJV die Aufnahmeziffern der einzelnen juristischen Fakultäten für das Wintersemester mit, die sich insgesamt auf 785 beliefen. Wende beantragte nach Rücksprache mit Melsheimer lediglich für Halle eine Erhöhung des Kontingents von 100 auf $115^{81}$. Die sowjetische Besatzungsmacht wollte folglich die akademische Juristenausbildung grundsätzlich beibehalten, nicht aber die stark ausgedünnten juristischen Fakultäten verstärken. Die DJV wiederum besaß zwar ein stärkeres Interesse an einer Ausweitung der juristischen Universitätsausbildung, mußte jedoch dem Dozentenmangel Rechnung tragen, so daß sie nur eine geringfügige Anhebung des Kontingents empfehlen konnte. Insgesamt stiegen die Zahlen der Jura-Studenten auf 1408 im Wintersemester 1946/47 und auf 1845 im Wintersemester 1947/4882. An die Zahlen in Westdeutschland kam man damit nicht heran: Dort waren im Wintersemester 1946/47 bereits 12382 Studenten eingeschrieben ${ }^{83}$.

Nur spärlich sind in den Akten der DJV Materialien überliefert, die auf die politische Haltung und soziale Zusammensetzung der Jurastudenten in der unmittelbaren Nachkriegszeit eingehen. Während ein „Bericht über die juristische Fakultät“ der Berliner Universität vom Juni 1946 das politische Interesse in der Fakultät als „,besonders stark“ charakterisierte ${ }^{84}$, erweckt eine Aufzeichnung Benjamins den Eindruck, als seien die Studenten vornehmlich auf ihr Studium konzentriert, unpolitisch, aber generell mißtrauisch gegenüber einer ideologischen Beeinflussung von links gewesen. Die politische Einstellung der Mehrzahl der

78 Zu den Zulassungsvorschriften und deren Handhabung in der britischen Zone siehe Phillips, Wiedereröffnung, S. 44 f., und den Erinnerungsbericht von Bird, Wiedereröffnung, S. 169. Berufsoffiziere etwa wurden in der britischen Zone nicht automatisch vom Studium ausgeschlossen.

79 Vgl. Müller/Müller, Festung Wissenschaft, S. 76.

80 Chef der DJV an DVV, 16. 7. 1946, BAB, DP1 SE Nr. 3559.

81 Vermerk Wendes, 9. 8. 1946, BAB, DP1 SE Nr. 3478.

82 Die Situation der juristischen Fakultäten in der Ostzone, 9. 1. 1948, BAB, DP1 VA Nr. 10, B1. 112115, hier 112. Inhalt und Zielrichtung des Papiers deutet auf seine Entstehung im SED-Parteiapparat hin.

${ }_{83}$ Zahlen nach: Die Zahl der juristischen Lehrkräfte und Studenten an den deutschen Universitäten, in: DRZ 2 (1947), S. 30, und Coing, Berufsaussichten, S. 485.

84 Bericht über die juristische Fakultät [Berlin], 13.6. 1946, BAB, DP1 VA Nr. 3478. Verfasser war ein der SED angehörender Student. 
Studierenden bezeichnete sie als „bürgerlich-sozialdemokratisch “85. Etwas informativer ist der Bericht Hartwigs und Abendroths über ihren Besuch bei der Leipziger Juristenfakultät im Juli 1947. Von den 296 Eingeschriebenen hätten vier der NSDAP und 140 der HJ bzw. dem BDM angehört, während 152 Studenten „politisch völlig unbelastet" seien. Auf den ersten Blick überraschend ist der hohe politische Organisationsgrad der Studenten: So gehörten 156 der SED, 53 der LDP und 28 der CDU an. Die Verfasser wollten dies aber nicht als Ausdruck politischer Überzeugungen bewerten, sondern hatten vielmehr den - wohl zutreffenden - Eindruck, „daß ein nicht unerheblicher Teil der Studentenschaft sich nur deshalb einer politischen Partei angeschlossen hat, weil er sich davon Erleichterungen bei der Zulassung zum Studium verspricht" ${ }^{\text {86. }}$. Bei der sozialen Zusammensetzung der Studentenschaft wurde ein Anstieg des Anteils aus dem Arbeitermilieu registriert: 1946/47 lag er bei durchschnittlich 17,8, ein Jahr später bereits bei 28,4 Prozent ${ }^{87}$. Die „forcierte Gegenprivilegierung " 88 der bisher im Bildungswesen unterprivilegierten Schichten zeigte erste Erfolge, die wesentlich, aber nicht ausschließlich auf die Einrichtung sogenannter Vorstudienanstalten zurückzuführen waren. An diesen für Arbeiter, Bauern und deren Kinder gedachten Einrichtungen, die 1949 in "Arbeiter-und-Bauernfakultäten" umbenannt wurden ${ }^{89}$, konnte ein Äquivalent zur Hochschulreife erworben werden. Zum Wintersemester 1947/48 hatten von den insgesamt 486 neu immatrikulierten Jura-Studenten 215 die Vorstudienanstalten durchlaufen ${ }^{90}$. Jedoch war dies aufgrund der damals noch kaum parteipolitisch ausgerichteten Ausbildung keine Gewähr für eine im Sinne der SED politisch orientierte Studentenschaft. Anfang 1948 ging der Präsident der Deutschen Verwaltungsakademie, Peter A. Steiniger (SED), der ebenfalls an der Berliner Universität lehrte, von einer überwiegenden Ablehnung der sowjetischen Besatzungsmacht und der SED durch die Hochschüler aus, wenngleich er deren Abneigung gegen den Sozialismus als "nicht sehr stark und nicht unüberwindlich" einschätzte91.

Trotz des Anstiegs der Studentenzahlen stagnierte die Anzahl der Referendare auf relativ niedrigem Niveau. Deren Gesamtzahl stieg nur geringfügig von $170 \mathrm{im}$ August/September 1947 auf 181 im März 194892. In einer Analyse vom Juli $1948^{93}$ führte Benjamin das Auseinanderklaffen zwischen Studenten- und Referendar-

85 Hilde Benjamin, Die Lage innerhalb der Berliner Studentenschaft, o.D. [Juni 1946], ebenda.

86 Bericht Hartwigs und Abendroths über den Besuch der Leipziger Juristen-Fakultät am 15. und 16. 7. 1947, 18. 7. 1947, BAB, DP1 SE Nr. 3553. Daß Studenten hofften, über einen Parteieintritt ihre Immatrikulationschancen zu verbessern, belegt das Beispiel Wolfgang Schollwers: vgl. Schollwer, Potsdamer Tagebuch, S. 23.

87 Zahlen nach: Die Situation der juristischen Fakultäten in der Ostzone, 9. 1. 1948, BAB, DP1 VA Nr. 10, Bl. 112.

88 Begriffsschöpfung von Schneider, Chancengleichheit, S. 961, nach Geißler, Sozialstruktur, S. 264.

89 Vgl. dazu jüngst auf breiter archivalischer Grundlage Schneider, Chancengleichheit, und ders., Bildung.

90 Chef der DJV an SMAD-Rechtsabteilung, 17. 2. 1948, BAB, DP1 SE Nr. 3551.

91 Steinigers Auffassung in: Die Situation der juristischen Fakultäten in der Ostzone, 9. 1. 1948, BAB, DP1 VA Nr. 10, Bl. 112.

92 DJV an SMAD-Rechtsabteilung, 24. 8. 1946, BAB, DP1 VA Nr. 7676, Bl. 146; Vermerk, 23. 12. 1947, BAB, DP1 VA Nr. 997; Hilde Benjamin, Zur Frage des Nachwuchses an Referendaren, o.D. [Juli 1948], BAB, DP1 VA Nr. 6533.

93 Ebenda. 
zahlen zu Recht darauf zurück, daß „nur ein kleiner Teil“ derjenigen, die das Studium erfolgreich abgeschlossen hatten, auch in den Vorbereitungsdienst eintrat. Dies hing weniger damit zusammen, daß diese sich aufgrund ihrer politischen „Belastung“ keine Chance ausrechneten, zum Referendardienst zugelassen zu werden, sondern daß ihnen „von der Industrie, besonders auch den Sowjet-Aktiengesellschaften, finanziell so glänzende Angebote gemacht würden, daß eine Tätigkeit im Justizdienst nicht verlockend“" sei. Hinzu kam, daß von den 181 im Vorbereitungsdienst befindlichen Referendaren nach den Kategorien des Befehls Nr. 204 vom 23. August 194794114 als "politisch belastet" (davon 73 aufgrund $\mathrm{HJ}$-Mitgliedschaft) und nur 67 als unbelastet galten. In diesem Zusammenhang monierte Benjamin, „daß die Länder ihrer Verpflichtung, politisch belastete Referendare durch die Deutsche Justizverwaltung überprüfen zu lassen, nur sehr ungleichmäßig nachgekommen" seien. Insgesamt hatte die DJV bis Juli 1948 von 123 überprüften Referendaren 68 zum Vorbereitungsdienst zugelassen und 55 abgelehnt. Das wichtigste Ergebnis der Aufzeichnung war freilich, daß seit 1946 nur sehr wenige Volljuristen ihre Ausbildung abgeschlossen hatten und anschließend in den Justizdienst eingetreten waren. Von den 25 geprüften Referendaren hatten 23 das zweite Staatsexamen bestanden. Bei vier von diesen handelte es sich um keine neuen Kräfte, da sie bereits vor ihrer Prüfung im Justiz- oder Verwaltungsdienst tätig waren und lediglich ihr Examen, zu dem sie 1933 nicht zugelassen worden waren, nachgeholt hatten. Von den verbliebenen 19 Assessoren waren vier politisch „belastet“, so daß nur 15 die Einstellungskriterien erfüllten. Da von diesen jedoch zwei Rechtsanwälte wurden und drei weitere in einen unbekannten Beruf wechselten, blieben lediglich zehn im Justizdienst verwendbare Volljuristen übrig. „Bisher“, so faßte Benjamin zusammen, „ist durch die neu geprüften Assessoren ein nennenswerter Zuwachs an Richtern und Staatsanwälten nicht eingetreten."

Diese ernüchternde Bilanz zeigt, daß Anzahl und Eignung des akademischen Juristennachwuchses keineswegs ausreichten, um die durch die Entnazifizierung entstandene Personalnot zu beheben. Dies lag vor allem an den strikten Entnazifizierungsvorschriften, die, wenngleich abgemildert, auch auf Referendare und Assessoren übertragen wurden. Ja, nach der Neuregelung vom September 194795 durften „belastete“ Referendare auch mit einer Ausnahmegenehmigung nach ihrer Prüfung nicht mehr zu Richtern und Staatsanwälten ernannt, sondern nur noch als Rechtsanwälte, Notare oder technische Kräfte tätig werden. Hinzu kam, daß die Bezahlung im Justizdienst so gering war ${ }^{96}$, daß viele Juristen bereits nach

94 Gedruckt in: ZVOBl. 1947, S. 191. Befehl Nr. 204 hob zwar die Entnazifizierungsbestimmungen von Befehl Nr. 49 auf, schloß aber ehemalige Mitglieder der NSDAP und ihrer Gliederungen vom Richteramt aus.

45 Vgl. dazu Kap. A.III.

96 Vgl. Arno Barth, Besoldung der Richter und Staatsanwälte, 12.6. 1947, BAB, DP1 VA Nr. 2, Bl. 330-332. Daraus geht hervor, daß ein 35jähriger verheirateter Amts- oder Landgerichtsrat mit zwei Kindern in der Ortsklasse C monatlich netto RM 354,61 und nach zehn Besoldungsdienstjahren RM 404,67 erhielt. Barth beklagte, daß „die Bezahlung der Richter und Staatsanwälte hinter den Gehältern zurückbleibt, die ein leistungsfähiger Mensch außerhalb des Staatsdienstes verdient. Aber auch im Vergleich zu den Gehältern und Aufstiegsmöglichkeiten der übrigen Staatsbediensteten werden die Gehälter der Richter und Staatsanwälte der Bedeutung ihrer Stellung nicht gerecht." 
ihrem ersten Examen in finanziell attraktivere Berufe abwanderten, die zudem kein dreijähriges Referendariat erforderten.

\section{Ausbildung, Weiterbildung und Einsatz der Volksrichter}

\section{Anfänge der Volksrichterausbildung}

Aufgrund des Personalmangels unter den Justizjuristen wurde in der SBZ trotz Wiederaufnahme der akademischen Juristenausbildung bereits 1945 erwogen, den Nachwuchs für diese Berufe auch durch Schnellkurse außerhalb der Universität zu rekrutieren ${ }^{97}$. Dies bedeutete einen tiefen Bruch mit dem traditionellen Ausbildungsgang für das Personal des höheren Justizdienstes, der im Gerichtsverfassungsgesetz von 1877 erstmals verbindlich für das ganze Deutsche Reich festgelegt worden war. Wenn vor 1945 gelegentlich darüber diskutiert wurde, auch solchen Personen die Ablegung der Assessorprüfung zu ermöglichen, die nicht die vorgeschriebene Ausbildung absolviert hatten ${ }^{98}$, blieb dies ohne Auswirkungen auf die Praxis.

Dem sowjetischen Justizwesen hingegen war der Einsatz von Laien und deren Schulung durch besondere Bildungseinrichtungen sehr wohl bekannt, so daß hier die Ursprünge für die Volksrichterausbildung zu suchen sind. Laut sowjetischem Gerichtsverfassungsgesetz von 1938 besaßen die Volksgerichte als erstinstanzliche Gerichte sowohl in Zivil- als auch in Strafsachen sehr weitgehende Zuständigkeiten; die hier tätigen, de jure vom Volk gewählten Richter mußten mindestens 23 Jahre alt sein, das aktive Wahlrecht besitzen und durften keine Vorstrafen aufweisen ${ }^{99}$. Hatte das GVG der RSFSR von 1924 noch eine Betätigung der Volksrichter „in der gesellschaftspolitischen Arbeit der gesellschaftlichen, beruflichen oder Parteiorganisationen der Arbeiter und Bauern oder in der praktischen Arbeit der sowjetischen Justizorgane oder der ihnen entsprechenden staatlichen Verwaltungsorgane" vorgeschrieben ${ }^{100}$, wies das GVG von 1938 keinerlei derartige Bestimmungen auf. Wenngleich die Grundsätze von 1924 auch nach 1938 weiter Beachtung fanden, wurde bei der Ausarbeitung des GVG von 1938 einer sowjetischen Publikation zufolge der Vorschlag abgelehnt, einen bestimmten Bildungsgrad für die Richteranwärter zu fordern, „da eine solche Forderung eine Einschränkung der Willensäußerung des Volkes [gewesen] wäre"101. Sehr viel plausibler erklärt Reinhart Maurach das Fehlen einer solchen Festlegung mit dem Hinweis auf den „außerordentlichen Richtermangel, der sich gerade um 1938 [...]

97 Zur Volksrichterausbildung siehe Pfannkuch, Volksrichterausbildung; Amos, Justizverwaltung, S. 151-172; Feth, Volksrichter; Gängel, Volksrichterausbildung; Wentker, Volksrichter.

${ }^{98}$ Es ist bezeichnend, daß Benjamin 1948 in der Neuen Justiz an eine derartige Debatte des Preußischen Landtags aus dem Jahre 1921 erinnerte: „Volksrichter“ vor 27 Jahren.

99 Maurach, Handbuch, S. $298 \mathrm{f}$. Die Wahl der Volksgerichte durch die Bevölkerung wurde erstmals 1948 und 1949 durchgeführt. Bis zu diesem Zeitpunkt wählten die örtlichen Sowjets der Bezirke oder die Exekutivkomitees der Bezirkssowjets die hauptamtlichen Volksrichter: siehe Meder, Sowjetrecht, S. 340.

100 Ebenda, S. 201.

101 Poljanski, Justiz, S. 20. 
empfindlich bemerkbar" gemacht habe ${ }^{102}$. Vor diesem Hintergrund wird verständlich, warum mehr als die Hälfte der damals tätigen Volksrichter nicht juristisch ausgebildet war ${ }^{103}$. Unter den wenigen juristisch vorgebildeten befand sich ein verschwindend geringer Anteil mit Hochschulbildung, während die übergroße Mehrheit nur eine kurze Fachschulung genossen hatte104. Dabei gewannen die sogenannten „Rechtsschulen“ an Bedeutung, die zwischen 1935 und 1939 einjährige und anschließend zweijährige Lehrgänge durchführten. Mitte 1939 existierten in der RSFSR 27 dieser Rechtsschulen mit insgesamt 2825 Hörern; unterrichtet wurden dort allgemeinbildende, sozialökonomische, zivilrechtliche und strafrechtliche Fächer ${ }^{105}$. Trotz aller Verbesserungsbemühungen erschienen die Mängel der juristischen Ausbildung der sowjetischen Führung nach dem Kriege als so gravierend, daß das ZK der KPdSU am 5. Oktober 1946 mit einen Beschluß "Über die Erweiterung und Verbesserung der juristischen Ausbildung im Lande“ faßte. Dieser sah unter anderem eine Optimierung und Erweiterung der juristischen Hochschulausbildung, die Herausgabe einer Reihe von Lehrbüchern, die Weiterbildung von bereits tätigen Justizangestellten, Fernunterricht und eine Intensivierung der Forschung vor. Die bereits tätigen Volksrichter sollten neunmonatige Umschulungslehrgänge durchlaufen, während in die Zweijahreslehrgänge nur noch Personen mit einem Mindestalter von 23 Jahren aufzunehmen waren, die über eine abgeschlossene mittlere Schulbildung sowie „über Erfahrungen in der parteilichen, staatlichen und gesellschaftlichen Arbeit" verfügten ${ }^{106}$.

Die Vertreter der Besatzungsmacht hatten aufgrund der Praxis in ihrer Heimat daher keine Hemmungen, entweder Personen ohne juristische Vorbildung als Richter einzusetzen oder deren Ausbildungsweg drastisch zu verkürzen. So unterbreitete am 31. Oktober 1945 die SMAD-Rechtsabteilung im Alliierten Kontrollrat den Vorschlag, das deutsche Gerichtsverfassungsgesetz dahingehend zu ändern, daß Personen mit einer entsprechenden Lebenserfahrung auch ohne Universitätsausbildung zu Richtern und Staatsanwälten ernannt werden sollten. Die in den OMGUS-Akten überlieferte, im Kontrollrat nicht weiter diskutierte Empfehlung enthält daneben folgenden Satz, der Ziele und Praxis der Volksrichterausbildung vorwegnahm: „It would be quite expedient to have established brief law courses where legal training might be afforded to persons without any previous experience in this field and who, from a political standpoint, might be able to afford vital assistance in the democratisation of the German judicial system."107

Solche Überlegungen wurden angesichts der Mitverantwortung der deutschen Justiz für die Untaten des Dritten Reiches und angesichts erster Entnazifizierungsmaßnahmen auch von deutscher Seite angestellt. Der spätere Leiter des

102 Maurach, Handbuch, S. 280.

103 Nach den amtlichen Angaben für 1937 besaßen von den 4.616 Volksrichtern der RSFSR 47,7\% keine fachliche Vorbildung; in den anderen Sowjetrepubliken variierten diese Zahlen zwischen 58,2 (Ukraine) und 71,1\% (Georgien); siehe Werther, Juristische Kader, S. 106.

104 Unter den Volksrichtern der RSFSR befanden sich Ende 1935 48,5\% ohne fachliche Vorbildung, 4,2\% mit Hochschulbildung und 47,3\% mit kurzfristiger Fachschulung: ebenda.

105 Vgl. Kucherov, Organs, S. 296; Blumenfeld, Juristische Ausbildung, S. 77.

106 Zit. nach Meissner, Zu der juristischen Ausbildung, S. 172-174; vgl. dazu Kucherov, Organs, S. 278-282.

107 IfZ, OMGUS-Akten 2/125-2/8-10; vgl. dazu Broszat, Siegerjustiz, S. 488 f. 
Richterlehrgangs in Sachsen, Kurt Ebert (SPD/SED), äußerte bereits im Juni 1945 gegenüber dem sächsischen Generalstaatsanwalt, John Ulrich Schroeder, „daß wir Schulen einrichten müssen, um neue Richter zu schaffen "108. Der Oberbürgermeister von Leipzig, Erich Zeigner, setzte zwar nicht auf Sonderlehrgänge, sondern auf die juristische Universitätsausbildung, wollte diese aber für Menschen aus Arbeiterkreisen zugänglich machen ${ }^{109}$. „Die demokratische Erneuerung des Justizapparats und der Justizverwaltung “ über "die beschleunigte Heranziehung geeigneter Kräfte aus den Kreisen des Volkes“ war ebenfalls eine Forderung der KPDFührung. Ulbrichts Vorschlag vom 5. Oktober gegenüber der SMAD-Rechtsabteilung setzte indes primär auf Universitätsstudium und Referendardienst, die auf jeweils zwei Jahre gekürzt werden und befähigten Volksschülern offenstehen sollten $^{110}$. Karassjow antwortete am 27. Oktober, daß Ulbricht "die Frage vollkommen richtig gestellt [habe], daß nämlich für die Rechtsprechung Personen aus Volkskreisen herangezogen werden sollen, um das Justizsystem zu demokratisieren"111. Auf die Form der Ausbildung ging er, im Unterschied zu seinem Memorandum vom 31. Oktober, nicht ein.

Mit dieser Frage hatten sich bis zu diesem Datum auch leitende Mitarbeiter der $\mathrm{DJV}$ befaßt ${ }^{112}$. Über den Gang der Diskussion informiert insbesondere ein $\mathrm{Be}$ richt von Bertz, den dieser am 14. Dezember 1945 an das Sekretariat des KPDZentralkomitees übersandte113. Seinen Ausführungen zufolge hatte er selbst die Diskussion initiiert, was zweifelhaft erscheint. Denn er wollte vor allem den Genossen im Sekretariat die Unentbehrlichkeit seiner Person in der DJV vor Augen führen, um auf diese Weise den Konflikt mit Schiffer zu seinen Gunsten zu entscheiden ${ }^{114}$.

Die erste Diskussionsrunde wurde am 24. September von Fritz Corsing mit einer angeblich auf Veranlassung von Bertz verfaßten Aufzeichnung eröffnet. Darin ging es, ganz im Sinne der Reformbestrebungen Schiffers, darum, „den Kreis der Richter volkstümlicher zu gestalten, ohne zugleich die Qualität des Richterstandes zu senken“. Dazu schlug Corsing vor allem den Rückgriff auf Personal vor, das, wie etwa Steuerberater, Gewerkschaftssekretäre und Justizbeamte des gehobenen Dienstes, bereits in Berührung mit juristischen Angelegenheiten gekom-

108 So Ebert auf der Tagung des SED-Rechtsausschusses am 3./4. 1. 1948, SAPMO, DY 30 IV 2/1.01/ 70, Bl. 194.

109 Sozialdemokratische Partei des Landes Sachsen, Stenographischer Bericht über die Verhandlungen des Landes-Parteitages [1945], S. 60. Unter dem Titel: "Gründliche Neugestaltung des deutschen Rechtes“ wurden angebliche Äußerungen Zeigners auf dieser Veranstaltung unter „vollkommene[r] Zustimmung" der Redaktion im KPD-Zentralorgan Deutsche Volkszeitung am 9.11. 1945 abgedruckt. Diese stimmen mit denen des stenographischen Berichts nicht überein, wurden aber von Anders, Demokratisierung, S. 50, zitiert und dienen als Beleg für Zeigners Wunsch nach Volksrichterschulen.

110 Vorschlag des Sekretariats des ZK der KPD zur Justizreform, 5. 10. 1945, SAPMO, NY 4182/ $1118, \mathrm{Bl} .63 \mathrm{f}$.

111 Karassjow an Ulbricht, 27. 10. 1945 (Übersetzung), SAPMO, NY 4182/1185, Bl. 4.

$112 \mathrm{Zu}$ dieser Debatte sehr knapp Pfannkuch, Volksrichterausbildung, S. 14-17, und Amos, Justizverwaltung, S. 153-155.

13 Bertz an das Sekretariat des ZK der KPD, 14. 12. 1945, und sein Bericht über die Entwicklung der Frage des Volksrichters in der Deutschen Zentralen Justizverwaltung in: Wentker, Volksrichter, Dok. 1 und 2, S. 96-99.

114 Vgl. Kapitel A.I.4. 
men sei; aber auch aus dem Kreis erfahrener, älterer Arbeiter könne man möglicherweise entsprechende Persönlichkeiten rekrutieren. Die nach einer Eignungsprüfung ausgewählten Kandidaten müßten dann theoretisch und praktisch geschult werden, um sie, gegebenenfalls nach einer Endprüfung, als Richter oder Staatsanwälte einsetzen zu können ${ }^{115}$.

Der Kommentar Melsheimers zeigt, daß er keineswegs von Anfang an ohne Einschränkung für die Ablösung der alten Juristenschicht durch Volksrichter eintrat ${ }^{116}$. Er stimmte den Ausführungen Corsings zu, wollte den bisherigen Ausbildungsweg jedoch grundsätzlich beibehalten und daher „Volksrichter“ nur für die durch Personalknappheit gekennzeichnete Übergangszeit einstellen. Zudem sprach er sich dafür aus, diesen die Freiwillige Gerichtsbarkeit und die sog. Bagatellgerichtsbarkeit an Amtsgerichten zu übertragen, während wichtigere Sachen an den Landgerichten von volljuristischen Berufsrichtern verhandelt werden sollten ${ }^{117}$.

Benjamin unterschied in ihrer Stellungnahme den juristisch völlig unausgebildeten, lebenserfahrenen, aufgrund seiner Berufs- und Menschenkenntnis tätigen Richter - und nur diesen wollte sie als „Volksrichter" bezeichnen - von dem „beschleunigt und auf neuem Wege ausgebildete[n] Richter". Notwendig seien beide Richtertypen; geklärt werden müßten noch Details im Hinblick auf die Existenzsicherung der angehenden Richter während ihrer Ausbildung118. Sie vertrat damit keineswegs die Auffassung, Corsing habe seine Aufgabe, ein Konzept zur Volksrichterausbildung auszuarbeiten, verfehlt ${ }^{119}$, da dieser den Begriff „Volksrichter“ gar nicht benutzt hatte. Ihre begriffliche Klarstellung bezog sich vielmehr auf den Kommentar Melsheimers, der als Volksrichter auch jene bezeichnet hatte, die eine juristische Kurzausbildung erhalten sollten. Auffällig an ihrer Stellungnahme ist indes, daß sie die Richter im Soforteinsatz - denn um nichts anderes handelt es sich bei den von ihr so genannten "Volksrichtern“ - beibehalten und neue Richter nicht auf traditionelle Weise, sondern „auf neuem Wege“ ausbilden wollte.

Schiffer beendete die erste Diskussionsphase, indem er entschied, zunächst nichts weiter zu unternehmen und „zu gegebener Zeit“ auf die Angelegenheit zurückzukommen. Die zweite Phase war von zwei parallelen Vorgängen geprägt: Zum einen fertigte Benjamin Mitte Oktober eine „private Arbeit“ zur Volksrichterausbildung 120 an, und zum anderen ließ Schiffer ohne Beteiligung der Gesetzgebungsabteilung eine „1. Verordnung betr. Gerichtsverfassung“ ausarbeiten, die am 29./30. Oktober in Karlshorst eingereicht wurde. Unter Rückgriff auf seine Vorstellungen aus der Zwischenkriegszeit wollte Schiffer neben dem Volljuristen auch denjenigen als Berufsrichter zulassen, der „den Vollbesitz von Rechtskenntnissen durch den Besitz anderer Eigenschaften ersetzt, die ihn zum Richter beson-

115 Anlage 1, Abschrift, 24. 9. 1945, in: Wentker, Volksrichter, Dok. 3, S. 101-103.

116 Dies widerlegt die Aussage Benjamins, daß die "Genossen“ der DJV „von Anfang an“ die Volksrichterausbildung nicht als Notlösung, sondern als „wichtige Maßnahme zur Zerschlagung der reaktionären deutschen Richterkaste“ betrachtet hätten: Benjamin, Volksrichter, S. 729.

11 Anlage 2, gez. Melsheimer, o.D., in: Wentker, Volksrichter, Dok. 4, S. $103 \mathrm{f}$.

118 Anlage 3, Zur Frage der Volksrichter, gez. Benjamin, o.D., ebenda, Dok. 5, S. 104.

119 So Pfannkuch, Volksrichterausbildung, S. 15.

120 Die Ausarbeitung in: BAB, DP1 VA Nr. 6645, Bl. 32-42. Am 5. 11.1945 übersandte Bertz eine Abschrift an Ulbricht, SAPMO, NY 4182/1185, Bl. 6, 29-37. 
ders geeignet machen". Er dachte dabei offensichtlich an bürgerliche Honoratioren, die - wie etwa Bürgermeister - bereits öffentliche Ämter bekleideten. Amtsrichter sollten auch die werden können, die sich im Justizdienst praktisch bewährt hatten und über ein Mindestmaß an Rechtskenntnissen verfügten: Er hatte dabei vor allem die Rechtspfleger im Auge. Volksrichter - wie Schiffer sie verstand - waren ausschließlich für die frei gewählte Ehren- und Schiedsgerichtsbarkeit vorgesehen ${ }^{121}$. Bertz, Kleikamp und Melsheimer protestierten gegen das eigenmächtige Vorgehen des DJV-Präsidenten bei Ausarbeitung und Weiterleitung dieses Entwurfs, dem somit kein Erfolg beschieden war ${ }^{122}$.

Die dritte Diskussionsphase wurde von Schiffer eingeleitet, der nach dem Scheitern seiner Strategie, die Frage unter Umgehung der Gesetzgebungsabteilung zu lösen, am 3. November Melsheimer beauftragte, Ausarbeitungen über Möglichkeiten zur Einsparung von Richterkräften und zur Volksrichterfrage vorzulegen ${ }^{123}$. Bei seiner Erörterung der möglichen Maßnahmen zur Entlastung der Gerichte kam dieser zu dem Ergebnis, daß dadurch kaum Richter frei würden ${ }^{124}$. Auf seine Anregung hin wurde die Denkschrift zur Volksrichterausbildung Hilde Benjamin übertragen. Sie konnte dabei auf ihre Arbeit vom Oktober zurückgreifen, die sie bis zum 6. November erweiterte und präzisierte. Im Unterschied zu ihrem ersten Kommentar „Zur Frage der Volksrichter" bezeichnete sie in ihrem Memorandum jeden als Volksrichter, "der, ohne den Voraussetzungen des $\$ 2$ GVG zu entsprechen, das Amt eines Richters oder Staatsanwalts in vollem Umfange ausübt". Sowohl die Richter im Soforteinsatz als auch die in Lehrgängen ausgebildeten Richter ließen sich unter diesem Begriff zusammenfassen. Ihren Ausgangspunkt bildete der durch die Entnazifizierung der Justiz hervorgerufene Richtermangel und die fehlende Eignung der vielfach überalterten, noch im Amt befindlichen Richter, die „ideologisch zu einem Teil nicht das Richtertum dar[stellen], das der neue Staat braucht“: Beide Mängel waren durch Volksrichter zu beheben. Des weiteren behandelte sie Mindest- und Höchstalter der Kandidaten (30-50 Jahre), Modalitäten der Zulassung zu den Richterkursen (durch besondere Prüfungskommissionen) sowie Einsatz und Ausbildung der Volksrichter. Ein Teil der Volksrichter war sofort einzusetzen und parallel zu ihrer Tätigkeit auszubilden, während die anderen erst nach ihrer Ausbildung zum Einsatz kommen sollten. Zwar ging sie grundsätzlich davon aus, daß die zweite Form des Volksrichters nur so lange notwendig sei, bis der Nachwuchs aus den Universitäten wieder zur

121 Zit. nach der Aufzeichnung von Bertz, in: Wentker, Volksrichter, Dok. 2, S. 97 f. Am 20. 10. 1945 wies Schiffer außerdem Wende an, den Entwurf einer "Regelung der Zulassung von Laien zum Richteramt" anzufertigen, die vor allem auf die Typen „Oberbürgermeister" und „Rechtspfleger“ zugeschnitten sein sollte. Wende legte am 22.10. einen ersten Entwurf vor, der aufgrund einer Besprechung am 2.11. einen Tag darauf in leicht geänderter Fassung erneut Schiffer zugeleitet wurde: BAB, DP1 SE Nr. 3478.

122 In der DJV wurde er mehrheitlich abgelehnt. Nach Informationen Benjamins war der Plan im Frühjahr 1946 „von Karlshorst nach Moskau gegeben“ worden; die Meinungsbildung auf sowjetischer Seite war also noch nicht abgeschlossen: siehe Wentker, Volksrichter, Dok. 14, S. 128.

123 Vermerk Melsheimers, 9. 11. 1945, BAB, DP1 VA Nr. 2, Bl. 98. Schiffer hatte ebenfalls eine Denkschrift „über die Besetzung und Zuständigkeit der Gerichte und über den Instanzenzug nach dem Gesetz Nr. 4 des Kontrollrats vom 30. 10. 1945" angefordert.

${ }^{124}$ Denkschrift über Möglichkeiten einer Einsparung von Richterkräften, BAB, DP1 VA Nr. 2, Bl. 99-101. 
Verfügung stünde; einschränkend fügte sie aber hinzu: „Ob dann die Voraussetzungen für die Sonderausbildung des V[olks]R[ichters] fortfallen, wird davon abhängen, inwieweit dann dieser Nachwuchs die Gewähr dafür bietet, daß er die Eigenschaften des Berufsrichters mit denen des V[olks]R[ichters] vereint." Volksrichter waren für Benjamin daher durchaus als permanente Einrichtung denkbar. Die Ausbildung an der jeweiligen Landesuniversität in Verbindung mit dem dortigen Land- oder Oberlandesgericht mußte Benjamin zufolge die Vermittlung von Kenntnissen im materiellen und Verfahrensrecht, die Unterrichtung über die aktuelle Gesetzgebung und Rechtsprechung sowie eine "rechtspolitische Schulung“ enthalten, „die sie [die Lehrgangsteilnehmer] die gegenwärtige Form des Rechts erkennen läßt als Ausdruck der gegebenen wirtschaftlichen und gesellschaftlichen Verhältnisse". Sie wollte die Volksrichterausbildung folglich auch zur Vermittlung eines eindeutig marxistischen Rechtsbegriffs nutzen ${ }^{125}$.

Wende nahm zur Denkschrift Benjamins kritisch Stellung ${ }^{126}$. Seiner Meinung nach durften die Volljuristen nicht gegenüber den Volksrichtern benachteiligt werden, so daß er dafür plädierte, eine andere Bezeichnung für die neuen Richter zu wählen, da „der sogenannte gelehrte Richter [...] schließlich auch im Namen des Volkes Recht spricht". Zudem wollte er die Professionalität der Volksrichterausbildung vor allem durch die Beteiligung der staatlichen Justizprüfungsämter bei der Abnahme des Abschlußexamens sicherstellen. Sein Kommentar wurde zusammen mit der Denkschrift Benjamins Schiffer vorgelegt, der die Dokumente indes nicht nach Karlshorst weiterleitete ${ }^{127}$. Denn Schiffer war damals noch bestrebt, seine eigenen Vorstellungen zu verwirklichen, die vor allem auf die Rekrutierung und Weiterbildung bereits juristisch geschulten Personals hinausliefen. Damit biß er bei der SMAD-Rechtsabteilung aber auf Granit. Karassjow forderte ihn am 14. November auf, „schnellstens einen Entwurf für die Schaffung juristischer Schulen auszuarbeiten", die innerhalb von sechs Monaten von den demokratischen Parteien überprüften Antifaschisten „eine elementare juristische Ausbildung vermitteln" sollten. Ein von Schiffer übersandter Entwurf zu dieser Thematik, der die Umschulung von Personen mit juristischen Kenntnissen behandle, entspreche dieser Aufgabe „in keiner Weise“. Die Rechtsabteilung habe „eine andere Frage gestellt - die Frage der Ausbildung von Personen, die keine juristische Bildung besitzen, aber überprüfte Demokraten im antifaschistischen Kampfe sind, durch juristische Schulen“. „Wenn Sie den Entwurf über die Organisation der juristischen Schulen nicht ausarbeiten können“, fuhr Karassjow fort, „so teilen Sie uns das mit." 128

Die massive sowjetische Kritik beendete die dilatorische Behandlung der Volksrichterfrage durch den DJV-Präsidenten. Die vierte Diskussionsphase be-

125 Anlage 4, Zur Frage des Volksrichters, o.D., in: Wentker, Volksrichter, Dok. 6, S. 105-112.

126 Anlage 5, Wende an Melsheimer, 12. 11. 1945, Abschrift, ebenda, Dok. 7, S. 112-114. Wende hatte auch die Denkschrift Benjamins mit kritischen Marginalien versehen: siehe die Anmerkungen zu Dok. 6, ebenda, S. 108-110.

127 Siehe ebenda, Dok. 2, S. 98.

${ }_{128}$ Chef der SMAD-Rechtsabteilung an den Chef der DJV, 14. 11. 1945, geheim! Übersetzung, BAB, DP1 VA Nr. 2, Bl. 102-104, hier 103 (teilweise zit. in: Pfannkuch, Volksrichterausbildung, S. 16). Weder die Anfrage der SMAD-Rechtsabteilung noch der Entwurf Schiffers waren in den einschlägigen Beständen auffindbar. 
gann mit einer Verlesung des Briefes aus Karlshorst am 19. November in Anwesenheit Schiffers, der Abteilungsleiter und Benjamins. Mit der Ausarbeitung des Ausbildungsplanes beauftragte Schiffer indes den Leiter der zuständigen Abteilung, Wende, der tags darauf einen entsprechenden Entwurf vorlegte ${ }^{129}$. Am Nachmittag dieses Tages fand eine Beratung darüber statt, deren Ergebnisse von Wende bei der Ausarbeitung der nach Karlshorst übersandten Endfassung des Ausbildungsplans berücksichtigt wurden ${ }^{130}$.

Da die SMAD-Rechtsabteilung nur die Lehrgangsdauer und die Auswahl der Kandidaten vorgeschrieben hatte, behielt die DJV noch einen relativ großen Spielraum bei der Ausgestaltung der Kurse. Aufgenommen in den Plan wurden u.a. Benjamins Vorstellungen über Mindestalter (30 Jahre) und Anzahl der jeweiligen Lehrgangsteilnehmer (40) sowie die Ausbildungsorte (Landesuniversität oder Oberlandesgericht). Ihre Überlegungen zur Weiterbildung von bereits tätigen Richtern im Soforteinsatz kamen in der Ausbildungsordnung indes nicht zum Tragen $^{131}$. Auf Wende sind vor allem drei Festlegungen zurückzuführen, die in dem Entwurf Benjamins keine bzw. nur eine untergeordnete Rolle gespielt hatten: die Teilung der Lehrgänge ab dem dritten Ausbildungsmonat in einen zivilrechtlichen und einen strafrechtlichen Zweig, die Möglichkeit, Lehrgangsteilnehmer wegen mangelnder Begabung oder unzulänglicher Leistungen auszuschließen und die Bestimmungen über die Abschlußprüfung. Alle drei Maßnahmen bildeten den Versuch, trotz einer nicht-akademischen, stark verkürzten Juristenausbildung einen möglichst hohen Standard zu bewahren, auch wenn Gründlichkeit in einem Fachgebiet durch Spezialisierung erkauft wurde ${ }^{132}$. Für das Abschlußexamen waren zwei Klausuren und eine sich an einen Aktenvortrag anschließende mündliche Prüfung vorgesehen. Der Prüfungsausschuß sollte aus einem Vertreter des Chefs der DJV, einem Vertreter der jeweiligen Landesjustizverwaltung, dem Lehrgangsleiter und einem weiteren Mitglied des Lehrkörpers bestehen: mithin aus vier Juristen, und nicht, wie Benjamin noch vorgeschlagen hatte, aus zwei Repräsentanten des öffentlichen Lebens, einem Gewerkschafter und jeweils einem Vertreter der DJV und der Landesjustizverwaltung.

Mit diesem Entwurf, der die sowjetischen Vorgaben zwar berücksichtigte, in seiner Ausgestaltung aber trotz Rückgriff auf Benjamins Ausführungen die Handschrift Wendes deutlich erkennen ließ, wurde die Diskussion in der DJV vorläufig beendet. Während Karlshorst bis Mitte Dezember noch keine verbindlichen Entscheidungen in der Volksrichterfrage getroffen hatte, war die Sowjetische Militäradministration in Sachsen (SMAS) bereits einen Schritt weiter. Aus der Presse erfuhren die DJV-Mitarbeiter Mitte November, daß in Sachsen auf An-

129 Der Entwurf wurde Schiffer von Wende am 20.11. „als erste Unterlage für die heute nachmittag angesetzte Besprechung" vorgelegt, BAB, DP1 SE Nr. 3478.

130 Der Ausbildungsplan mit dem Titel „Ordnung betreffend die Einrichtung von juristischen Fachschulen" in: Wentker, Volksrichter, Dok. 8, S. 114-116; zu diesen Vorgängen in der DJV siehe ebenda, Dok. 2, S. $98 \mathrm{f}$.

131 Die Ausbildungsordnung stellte es diesen Personen frei, sich zur Teilnahme an einem Lehrgang beurlauben zu lassen oder sich neben ihrer Tätigkeit selbst fortzubilden.

132 Laut Bertz versuchten Melsheimer und Benjamin erfolglos bei der Beratung am 20.11. 1945 eine Nachschulung für die Straf- und Zivilrichter auf dem jeweils anderen Gebiet zu erreichen: siehe ebenda, Dok. 2, S. 99. Die Zweiteilung der Lehrgänge wurde demnach nicht, wie Amos, Justizverwaltung, S. 163, schreibt, von der SMAD vorgegeben. 
regung der dortigen Militärverwaltung ein Lehrgang zur Heranziehung von Richtern aus Laienkreisen eingerichtet werden sollte ${ }^{133}$. Auf Nachfragen der DJV informierte die sächsische Justizabteilung am 24. November über die Hintergründe der Pressemeldungen ${ }^{134}$. Am 29. Oktober hatte der erste Vizepräsident des Landes Sachsen, Kurt Fischer (KPD), der Justizabteilung die „Anregung“ des Chefs der SMAS, Generalmajor Dubrowski, übermittelt, sieben- bis achtmonatige Kurse zur Ausbildung von 120 bis 150 Personen zu Richtern und Staatsanwälten einzurichten. Die Teilnehmer sollten gemeinsam mit den zugelassenen Parteien ausgewählt werden und ausschließlich aus überzeugten Antifaschisten bestehen. Die Justizabteilung bat daraufhin die vier Parteien um die Benennung von jeweils etwa 30 geeigneten Kandidaten; die Einberufung zum Lehrgang sollte nach einer persönlichen Vorstellung der Bewerber erfolgen. Ein von der Justizabteilung aufgestellter Lehrplan legte fest, den Stoff in 16 Arbeitsgemeinschaften und Einzelvorträgen zu behandeln. Während die Arbeitsgemeinschaften die juristischen Grundbegriffe, Grundkenntnisse aus den einzelnen Rechtsgebieten und Einblicke in die praktische Arbeit des Amtsrichters und des Rechtspflegers vermitteln sollten, dienten die Vorträge „vor allem dem Zweck, politische Fragestellungen, die mit dem Aufbau einer demokratischen Rechtspflege in Verbindung stehen, zu behandeln“. Als Ort für die Abhaltung des Lehrgangs war Bad Schandau vorgesehen, in dessen Kurhaus die zahlreichen Teilnehmer untergebracht werden konnten $^{135}$.

Beim Vergleich des sächsischen Lehrplans mit der in der DJV erarbeiteten „Ordnung betreffend die Einrichtung von juristischen Fachschulen“ stellte Kleikamp als einzige Gemeinsamkeit fest, daß auch in Sachsen ein allgemeinbildender, einführender Abschnitt in Aussicht genommen sei. Er bemängelte die Fülle des Stoffes, was zu einer Überlastung der Hörer führen könne. Als „interessant“ hob er lediglich hervor, daß der Lehrplan auf acht Monate konzipiert sei ${ }^{136}$. Wende unterzog das sächsische Vorhaben einer vernichtenden Kritik. So bezweifelte er, ob eine Verwaltungsstelle „überhaupt 120 Teilnehmer mit größerer Garantie für das Gelingen aussuchen kann", und beanstandete unter anderem die große Zahl der Lehrer, die unklare Gliederung des Stoffes und das Fehlen einer Prüfungsregelung. Abgesehen von der längeren Dauer des sächsischen Lehrganges, konnte er in dem Plan keine Vorzüge gegenüber dem der DJV erkennen ${ }^{137}$. Die Initiative der SMAS zeigte freilich, daß auf sowjetischer Seite noch Differenzen im Hinblick auf die Durchführung der Volksrichterlehrgänge bestanden. Zwar waren für die DJV die Anordnungen der SMAD-Rechtsabteilung maßgebend; aber Schiffer war auch angewiesen worden, mit den Ländern vertrauensvoll zusammenzuarbeiten und

${ }^{133}$ Siehe die Meldung in der Täglichen Rundschau vom 2.11. 1945 und den daraufhin verfaßten Vermerk Winkelmanns vom 13.11. 1945. Wende wandte sich aufgrund des Artikels „Richter aus Laienkreisen“, in: Der Morgen, 16. 11. 1945, in derselben Angelegenheit am selben Tag an die sächsische Justizabteilung. Die Zeitungsausschnitte, Vermerke und Briefe in: BAB, DP1 SE Nr. 3478.

134 Landesverwaltung Sachsen, Abt. Justiz, an Chef der DJV, 24. 11. 1945, in: Wentker, Volksrichter, Dok. 9, S. $117 \mathrm{f}$.

135 Die Angaben zum Lehrplan in: Landesverwaltung Sachsen, Abt. Justiz, an den Chef der SMAS, General Dubrowski, 6. 11. 1945, BAB, DP1 SE Nr. 3478.

136 Kleikamp an Wende, 12.12.1945, ebenda.

137 Wende an Kleikamp, 15. 12. 1945, ebenda. 
die „Methode des Diktats“ zu vermeiden ${ }^{138}$. Was aber war zu tun, wenn eine Landesverwaltung aufgrund einer sowjetischen Anweisung Pläne entwickelte, die den Vorgaben der SMAD-Rechtsabteilung widersprachen?

Das unkoordinierte sowjetische Vorgehen verdeutlicht, daß die Militärverwaltung zwar grundsätzlich auf „Richter aus dem Volk“ zurückgreifen wollte, zu diesem Zeitpunkt aber noch nicht über ein durchdachtes Konzept zu ihrer Ausbildung verfügte ${ }^{139}$. Diese Phase der Unklarheit über die sowjetischen Absichten wurde am 17. Dezember beendet, als Karassjow eine Anordnung des Chefs der SMAD übermittelte, in allen Ländern „juristische Kurse" einzurichten ${ }^{140}$. Offensichtlich unter Verwendung der Vorarbeiten aus der DJV hatten Karassjow und sein Vorgesetzter Semjonow in der zweiten Novemberhälfte Schukow einen Befehlsentwurf unterbreitet. Sie waren sich dabei durchaus bewußt, daß es sich um eine Abweichung von der traditionellen deutschen Juristenausbildung handelte, verwiesen aber auf die "politische Notwendigkeit“, die einen solchen Schritt diktiere. Auf Empfehlung des Stellvertretenden Obersten SMAD-Chefs für Fragen der Zivilverwaltung, Generaloberst Serow, gab Schukow keinen regulären Befehl heraus, sondern beließ es bei einer Anweisung ${ }^{141}$. Einleitend wird darin auf entsprechende Anfragen „von einzelnen Organen der örtlichen Selbstverwaltung“ hingewiesen, auf die "der oberste Chef der SMA in Deutschland" mit der nun folgenden Anordnung reagiere. Wenngleich einzelne Landesverwaltungen bereits in dieser Frage tätig geworden waren ${ }^{142}$, dienten diese Bemerkungen - unabhängig von ihrem Wahrheitsgehalt - eher der Legitimation dieser dem deutschen Gerichtsverfassungsgesetz widersprechenden Maßnahme. Vorgegeben wurden die Lehrgangsstärken (30-40 Teilnehmer), die Lehrgangsdauer (6 Monate), die Anforderungen an die Teilnehmer („aktive Antifaschisten“, mindestens Volksschulbildung, Mindestalter 25 Jahre) und der allgemeine Lehrgangsbeginn (1. Februar 1946). Die Länder waren der Anweisung zufolge für die Auswahl der Teilnehmer, die Finanzierung der Lehrgänge und die Ernennung der Lehrgangsleiter verantwortlich, während der DJV „die methodische Leitung dieser Kurse sowie die Aufstellung der Programme und Lehrpläne übertragen" wurde.

Bei der Übermittlung der sowjetischen Anordnung an die Justizabteilungen signalisierte Schiffer, daß er sich auch mit 30 Teilnehmern pro Kurs zufrieden geben würde, und begründete dies mit der neuartigen Unterrichtssituation sowie mit dem „gegenwärtige[n] besondere[n] Bedarf an Richtern und Staatsanwälten“. $\mathrm{Da}$

${ }^{138}$ Chef der SMAD-Rechtsabteilung an den Chef der DJV, 14. 11. 1945, geheim! Übersetzung, BAB, DP1 VA Nr. 2, Bl. 102-104, hier Bl. 102 (teilweise zit. in Lorenz, Zentralverwaltung, S. 143).

139 Im Gegensatz zu Amos, Justizverwaltung, S. 155, die behauptet, daß „die Entscheidung über den Plan einer Ausbildung von juristisch nicht geschulten Personen zu ,Volksrichtern' in den letzten Tagen des Oktober 1945 in der SMAD-Rechtsabteilung entschieden wurde [sic]“.

140 Rechtsabteilung der SMAD an den Chef der DJV, gez. Karassjow, 17. 12. 1945, in: Wentker, Volksrichter, Dok. 10, S. 118 f. Die Anordnung richtete sich nicht, wie Amos, Justizverwaltung, S. 155 schreibt, an die Länder und Provinzen der SBZ.

141 Vgl. Nikitin, Sowjetische Militäradministration und die Justiz (Manuskript), S. 9 f.

142 Bertz nennt in seinem Bericht (in: Wentker, Volksrichter, Dok. 2, S. $99 \mathrm{f}$.) das Land Sachsen, die Provinz Sachsen und Mecklenburg. Freilich war das Land Sachsen von der SMAS zu diesem Schritt veranlaßt worden; inwiefern die Verwaltung der Provinz Sachsen aus eigenem Antrieb gehandelt hatte, ist unklar (siehe dazu die Notiz "Richter aus dem Volk - für Provinz Sachsen “, in: Deutsche Volkszcitung, 12. 12. 1945); in Mecklenburg hatte sich die Personalreferentin bei einer Rücksprache mit Benjamin (!) an der Frage interessiert gezeigt. 
gerade der Bedarf eine Orientierung an der höheren Zahl nahegelegt hätte, beabsichtigte Schiffer wohl vor dem Hintergrund seiner Kenntnisse der sowjetischen Überlegungen ${ }^{143}$, die Zahl der Volksrichter relativ gering zu halten. In den weiteren Absätzen der Rundverfügung griff er auf die „Ordnung betreffend die Einrichtung von juristischen Fachschulen" zurück, deren Formulierungen er teils wörtlich übernahm ${ }^{144}$. Auf die sowjetische Aufforderung vom 17. Dezember, bis zum 1. Januar 1946 die „Programme und Lehrpläne“ für die Lehrgänge vorzulegen, antwortete Schiffer, daß in der "Ordnung betreffend die Einrichtung von juristischen Fachschulen“ bereits entsprechende Ausführungen enthalten seien; für die endgültige Aufstellung der Lehrpläne wollte er die Lehrgangsleiter in der ersten Januarhälfte zu einer Besprechung in die DJV einberufen ${ }^{145}$. Die von der Rechtsabteilung genehmigte Beratung ${ }^{146}$ am 12. Januar 1946 ergab, nachdem die Bedenken der sächsischen Vertreter gegen die Gliederung des Lehrgangs beseitigt waren, keine Änderungen des Lehrplanentwurfs der DJV ${ }^{147}$.

$\mathrm{Da}$ die SMAD-Rechtsabteilung sehr großen Wert auf die Einrichtung der Volksrichterkurse gelegt hatte, waren Wende und Kleikamp überrascht, als Nikolajew ihnen am 12. Januar 1946 zwar mitteilte, „daß der Unterricht [in den Lehrgängen] im richtigen antifaschistischen und demokratischen (dialektischen) Geist durchgeführt" werden müsse, zugleich aber betonte, daß die Kurse "nur als temporäre zeitbedingte Maßnahme zur Deckung des augenblicklichen tatsächlichen Bedarfs an Richtern gedacht seien“148. Kleikamp riet zur Vorsicht, da es sich „nur um eine mündliche Mitteilung "Nikolajews handle, die zudem im Zusammenhang mit der für den sächsischen Lehrgang in Aussicht genommenen großen Teilnehmerzahl gemacht worden sei; außerdem sei die schriftliche Anweisung, "daß es sich bei diesen Kursen um eine beständige Einrichtung handeln soll“, nicht aufgehoben ${ }^{149}$. Schiffer stimmte zu, bemerkte aber „zur Sache selbst, daß gleich zu Beginn der Verhandlungen über diesen Gegenstand G. Mainalow [?] nachdrücklich erklärte, die akademische Ausbildung müsse die Regel bilden und Ausnahmen seien nur in ganz engem Rahmen, in einer Anmerkung" vorgesehen" 150 . Die Mitteilung Nikolajews trug sicherlich zur Beruhigung der in der DJV tätigen Volljuristen bei, die noch schwerwiegende Bedenken gegen die neue Form der Richter-

${ }^{143}$ Siehe dazu den nächsten Absatz.

144 Chef der DJV an Landes- und Provinzialverwaltungen/Abt. Justiz, 28. 12. 1945, BAB, DP1 SE Nr. 3561.

145 Chef der DJV an SMAD-Rechtsabteilung, 28. 12. 1945, BAB, DP1 SE Nr. 3478.

146 Aktenvermerk über eine Besprechung mit Nikolajew und Türksch, 8.1. 1946, BAB, DP1 VA Nr. 7313.

147 An der Besprechung nahmen Wilhelm Weiland und Ebert aus Dresden, Walther Hoeniger und Horst Schulze aus Potsdam, Willy Lange aus Magdeburg, Max Zwanziger aus Gera, sowie Fritz Paech und Wende von der DJV teil, siehe Anwesenheitsliste BAB, DP1 SE Nr. 3478. Zur Besprechung siehe den Vermerk Wendes vom 15. 1. 1946, BAB, DP1 VA Nr. 7320.

148 Vermerk über eine Besprechung von Nikolajew mit Kleikamp am 12.1. 1946, BAB, DP1 SE Nr. 3561 (daraus auch die Zitate); Vermerk Wendes, 15. 1. 1946, BAB, DP1 SE Nr. 3478.

149 Kleikamp an Wende, 21. 1. 1945 [sic, gemeint ist 1946], in: Wentker, Volksrichter, Dok. 11, S. $119 \mathrm{f}$. Nur die sächsische Justizabteilung wurde von der Äußerung Nikolajews unterrichtet und angewiesen, den Lehrgang in Bad Schandau nicht, wie vorgesehen, mit 70-80, sondern mit 30-40 Teilnehmern zu eröffnen: Kleikamp an Wende, 14. 2. 1946, Wende an Kleikamp, 15. 2. 1946, BAB, DP1 SE Nr. 3478.

150 Handschriftlicher Vermerk Schiffers, 23. 1. 1946, zu: Kleikamp an Wende, 21. 1. 1946, in: Wentker, Volksrichter, Dok. 11, S. 120; zur Identität G. Mainalows können keine Angaben gemacht werden. 
ausbildung hegten. Die SMAD-Rechtsabteilung, so kann aus dieser und einer ähnlichen Mitteilung vom Juli $1946^{151}$ geschlossen werden, wollte zwar den Richtermangel mit Hilfe von Volksrichterkursen beheben, war sich aber unsicher, welche Bedeutung dieser Ausbildungsform für die Heranziehung des juristischen Nachwuchses insgesamt zukommen sollte.

Auch in der Frage der Zweiteilung der Kurse in angehende Zivil- und Strafrichter war die SMAD-Rechtsabteilung im Frühjahr 1946 noch unentschieden. Als Schiffer am 18. März in Karlshorst über die Einwände von Vertretern der brandenburgischen Provinzialverwaltung gegen die Trennung der Lehrgänge berichtete, schloß sich Karassjow dessen Meinung an, daß die Teilung beizubehalten sei, da sechs bis acht Monate nicht ausreichten, „um die Kursusteilnehmer auf allen Gebieten genügend auszubilden"152. Noch bevor die entsprechende Anweisung Schiffers in Potsdam eingetroffen war153, forderte der Präsident der brandenburgischen Provinzialverwaltung Steinhoff die DJV in einem ausführlichen Schreiben auf, dieses Problem „nochmals mit der Rechtsabteilung der SMA in Karlshorst zu erörtern". Er begründete sein Plädoyer für die Aufhebung der Teilung damit, daß die Justiz universell einsetzbare Richter benötige, Zivilrecht und Strafrecht in der Praxis nicht voneinander zu trennen seien, die Teilnehmer sich nicht nach zwei Monaten für einen Rechtszweig entscheiden könnten und die Volksrichter im Volk dieselbe Autorität genießen müßten wie die Volljuristen. Das Argument der DJV, daß Spezialisierung zumindest in einem Fach auch gründlichere Kenntnisse mit sich bringe, ließ er nicht gelten, da das Niveau der Volljuristen ohnehin nicht erreicht werde; außerdem sei auch eine Fortbildung eher möglich, wenn auf bereits bekanntem Stoff aufgebaut werden könne ${ }^{154}$. Die DJV übersandte dieses Schreiben am 18. April an Karlshorst und teilte gleichzeitig mit, daß auf Anweisung der Sowjetischen Militäradministration in Brandenburg der dortige Richterlehrgang ungeteilt ablaufen würde ${ }^{155}$.

Bereits am 9. März 1946 hatte auch Ulbricht gegenüber der SMAD-Rechtsabteilung Bedenken hinsichtlich der Zweiteilung der Kurse vorgebracht, da dadurch "die Position dieser jungen Kader gegenüber den alten Richtern" erheblich geschwächt würde und da die neuen Volksrichter an unteren Gerichten mit nur einem Richter nicht einsetzbar seien ${ }^{156}$. Die Rechtsabteilung reagierte jedoch erst, als ihr das Schreiben Steinhoffs vorlag - möglicherweise ein Indiz dafür, daß sie sich damals in Justizangelegenheiten weniger auf die Ratschläge der deutschen Kommunisten als die der deutschen Behörden stützen wollte. Unter ausdrücklicher Bezugnahme auf die "Wünsche der Provinzialverwaltung Brandenburg" riet

151 Vermerk Wendes über eine Unterredung mit Lyssjak am 4. 7. 1946, BAB, DP1 SE Nr. 3561: „Herr Lyssiak fragte hierauf, ob es meine Absicht sei, die Ausbildung von Volksrichtern jetzt in den Vordergrund zu stellen. Als ich das unter Hinweis auf den gegenwärtigen Bedarf bejahte, erklärte er, grundsätzlich müsse der Richterstand sich weiter aus akademisch gebildeten Richtern ergänzen.“ 152 Vermerk über Besprechung Schiffers mit Karassjow am 18. 3. 1946, BAB, DP1 VA Nr. 11, Bl. 27.

153 Chef der DJV an den Präsidenten der Provinzialverwaltung Mark Brandenburg, Abt. Justiz, 26. 3.

1946, BAB, DP1 VA Nr. 10, Bl. 9.

154 Präsident der Provinzialverwaltung Mark Brandenburg an den Chef der DJV, 26. 3. 1946, in: Wentker, Volksrichter, Dok. 12, S. 120-123.

155 DJV an Rechtsabteilung der SMAD, 18. 4. 1946, BAB, DP1 SE Nr. 3478.

156 Ulbricht an den Chef der SMAD-Rechtsabteilung, 9. 3. 1946, in: Wentker, Volksrichter, Dok. 13, S. 124. 
Karassjow Schiffer am 13. Mai, von der Teilung der Lehrgänge in einen zivil- und einen strafrechtlichen Zweig abzusehen ${ }^{157}$. Auch dieses Verhalten zeigt, daß die SMAD-Rechtsabteilung damals nicht über ein geschlossenes Konzept zur Volksrichterausbildung verfügte, sondern, abgesehen von allgemeinen Vorgaben, bei der Ausgestaltung der Lehrgänge der DJV und den Landesverwaltungen einen relativ großen Handlungsspielraum gewährte. Kam es indes zu Konflikten zwischen den Verwaltungen in der Zentrale und den Ländern, stand die Rechtsabteilung als Schlichtungsinstanz bereit. Damit war auch sichergestellt, daß das endgültige Entscheidungsrecht ihr vorbehalten blieb.

\section{Die ersten Jabre der Volksrichterausbildung (1946-1948)}

Den Handlungsspielraum, der sich durch die weitgehende Zurückhaltung der SMAD-Rechtsabteilung ergab, wollte vor allem Hilde Benjamin nutzen, die in der SED im Hinblick auf die Volksrichterfrage tonangebend wurde. Im Frühjahr 1946 ging sie davon aus, daß „mit einer grundlegenden allgemeinen neuen Gesetzgebung zurzeit [sic] nicht zu rechnen “ sei158. Neuerungen im Justizwesen seien nur durch eine Rechtsprechung zu erreichen, die mit den „politischen Forderungen [der SED] über die Ausgestaltung des Staates" im Einklang stünden. Und eine derartige "demokratische Rechtsprechung“ könne nur „durch den demokratischen Richter gesichert“ werden. Ihre logische Schlußfolgerung lautete: „Die Demokratisierung der Richterschaft ist die Kernfrage nicht nur für den Aufbau der Kader in der Justiz, sondern für die Entwicklung der Justiz überhaupt.“

Vor diesem Hintergrund ging ihr die Entnazifizierung der Justiz nicht weit genug: Politisch untragbar, da für die "demokratische Justiz“ in ihrem Sinne unbrauchbar, erschienen ihr nicht nur die ehemaligen NS-Juristen, sondern auch die älteren, durch das Dritte Reich nicht diskreditierten Richter und Staatsanwälte, „die durch alle 3 Systeme der letzten Jahrzehnte sich hindurchgewunden“ hätten. Freilich sah sie in Personalknappheit und Überalterung - sie rechnete mit einem Sofortbedarf von mindestens 800 und einem laufenden Bedarf von jährlich über 200 Richtern - „die entscheidende Chance“ für die „Demokratisierung der Richterschaft und damit der Rechtsprechung“. Den einzig erfolgversprechenden Weg zu diesem Ziel bildete für Benjamin folglich „die beschleunigte Heranbildung von Laien, d.h. der Volksrichter". Um in ihrem Sinne einsetzbar zu sein, mußten bei der Kandidatenauswahl für die Lehrgänge folgende Kriterien den Ausschlag geben: „politisch klare Ausrichtung, Bewußtsein der politischen Stellung, Rechtsempfinden, praktische Erfahrung - und auch Lernfähigkeit“. In ihren Formulierungen zeichneten sich bereits die Konturen eines neuen Richtertyps ab: Gefragt war nicht mehr der primär sachkompetente, unpolitische, ausschließlich dem Recht und der Gerechtigkeit verpflichtete Richter, sondern der auf die politischen Forderungen der SED eingeschworene und organisatorisch in die Partei eingebundene ${ }^{159}$ Justizfunktionär. Daher plädierte Benjamin abschließend dafür, in den

157 Rechtsabteilung der SMAD an den Chef der DJV, 13.5. 1946, Übersetzung, BAB, DP1 SE Nr. 3478.

158 Zur Kaderfrage in der Justiz, o.D., in: Wentker, Volksrichter, Dok. 14, S. 125-133.

${ }^{159}$ In dem Dokument heißt es auch, daß der Volksrichter nur durch „die Aufrechterhaltung des le- 
Volksrichtern keinen "Notbehelf“ zu sehen, die Richterschulen neben den Universitäten als zweite Ausbildungsstätte für Juristen auszubauen und auch nach Deckung des gegenwärtigen Personalbedarfs beizubehalten.

Die tatsächliche Entwicklung der Volksrichterausbildung zwischen 1946 und 1948 entsprach indes nicht dieser deutlich umrissenen Zielperspektive. Denn der maßgebende Einfluß auf die Volksrichterausbildung in der DJV wurde auch weiterhin von anderen Personen als Benjamin ausgeübt. Schiffer fand sich zwar im Verlauf dieser Zeit mit der Institution der Volksrichter ab, verfolgte damit aber eine andere Zielsetzung als Benjamin. Die wissenschaftliche Jurisprudenz, so führte er im Februar 1947 aus ${ }^{160}$, habe die von ihm beklagte Entfremdung von Recht und Volk nicht verhindern können. Im Unterschied zu 1945, als er noch daran gedacht hatte, bürgerliche Honoratioren und Rechtspfleger in den höheren Justizdienst aufzunehmen, sah er nun in der Volksrichterausbildung, deren erste Ergebnisse seine - offensichtlich geringen - Erwartungen übertroffen hatten, eine Möglichkeit nicht nur „zur Abhilfe der akuten Richternot“, sondern auch „zur Abhilfe der chronischen Rechtsnot". Seiner Ansicht nach sollten sich Volksrichter und Volljuristen gegenseitig ergänzen. Durch ihre Zusammenarbeit in der Praxis sollten bei den älteren, traditionell ausgebildeten Richtern „die letzten Reste von Kastengeist und Standeshochmut sowie von bürokratischer Kleinlichkeit und Engherzigkeit verschwinden“, während die neuen Richter von ihren Kollegen fachlich profitieren und dadurch „Selbstvertrauen gewinnen, Minderwertigkeitsgefühle abstreifen und sich mit ganzer Seele ihrem Berufe hingeben" würden. Seine Vision umriß er mit folgenden pathetischen Sätzen: „Beide Ströme werden sich zu einem großen und starken Strom vereinigen, der das glückhafte Schiff der deutschen Justiz in die Zukunft tragen soll. Sein Wimpel zeige die Worte: Demokratischer Rechtsstaat."

Zwar hatte sich Schiffer (wie auch der thüringische Justizminister Külz161) mit seinen anerkennenden Worten gegenüber den Volksrichtern von früheren Positionen getrennt ${ }^{162}$; er beharrte jedoch darauf, daß eine gute juristische Vorbildung für einen Richter unabdingbar sei ${ }^{163}$. Darin stimmte er mit Wende überein, der das Ziel einer möglichst professionellen Richterausbildung verfolgte ${ }^{164}$. Dessen Nachfolger als Abteilungsleiter, Otto Hartwig (CDU), arbeitete seit 1947 eng mit Hilde Benjamin zusammen und erwies sich als so anpassungsfähig, daß er zu den wenigen nicht der SED angehörenden Angestellten zählte, die aus der DJV ins DDRJustizministerium übernommen wurden. Dies änderte freilich nichts daran, daß

bendigen Zusammenhanges mit den politischen Organisationen der Arbeiterschaft " davor bewahrt werden könne, sich den noch tätigen alten Richtern anzupassen, ebenda, S. 131.

160 Eugen Schiffer, Volksrichter, in: Tägliche Rundschau, 21. 2. 1947.

161 Vgl. Justizminister Külz über den Richterberuf, in: Der Morgen, 30.1. 1947. Külz hatte diesem Artikel zufolge in einem Interview ausgeführt, "daß der mit der Berufung von Volksrichtern gemachte Versuch im wesentlichen als gelungen anzusehen sei“. Külz sah in der Volksrichterausbildung jedoch nur eine temporäre Maßnahme und strebte langfristig wieder den akademisch gebildeten Volljuristen an.

162 Die Äußerungen von Schiffer und Külz wurden von Benjamin auf der 1. Juristenkonferenz der SED am 1./2. 3. 1947 positiv registriert, SAPMO, DY 30 IV 2/1.01/37, Bl. 46.

${ }^{163}$ So Schiffer auf einer Dienstbesprechung der DJV am 16. 10. 1946, BAB, DP1 VA Nr. 7345.

164 Vgl. dazu den Bericht: Der erste Richterlehrgang, in: Wentker, Volksrichter, Dok. 16, S. 135-146, insbesondere die Äußerungen zur Auswahl der Hörer sowie zum Ziel der Abschlußprüfung. 
die DJV bis ins Jahr 1948 hinein vor allem um eine Optimierung, nicht aber um eine Ideologisierung der Volksrichterausbildung bemüht war. Deutlich wird diese Zielsetzung 1946 an den Lehrplänen und der Verlängerung der Lehrgangsdauer von sechs auf acht Monate. Das von der DJV am 17. Januar 1946 der SMADRechtsabteilung eingereichte Lehrprogramm ${ }^{165}$ entsprach genau den Ausführungen der „Ordnung betreffend die Einrichtung von juristischen Fachschulen“ und wurde am 24. Januar von Karassjow als „Musterlehrplan der juristischen Kurse“ bestätigt ${ }^{166}$. Dieser ging jedoch noch von der Aufteilung der Kurse in einen zivilrechtlichen und einen strafrechtlichen $Z$ weig aus und war daher mit der Aufhebung der Zweiteilung durch Karassjow überholt. Aufgrund von Erfahrungen mit den Lehrgängen in Schwerin ${ }^{167}$ sowie einer Anfrage der sächsischen Landesverwaltung beantragte Schiffer zudem am 14. Juni 1946 bei der SMAD-Rechtsabteilung, die Kurse „um wenigstens einen Monat" zu verlängern. Denn es schien ihm „wichtiger, auf den Zuwachs an neuen Richtern und Staatsanwälten [...] noch einen Monat länger zu warten, als ungenügend vorgebildete Kräfte verfrüht in die Praxis aufzunehmen"168. Da schon bald klar wurde, daß auch sieben Monate nicht ausreichten, bat Schiffer bereits am 2. Juli in Karlshorst darum, einer Verlängerung "um wenigstens zwei Monate zuzustimmen" 169 . Beide Anträge wurden von der SMAD-Rechtsabteilung positiv beschieden ${ }^{170}$.

Der daraufhin geänderte, ab dem zweiten Lehrgang gültige Lehrplan sah vor allem mehr Zeit für die Vertiefung des vermittelten Stoffs in sogenannten „konversatorischen Übungen" vor. Zudem sollte stärker auf die Verbindung von Theorie und Praxis geachtet, also den Lehrgangsteilnehmern Gelegenheit gegeben werden, sich mit der Arbeit eines Juristen an einem Gericht vertraut zu machen. Eine soziologische Vorlesung über „Recht, Gesellschaft und Wirtschaft“, deren Programm in Karlshorst aufgestellt werden sollte, wurde auf 24 Stunden beschränkt. Zwar war damit deutlich geworden, daß die SMAD-Rechtsabteilung sich des ideologisch relevanten Teils der Ausbildung besonders annehmen wollte; deren Gewicht war jedoch im Vergleich zur Gesamtstundenzahl eher zu vernachlässigen. Insgesamt wurde daher die Verlängerung des Lehrgangs nicht für eine Ideologisierung, sondern für eine Verbesserung der fachlichen Ausbildung genutzt ${ }^{171}$.

Wende, der sich noch dem Grundgedanken der akademischen Juristenausbildung verpflichtet fühlte, erschien ein Mindestmaß an wissenschaftlicher Ausbildung als eine auch für die Volksrichter unabdingbare Voraussetzung, um sich in

165 Chef der DJV an SMAD-Rechtsabteilung, 17. 1. 1946, BAB, DP1 VA Nr. 1049, Bl. 7.

166 SMAD-Rechtsabteilung an Chef der DJV, 26. 1. 1946, ebenda, Bl. 9; „Musterlehrplan der juristischen Kurse" ebenda, Bl. 11.

167 Siehe den Zusatzbericht über die Juristischen Schulen der Selbstverwaltung des Landes Mecklenburg-Vorpommern, 29. 4. 1946, BAB, DP1 VA Nr. 10, Bl. 13-17, und das darauf an die Justizabteilung in Schwerin gesandte Schreiben der DJV, 1. 6. 1946, BAB, DP1 SE Nr. 3478.

168 DJV an Rechtsabteilung der SMAD, 14. 6. 1946, BAB, DP1 VA Nr. 824, Bl. 8.

169 DJV an Rechtsabteilung der SMAD, 2.7. 1946, ebenda, B1. 21.

170 SMAD-Rechtsabteilung an DJV, 17.7. 1946, BAB, DP1 SE Nr. 3478; Niederschrift über die Besprechung am 17.8.1946, BAB, DP1 SE Nr. 3556.

171 DJV an Landes- und Provinzialverwaltungen/Abt. Justiz, 24. 9. 1946, BAB, DP1 VA Nr. 7676, Bl. 49; der beigefügte Lehrplan Bl. 50-53. Vgl. dazu auch Vermerk Wendes vom 31.7. 1946, SAPMO, DY 30 IV 2/13/445, und die Niederschrift über die Besprechung vom 17. 8. 1946, BAB, DP1 SE Nr. 3556. 
der Praxis zurechtzufinden ${ }^{172}$. Die Erwartungen an die Absolventen gingen indes über die unmittelbare juristische Befähigung hinaus. Da sie - im Unterschied zu Universitätsabsolventen - über „eine in den verschiedensten Berufen geübte Lebenserfahrung verfügten“, sollten sie, wie es in einer ersten Rundverfügung der Justizverwaltung zur Volksrichterausbildung hieß, „in besonderem Maße dazu beitragen, die staatliche Rechtspflege in engem Zusammenhang mit dem sozialen und wirtschaftlichen Leben zu halten“. Dazu sei in den Lehrgängen „auf die soziale Funktion des Rechts grundsätzlich und immer wieder größter Wert zu legen "173. Diese Aussage als Ergebnis kommunistischer Einflußnahme zu deuten, geht sicher zu weit; gerade der Verweis auf die Lebenserfahrung der Absolventen legt eher nahe, sie im Kontext der Bestrebungen Schiffers zu sehen, die Kluft zwischen Volk und Recht zu überwinden.

Um ihre Aufgabe der „methodischen Leitung“ der Kurse zu erfüllen, ließ sich die DJV Berichte aus den Ländern übersenden und führte Kontrollbesuche vor Ort durch. Anhand dieser Informationen gewann man in Berlin ein umfassendes Bild von den Lehrgängen. Auf dieser Grundlage gab die DJV vor allem methodische und didaktische Hinweise zur Qualitätsverbesserung der Ausbildung. Dazu zählten die Aufforderung, in Anlehnung an die Praxis im sächsischen Lehrgang den vormittags vorgetragenen Stoff am Nachmittag in konversatorischen Übungen nachzuarbeiten, und die Empfehlung, freiwillige Arbeitsgemeinschaften zu bilden, in denen stärkere Schüler den schwächeren beim Nacharbeiten des Stoffes behilflich sein könnten. Hinzu kamen ein Ratschlag an die Lehrgangsleiter, möglichst frühzeitig die Teilnehmer im mündlichen und schriftlichen Ausdruck zu üben, sowie der Hinweis auf die „tunlichst enge Verbindung des Unterrichts mit der gerichtlichen Praxis": Dazu forderte die DJV nicht nur die - entsprechend vorbereitete - Teilnahme an Gerichtssitzungen, sondern auch, daß den Hörern Einblicke in die sonstige Arbeit der Gerichte und Staatsanwaltschaften, etwa durch Aktenlektüre, gewährt würde ${ }^{174}$.

Eine möglichst effiziente und effektive Ausbildung hing freilich auch von der Unterbringung der Schule ab. Bereits am 19. Juni 1946 sprach sich Wende für die Unterrichtung der künftigen Volksrichter in einem Internat aus ${ }^{175}$, und am 2. Juli bat die DJV die SMAD-Rechtsabteilung, die Errichtung derartiger Lehranstalten in allen Ländern zu billigen und zu unterstützen ${ }^{176}$. Denn die Erfahrungen mit dem einzigen Volksrichter-Internat im sächsischen Bad Schandau hatten gezeigt, daß der enge Kontakt zwischen Dozenten und Hörern auf der einen und zwischen den Hörern untereinander auf der anderen Seite ein wesentlich intensiveres Lernen und Arbeiten ermöglichte als die Externate in den anderen Ländern. Hinzu kam, daß die Schüler eines Internats von den in der Nachkriegszeit besonders zeit- und kräfteraubenden wirtschaftlichen Sorgen des Alltags entlastet wur-

172 Wende, Der erste Richterlehrgang, in: Wentker, Volksrichter, Dok. 16, S. 144.

${ }_{173}$ DJV an Landes- und Provinzialverwaltungen/Abt. Justiz, 30.4. 1946, BAB, DP1 VA Nr. 10, Bl. 19.

174 Vgl. ebenda und den Bericht Wendes über den ersten Richterlehrgang, in: Wentker, Volksrichter, Dok. 16, hier S. $143 \mathrm{f}$.

175 Vermerk Wendes für Schiffer, 19. 6. 1946, BAB, DP1 VA Nr. 6782, Bl. 49.

176 DJV an SMAD-Rechtsabteilung, 2. 7. 1946, BAB, DP1 VA Nr. 824, Bl. 21. 
den. Zwar erkannte auch die sowjetische Besatzungsmacht diese Vorteile an ${ }^{177}$; angesichts der Zerstörungen des Bombenkrieges dauerte es bis zur Eröffnung eines weiteren Internates (in Schwerin-Zippendorf) jedoch bis zum dritten Lehrgang ${ }^{178}$. Aufgrund fehlender Räumlichkeiten konnten die Lehrgänge in Thüringen erst ab $1948^{179}$ und in Sachsen-Anhalt und Brandenburg erst ab 1949180 in Internaten durchgeführt werden. Zudem stellte der Mangel an Gesetzestexten und juristischer Fachliteratur ein ernsthaftes Problem dar. Die DJV appellierte zunächst an die Dozenten, für die Hörer Übersichten über gehaltene Lektionen zu erstellen, bemühte sich aber auch selbst um den Neudruck von Gesetzestexten sowie Kurzkommentaren und verwies die Landesjustizverwaltungen auf entsprechende Neudrucke in anderen Zonen. Aufgrund der allgemeinen Papierknappheit blieb die Versorgung mit dem einschlägigen Schrifttum aber unbefriedigend ${ }^{181}$.

Neben den materiellen Schwierigkeiten konnte fehlendes qualifiziertes Lehrpersonal den Erfolg der Lehrgänge beeinträchtigen. Dieses allgemeine Problem beschrieb Benjamin zutreffend mit den Worten: „Besteht schon allgemein ein Mangel an Juristen, sind die Rechtsanwälte z. Zt. allgemein überlastet, so ist es doppelt schwer, Lehrer zu finden, die Zeit, Liebe zur Sache und Verantwortung mit gründlichen juristischen Kenntnissen und pädagogischer Befähigung verbinden. “182 Wende teilte zunächst diese Einschätzung und kritisierte, „daß ein Teil der Dozenten im Anfang mit zu starker innerer Reserve an seine Aufgabe herangegangen" 183 sei, zog aber nach dem ersten Lehrgang eine positive Bilanz: Seines Erachtens war „ein entsprechend hohes Niveau fast durchweg erreicht worden“, und „der bei weitem größte Teil der Dozenten“ - die sich vornehmlich aus Angehörigen der Landesverwaltungen, der Gerichte und der Anwaltschaft zusammensetzten - sei seiner Aufgabe ,in einem erfreulichen Idealismus gerecht geworden“184. Kritik kam vor allem von kommunistischer Seite. Der u. a. für das Justizwesen zuständige Vizepräsident von Mecklenburg-Vorpommern, Gottfried Grünberg, bezichtigte die Lehrkräfte nicht nur, „mit einem gewissen Unglauben an diese Sache" herangegangen zu sein, sondern unterstellte ihnen auch, ihre Lehrtätigkeit nicht ernst genug zu nehmen: Ihre Rechtsanwaltskanzlei etwa sei ihnen wichtiger als ihre Arbeit in den Kursen. Sein Hauptvorwurf richtete sich freilich gegen die fehlende marxistische Fundierung ihres Unterrichts, was etwa dazu führe, daß den Lehrgangsteilnehmern „das Wesen des Staates nicht richtig“

177 Wende, Der erste Richterlehrgang, in: Wentker, Volksrichter, Dok. 16, S. 139.

178 Bericht über den Beginn des dritten Volksrichter-Lehrgangs, ebenda, Dok. 19, S. 153.

179 Das Internat wurde am 1. 9. 1948 in Gera-Roschütz eröffnet: vgl. Barth an DJV, 4. 10. 1948, BAB, DP1 SE Nr. 3545.

180 Das Internat in Sachsen-Anhalt wurde in Halle, das in Brandenburg im Schloß Potsdam-Babelsberg errichtet: vgl. Bericht über den Besuch des 4. Richterlehrgangs in Halle/S. am 23. und 24. 6. $1949, \mathrm{BAB}, \mathrm{DP} 1 \mathrm{VA} \mathrm{Nr} .6527$, und Bericht über den Besuch des Richterlehrgangs in Babelsberg [am 27. 5. 1949], BAB, DP1 SE Nr. 3552. Der erste Brandenburger Richterlehrgang hatte 1946 in Berlin stattgefunden und war aufgrund eines Befehls der SMA in Brandenburg zum 1.8.1946 nach Potsdam verlegt worden, Vermerk o.V., o.D. [Juli 1946], BAB, DP1 VA Nr. 6782.

181 Vgl. Wentker, Volksrichter, Dok. 16, S. 143, Dok. 18, S. 150.

182 Anregungen zur Behebung einiger Mängel an den Richterschulen, von Benjamin am 12.6. 1946 an Melsheimer übermittelt, BAB, DP1 VA Nr. 824, Bl. 12-15, hier 13.

${ }^{183}$ Niederschrift über die Besprechung vom 17. 8. 1946, BAB, DP1 SE Nr. 3556.

184 Wende, Der erste Richterlehrgang, in: Wentker, Volksrichter, Dok. 16, S. 138. 
erklärt werde ${ }^{185}$. Der Mangel an marxistischen Lehrkräften kam jedoch den Bestrebungen Wendes und anderer Nicht-Kommunisten in der DJV entgegen, den Unterricht in den Volksrichterschulen weitgehend ideologiefrei zu halten.

Vollkommen andere Voraussetzungen herrschten auf den ersten Blick bei den potentiellen Schülern: Die „aktiven Antifaschisten“, die über 25 Jahre alt waren und (mindestens) über Volksschulbildung verfügten, bildeten zweifellos ein sehr viel größeres Personalreservoir. Dennoch stellte die Auswahl hinreichend befähigter Schüler, die das Lehrgangsziel in der vorgeschriebenen knappen Zeit erreichten, ein Dauerproblem dar. Beim ersten Lehrgang besaßen die zugelassenen Parteien das Vorschlagsrecht; die endgültige Auswahl trafen die Landes- und Provinzialverwaltungen aufgrund von Einzelgesprächen mit den Kandidaten. Diesem Verfahren lag die Überlegung zugrunde, daß die Parteien vor allem für die ,antifaschistisch-demokratische Haltung" garantieren und die Verwaltungen die Bewerber vornehmlich unter fachlichen Gesichtspunkten beurteilen sollten. Die Auswahlpraxis für den ersten Lehrgang stieß schon bald auf Kritik bei der SMAD-Rechtsabteilung und der KPD-Führung186. Karassjow und Nikolajew beanstandeten, daß bei einigen Schülern des Richterlehrgangs in Gera die „antifaschistische Einstellung nicht nachgeprüft sei“"187. Die DJV überprüfte umgehend die personelle Zusammensetzung des Geraer Lehrgangs, wies die thüringische Landesjustizverwaltung zurecht ${ }^{188}$, und verdeutlichte in einem Rundschreiben, daß die Vorschrift, nur "aktive Antifaschisten“ zuzulassen, auch ehemalige HJMitglieder und Wehrmachtsoffiziere von der Teilnahme ausschloß; des weiteren wurden politische Zuverlässigkeit, geistige Eignung, Charakterfestigkeit und persönliche Reife als Auswahlkriterien genannt ${ }^{189}$.

Wende bemängelte an den für den ersten Lehrgang Ausgewählten vor allem dreierlei: zu geringes Allgemeinwissen, das zu hohe Alter einiger Personen sowie die oftmals falsche Einstellung zum künftigen Beruf. Eine Anzahl von Kandidaten hatte vornehmlich an eine politische Funktion gedacht und daher ihren Unmut über die intensive juristische Ausbildung geäußert. Wende, dem es primär auf die fachliche und persönliche Eignung ankam, unterbreitete daher Verbesserungsvorschläge für die Personalauswahl. Neben einer strikten Einhaltung der Altersgrenzen (25 Jahre Mindest- und 45 Jahre Höchstalter) setzte er vor allem auf eine stärkere Einbindung der Parteien in das Selektionsverfahren, indem die endgültige Entscheidung einem Ausschuß aus Vertretern der Parteien, der Landesverwaltung

185 Niederschrift über die Besprechung vom 17. 8. 1946, BAB, DP1 SE Nr. 3556. Um dieses Defizit zu beheben, wollte Grünberg den Dozenten Themen und ausgearbeitete Thesen vorgeben. Auch Benjamin hatte in ihren "Anregungen zur Behebung einiger Mängel an den Richterschulen" gefordert, "ganz genaue Grundrisse für jedes einzelne Fach in der Deutschen Justizverwaltung “ auszuarbeiten, BAB, DP1 VA Nr. 824, Bl. 13. Zur relativ geringen Politisierung der Lehrerschaft des 2. Richterlehrgangs in Bad Schandau vgl. Pfannkuch, Volksrichterausbildung, S. $47 \mathrm{f}$.

186 Polak an DJV, 27. 3. 1946, DP1 SE Nr. 3545.

187 Vermerk Wendes über eine Unterredung mit Karassjow und Nikolajew am 8. 4. 1946, BAB, DP1 SE Nr. 3478. Bei einer Überprüfung des Lehrgangs stellte Wende fest, daß 10 der 20 Teilnehmer bereits akademisch vorgebildet waren und sich unter ihnen ein ehemaliger Leutnant befand: Vermerk Wendes, 13. 4. 1946, BAB, DP1 SE Nr. 3545.

188 DJV an SMAD-Rechtsabteilung, 25. 4. 1946, BAB, DP1 SE Nr. 3478. Zum weiteren Verlauf und den Ergebnissen des Lehrgangs Weber, Justiz und Diktatur, S. 46.

189 DJV an Landes- und Provinzialverwaltungen/Abt. Justiz, 30. 4. 1946, BAB, DP1 VA Nr. 10, Bl. 18 . 
und der DJV übertragen wurde. Dadurch sollten die Parteien genötigt werden, bei ihren Empfehlungen nicht nur auf die politische Zuverlässigkeit, sondern auch auf die anderen Eigenschaften ihrer Kandidaten zu achten. Um genügend Auswahlmöglichkeiten zu erhalten - und wahrscheinlich auch, um die Dominanz von Bewerbern aus einer einzigen Partei zu verhindern -, sollte zudem jede politische Gruppierung so viele Vorschläge unterbreiten, wie Plätze in einem Lehrgang vorhanden waren. Schließlich wollte er die mündliche Aufnahmeprüfung - die Aufschluß über das Motiv des Bewerbers und seine geistige Aufnahmefähigkeit geben sollte - durch eine schriftliche Aufsichtsarbeit ergänzen, um das Verfahren zu objektivieren ${ }^{190}$.

Die SMAD-Rechtsabteilung lehnte diese Anregungen jedoch ab und hielt an dem bisherigen Verfahren fest ${ }^{191}$. Auch in den zweiten Lehrgang wurde daher eine Reihe ungeeigneter Kandidaten aufgenommen, die aufgrund „krimineller Belastung“, "politischer Unzulänglichkeit", „empfindlicher Lücken der allgemeinen Bildung" oder aufgrund "unzureichende[r] Auffassungsgabe" vorzeitig ausscheiden mußte ${ }^{192}$. Dies lag indes nicht nur an den Prüfungsverfahren, sondern auch an den Parteien, die ihre fähigsten Mitglieder selbst benötigten und nicht für den Justizdienst freigeben wollten ${ }^{193}$. Erst als die SMAD-Rechtsabteilung im April 1947 das Entfernen nicht geeigneter Schüler von den Lehrgängen untersagte ${ }^{194}$, billigte sie eine Reform des Auswahlverfahrens, wie sie Wende vorgeschlagen hatte: Alle Bewerber mußten nun auch eine schriftliche Arbeit anfertigen, und Vertreter der Parteien und Massenorganisationen konnten "mit beratender Stimme“ am Zulassungsausschuß beteiligt werden ${ }^{195}$. Da somit die Aufnahme von Bewerbern mit unzureichenden orthographischen und sprachlichen Fähigkeiten verhindert werden konnte, gelang beim dritten Lehrgang eine bessere und sorgfältigere Auslese der Teilnehmer als zuvor ${ }^{196}$. Freilich bot die schriftliche Aufnahmeprüfung eine zusätzliche Möglichkeit, die politische Einstellung der Bewerber zu überprüfen eine Möglichkeit, von der durchaus Gebrauch gemacht wurde ${ }^{197}$.

Auch bei den Abschlußexamina ging es den maßgeblichen DJV-Mitarbeitern um die Sicherung größtmöglicher Qualität. Die Prüfung bestand, wie in der "Ordnung betreffend die Einrichtung von juristischen Fachschulen" festgelegt, aus je einer Aufsichtsarbeit im Zivilrecht und im Strafrecht sowie aus einer münd-

190 Wende, Der erste Richterlehrgang, in: Wentker, Volksrichter, Dok. 16, S. 140-142, und Vermerk Wendes für Schiffer, 19. 6. 1946, BAB, DP1 VA Nr. 6782, Bl. 46-48.

${ }_{191}$ DJV an SMAD-Rechtsabteilung, 2. 7. 1946, BAB, DP1 VA Nr. 824, Bl. 20f. Zur Ablehnung siehe DJV an die SMAD-Rechtsabteilung 29. 4. 1947, BAB, DP1 SE Nr. 3476. Einer Kontingentierung der Bewerbervorschläge wurde hingegen zugestimmt: vgl. dazu Schiffer an Landesverwaltung Sachsen, 5. 8. 1946, in: Pfannkuch, Volksrichterausbildung, S. 43.

192 Bericht über den 2. Lehrgang für Richter und Staatsanwälte, 19.9. 1947, Wentker, Volksrichter, Dok. 18, S. 149.

193 Siehe ebenda und Schiffers Äußerungen vor dem zentralen Blockausschuß am 21.11. 1946, in: Suckut, Blockpolitik, S. $171 \mathrm{f}$.

194 Siehe dazu weiter unten, S. 153.

195 DJV an die Landes- und Provinzialregierungen/Justizministerien, 29.4. und 27. 5. 1947, BAB, DP1 SE Nr. 3478.

196 So das übereinstimmende Urteil der Lehrgangsleiter: siehe Bericht über die Zusammenkunft der Leiter der Richterlehrgänge in Bad Schandau vom 10.-12. 12. 1947, in: Wentker, Volksrichter, Dok. 20, S. 161.

197 Siehe die Aufstellung von Aufsatzthemen für den 3. sächsischen Lehrgang bei Welsh, Revolutionärer Wandel, S. 152. 
lichen Prüfung. Die Prüfungskommission sollte sich nach den Ausführungen von Major Solotajew von der SMAD-Rechtsabteilung vom August 1946 aus einem Vertreter der Landesverwaltung als Vorsitzendem, dem Lehrgangsleiter und einem Vertreter der Staatsanwaltschaften und der Gerichte zusammensetzen; die Dozenten der Prüfungsfächer waren hinzuzuziehen, und ein Mitglied der DJV konnte an der Kommission teilnehmen ${ }^{198}$. Trotz leichter Abweichungen von den Vorstellungen Wendes war damit gewährleistet, daß die DJV auf Einheitlichkeit und die Einhaltung von Mindeststandards bei den Examina achten konnte. Sie nutzte diese Möglichkeit der Qualitätssicherung, indem sie nicht nur ihre Vertreter zu den Abschlußprüfungen entsandte, sondern auch, indem sie die Klausuren zentral von Berlin für alle Lehrgänge stellte ${ }^{199}$.

Aufgrund der kurzen Ausbildungsdauer fiel es Wende schwer, die Anforderungen an die Examenskandidaten festzulegen. Eines stand für ihn jedoch fest: Ziel der Prüfung durfte nicht die Feststellung sein, „ob der Prüfling weltanschaulich und nach seiner politischen und sozialen Gesinnung geeignet ist, die besonderen Aufgaben des mit dem Wort, Volksrichter' gekennzeichneten neuen Typs Richter und Staatsanwalt zu erfüllen“, da dies bereits bei der Zulassung feststehen müsse. Die positive Bestimmung des Prüfungsziels, nämlich „die Feststellung, ob der Prüfling sich im Lehrgang das Maß an Wissen und Verständnis erworben hat, das von den nächsten ihm in der Praxis gestellten Aufgaben bestimmt wird“, blieb jedoch ebenso allgemein wie die Hinweise, daß es bei den Absolventen auf Sachkenntnis, Denkvermögen und die Fähigkeit zur praktischen Anwendung des Gelernten ankomme. Die konkreten Richtlinien, etwa, daß man nicht mehr verlangen könne, „als zur Bewältigung eines erfahrungsgemäß häufiger zu erwartenden, durchschnittlich schwierigen Falles erforderlich" sei, daß man von einem praktischen Fall ausgehen und eher abseitige, spezielle Wissensgebiete vermeiden solle, waren hingegen als konkrete Hilfestellungen für die Prüfer vermutlich von größerem Nutzen ${ }^{200}$.

Die Examensergebnisse fielen insgesamt zur Zufriedenheit der DJV aus: Hatten im ersten Lehrgang 97 von 122 Kandidaten (79,5 Prozent) die Prüfung bestanden, waren es im zweiten Lehrgang 128 von 155 (82,6 Prozent). Während Wende sich im Dezember 1946 noch mit dem Hinweis begnügt hatte, daß „Unterschiede in den Leistungen nach der Vorbildung oder dem Geschlecht" nicht hervorgetreten seien, hob Hartwig im Hinblick auf soziale Schichtung und schulische Vorbildung der Prüflinge des zweiten Lehrgangs hervor, „daß sich auch Arbeiter ohne gehobene Schulbildung unter den besten Absolventen der Lehrgänge befunden“ hätten. Der Prüfungsverlauf habe erwiesen, „daß die Arbeiterklasse und die Schichten, denen lediglich Volksschulbildung zur Verfügung stehen, Männer und Frauen in der Lage zu stellen sind, die auf Grund ihrer Intelligenz und Lebenserfahrung zu brauchbaren und sogar überdurchschnittlichen Richtern und Staatsanwälten

198 Niederschrift über die Besprechung vom 17. 8. 1946, BAB, DP1 SE Nr. 3556.

$199 \mathrm{Vgl}$. Wende, Der erste Richterlehrgang, in: Wentker, Volksrichter, Dok. 16, S. 144.

200 Vgl. die von der DJV am 2.11. 1946 an die Landesjustizverwaltungen versandten, von Wende ausgearbeiteten Prüfungsrichtlinien, BAB, DP1 VA Nr. 824, Bl. $36 \mathrm{f}$. Wie aus einem Entwurf der Richtlinien vom September 1946 hervorgeht, hatte Wende diese aufgrund von Beobachtungen der Prüfungen des ersten Lehrganges formuliert, BAB, DP1 VA Nr. 7320. 
herangebildet werden können"201. Diese Formulierungen deuten darauf hin, daß Hartwig, im Unterschied zu Wende, durchaus bereit war, im Sinne der SED zu argumentieren und zu handeln.

Nicht die Ergebnisse waren Anlaß zur Beunruhigung, sondern die Tatsache, daß zu wenige der ursprünglich aufgenommenen Schüler bis zur Prüfung kamen: Im ersten Kurs traten nur 122 von 172 Schülern (70,9 Prozent) und im zweiten 155 von 223 (69,5 Prozent) zum Abschlußexamen an. Zieht man nun noch die durchgefallenen Prüflinge ab, so hatten beim ersten Lehrgang nur 56,4 Prozent der Kursteilnehmer und beim zweiten nur 57,3 Prozent das Ziel erreicht ${ }^{202}$. Der Ausschluß von nicht geeigneten Schülern stellte eine qualitätssichernde Maßnahme dar, die Eingang in mehrere Rundverfügungen gefunden hatte ${ }^{203}$. Trotz Beanstandung durch die SMAD-Rechtsabteilung im August 1946 hielten die Verantwortlichen mit Billigung der DJV an diesem Verfahren fest ${ }^{204}$. Beim zweiten Kurs zeigte sich Karlshorst deutlich weniger zurückhaltend. Auf sowjetische Anordnung hin hatte die DJV der Rechtsabteilung Ende März 1947 Listen mit den Namen der aus dem Lehrgang Ausgeschiedenen übersandt. Darin waren 47 Teilnehmer aufgeführt, von denen sich 28 den Anforderungen nicht gewachsen gefühlt oder zu schwache Leistungen gezeigt oder die Zwischenprüfung nicht bestanden hatten $^{205}$. Die SMAD-Rechtsabteilung bezeichnete den Ausschluß eines großen Teils der Teilnehmer als „unbegründet" und fuhr fort: „Es hat sich erwiesen, daß Personen ausgeschlossen worden sind, die als Vertreter der breiten Volksmassen zu gelten haben und deren Heranziehung in die Justizbehörden notwendig ist. Die Tendenz, sich der Vorbereitung von Vertretern des Volkes zum Justizdienst zu entziehen, muß als antidemokratischer Versuch gewertet werden." Fortan, so die Rechtsabteilung, durften keine weiteren Hörer "wegen Nichtfolgenkönnens“ mehr ausgeschlossen werden, und sie war über „jeden Austritt oder Ausschluß eines Hörers" umgehend zu unterrichten ${ }^{206}$. Indem die DJV genötigt wurde, von ihrer bewährten Praxis abzurücken, mußte sie von dem angestrebten hohen fachlichen Niveau Abstriche machen. Die SMAD-Rechtsabteilung hatte zu erkennen gegeben, daß sie sich in der Volksrichterfrage nicht länger auf eine Zuschauerrolle beschränken wollte. Außerdem betrachtete sie die Lehrgänge offensichtlich nicht mehr nur als vorübergehende Maßnahme, um den Personalmangel im Justizwesen

$201 \mathrm{Vgl}$. Wende, Der erste Richterlehrgang, und Bericht über den 2. Richterlehrgang, in: Wentker, Dok. 16 und 18, S. $145 \mathrm{f} ., 151 \mathrm{f}$.

202 Die Zahlen ebenda, Dok. 16, S. 145, und Dok. 18, S. 152; die Teilnehmerzahlen bei Beginn des zweiten Lehrgangs befinden sich in einer ersten Fassung des Berichts über den 2. Lehrgang für Richter und Staatsanwälte, BAB, DP1 SE Nr. 3478.

${ }_{203} \mathrm{Vgl}$. Ordnung betreffend die Einrichtung von juristischen Fachschulen, o.D., in: Wentker, Volksrichter, Dok. 8, S. 116, sowie DJV an Landes- bzw. Provinzialverwaltungen/Abt. Justiz, 28. 12. 1945, BAB, DP1 SE Nr. 3561, 6. 4. 1946, BAB, DP1 SE Nr. 3478.

204 Vgl. dazu Wendes Schreiben an dic SMAD-Rechtsabteilung, 17. 8. 1946, BAB, DP1 VA Nr. 824, Bl. 28.

205 DJV an SMAD-Rechtsabteilung, 24.3., 31. 3. 1947, BAB, DP1 VA Nr. 7088.

206 Chef der Rechtsabteilung der SMAD an Chef der DJV, o.D. [9. 4. 1947], ebenda. Auf der Länderkonferenz am 11. 4. 1947 wiederholte Jakupow diesen Vorwurf, BAB, DP1 VA Nr. 6958, Bl. $29 \mathrm{f}$. Vgl. auch Abendroth, Justizreform, S. 1544, der die Abschaffung der Zwischenprüfung auf Anweisung der SMAD erwähnt. Die DJV setzte die Anordnung am 19.4. 1947 in eine Rundverfügung um, BAB, DP1 VA Nr. 7088. 
zu beheben; sie steuerte vielmehr - ähnlich wie die SED - die „Demokratisierung“ des Justizwesens durch einen umfassenden Personalwechsel an.

Auf einen im Vergleich zu 1945/46 größeren Gestaltungswillen der SMAD deutet auch Befehl Nr. 193 vom 6. August 1947 hin, der vor allem drei wesentliche Modifikationen gegenüber der bisherigen Praxis vorsah. Erstens befahl der Stellvertreter des Obersten Chefs der SMAD, Generalleutnant Dratwin, die Gesamtzahl der Teilnehmer auf 350 Personen zu erhöhen, von denen jeweils 80 in Sachsen, Sachsen-Anhalt und Thüringen, 60 in Brandenburg und 50 in Mecklenburg ausgebildet werden sollten. Zweitens wurde der Lehrgang auf ein Jahr verlängert, und drittens erfuhr die Rechtsstellung der Lehrgangsabsolventen durch Gleichstellung mit den Volljuristen eine verbindliche Regelung ${ }^{207}$. Im Unterschied zur Anordnung vom 17. Dezember 1945 hatte die SMAD diesen Befehl ohne nachweisbare Beratungen mit der DJV erlassen. Der Befehl hing möglicherweise mit den sowjetischen Bestrebungen zur Optimierung der juristischen Ausbildung im eigenen Lande zusammen. Die SMAD reagierte damit jedoch auch auf den nach wie vor bestehenden Mangel an Justizjuristen in der SBZ: Einer Aufstellung vom Herbst 1946 zufolge fehlten damals rund 400 Richter und 150 Staatsanwälte ${ }^{208}$. Mit der Verlängerung der Kurse auf ein Jahr kam die Militärverwaltung dem generellen Bedürfnis nach einer längeren Ausbildungszeit entgegen, ohne daß über diese Frage zuvor debattiert worden wäre.

Seit Abschluß des ersten Lehrgangs war außerdem deutlich geworden, daß die Rechtsstellung der Volksrichter normativ geregelt werden mußte. Denn Rechtsanwälte hatten, insbesondere in Sachsen, gegen Urteile von Volksrichtern wegen nicht ordnungsgemäßer Besetzung des Gerichts Revision eingelegt ${ }^{209}$. Daraufhin war die Frage, die auf „das besondere Interesse“ der SMAD stieß210, auf der Länderkonferenz vom 14. Dezember 1946 thematisiert worden. Grundlage der Diskussion bildete eine brandenburgische Verordnung über die Befähigung zum Richteramt vom 23. September 1946211, als deren "Vater" sich Ministerialdirektor Hoeniger bezeichnete. Er habe die Verordnung, die die Gleichberechtigung der Volksrichter mit denen gemäß $\$ 2$ GVG ausgebildeten Richter und Staatsanwälte festlegte, nach Absprache mit Melsheimer in Gegenwart eines Vertreters der SMA in Potsdam bei der Amtseinführung der Absolventen des ersten Lehrgangs verkündet; den Volksrichtern sollte damit das Bewußtsein vermittelt werden, „nicht als Richter zweiter Klasse" zu gelten. Jakupow kritisierte vor allem den brandenburgischen Alleingang und forderte eine gesamtzonale Regelung ${ }^{212}$. Erst sechs Monate später unterbreitete die DJV der SMAD-Rechtsabteilung einen entsprechenden Verordnungsentwurf „über die Fähigkeit der Absolventen der Richter-

207 Gedruckt in: ZVOBl. 1947, S. 165 f.

208 Aufstellung in: BAB, DP1 VA Nr. 10, Bl. $10 \mathrm{f}$.

${ }^{209}$ So Fenner auf der Länderkonferenz vom 13. 12. 1946, BAB, DP1 VA Nr. 6957, Bl. 227 f.; vgl. Feth, Volksrichter, S. 372.

210 Vermerk über Besprechung in Karlshorst am 4. 12. 1946, BAB, DP1 VA Nr. 6957, Bl. 174.

231 Verordnung über die Befähigung zum Richteramt, in: Verordnungsblatt der Provinziairegierung Mark Brandenburg 1946, S. 322.

212 Stenographisches Protokoll der Länderkonferenz vom 13.12. 1946, BAB, DP1 VA Nr.6957, Bl. 231 f., $238 \mathrm{f}$. 
lehrgänge zum Richteramt"213. Die Rechtsabteilung wollte die DJV jedoch nicht, wie von Schiffer vorgeschlagen, zum Erlaß einer gesamtzonalen Verordnung ermächtigen, sondern ordnete am 4. Juli an, den Entwurf den Landtagen „zur Erörterung und Annahme“ vorzulegen, da sie in der neuen Regelung „eine wesentliche Abänderung im GVG“ erblickte ${ }^{214}$. Gegenüber diesem Vorgehen, mit dem der Anschein einer zentralisierten, besatzungsrechtlich legitimierten Regelung vermieden werden sollte, bedeutete die Regelung der Frage durch einen SMAD-Befehl eine Wendung um $180 \mathrm{Grad}^{215}$. Auch daran wird deutlich, daß die Phase der Unsicherheit in der SMAD vorbei war: Nicht zuletzt aufgrund der Erfahrungen mit den ersten Lehrgängen setzte sie nun verstärkt auf Volksrichterkurse, um die Frage des juristischen Nachwuchses zu lösen.

Jakupow und Nikolajew hatten Melsheimer bereits am 25. Juli über eine mögliche Verlängerung der Lehrgänge auf ein Jahr informiert und um ein Konzept für die dann erforderliche Umgestaltung des Lehrplans gebeten ${ }^{216}$. Hartwig setzte trotz seiner größeren Anpassungsbereitschaft an die SED-Linie von Anfang an darauf, die zusätzliche Zeit für die Erweiterung schon bestehender Vorlesungen und für die Einführung einiger zusätzlicher Vorlesungen zu nutzen, „nach denen ein starkes Bedürfnis“ bestünde. Seine Vorstellungen wurden unverändert in die am 8. September 1947 an die Landesjustizministerien verschickten, verbindlichen Lehrpläne übernommen ${ }^{217}$. Das Begleitschreiben zu den Lehrprogrammen hob ausdrücklich hervor, daß die zusätzlichen Stunden der erweiterten Vorlesungen „für diejenigen Themen des 2. Volksrichterlehrgangs verwendet werden [sollten], die nach den Unterrichtserfahrungen den Schülern besonders schwer verständlich" seien. Das Stoffgebiet wurde vor allem in zweifacher Richtung erweitert: Es ging mit den Themen "Gesetzgebung der Besatzungsmächte“ und „Wirtschaftsstrafrecht" einmal um die Aufnahme aktueller Stoffe, die ein Richter oder Staatsanwalt in der SBZ beherrschen mußte, und zweitens um eine eingehendere, enger an das traditionelle Jura-Studium angelehnte Grundlegung der Ausbildung durch eine dreißigstündige „Einführung in die Rechtswissenschaft“ und einen auf zwanzig Stunden angelegten Abriß zur „rechtsgeschichtlichen Entwicklung in Deutschland“ vom Frühmittelalter bis zur Gegenwart. Die Vorlesung „Rechtssoziologie“, deren Gestaltung in den Händen der SED lag218, blieb trotz der Lehr-

${ }^{213}$ DJV an SMAD-Rechtsabteilung, 3. 6. 1947, BAB, DP1 VA Nr. 7161, Bl. 48.

214 Chef der SMAD-Rechtsabteilung an Chef der DJV, 4. 7. 1947, ebenda, Bl. 53. Mit Rundverfügung vom 18.7.1947 setzte die DJV die Weisung der SMAD-Rechtsabteilung um, ebenda, Bl. $54 \mathrm{f}$.

215 Obwohl nach Anfrage der DJV bei der SMAD am 19.9. 1947 der Gesetzentwurf mit deren Billigung per Rundschreiben vom 4. 10. 1947 zurückgezogen wurde (ebenda, Bl. 63, 66), verkündeten Mecklenburg und Sachsen auch nach dem Erlaß von Befehl Nr. 193 noch Gesetze über die Rechtsstellung der Volksrichter: siehe Gesetz über die Befähigung der Absolventen der Richterlehrgänge zum Richteramt, 12. 9. 1947, in: Regierungsblatt für Mecklenburg 1947, S. 249; Gesetz über die Fähigkeit der Absolventen der Richterlehrgänge zum Richteramt, 25. 2. 1948, in: Gesetz- und Verordnungsblatt Land Sachsen 1948, S. 137.

216 Vermerk Langes, 25. 7. 1947, BAB, DP1 VA Nr. 11, Bl. 115; Vermerk Hartwigs über eine Mitteilung Melsheimers, 25. 7. 1947, BAB, DP1 VA Nr. 1050, BI. 4.

217 Dies ergibt ein Vergleich des vorläufigen Vorschlags für die Abänderung der Lehrpläne der Volksrichter-Lehrgänge vom Juli 1947 (BAB, DP1 VA Nr. 1050, Bl. 7, dort das Zitat) mit dem verbindlichen Lehrplan (in: Wentker, Volksrichter, Dok. 25, S. 190 f.).

218 Siehe dazu unten S $161 \mathrm{f}$. 
gangsverlängerung auf 24 Stunden beschränkt ${ }^{219}$. Insgesamt wurde die zeitliche Ausweitung der Kurse von der DJV für eine Intensivierung der fachlichen Ausbildung, nicht aber zu einer verstärkten Ideologisierung genutzt.

Die SMAD-Rechtsabteilung nahm Befehl Nr. 193 auch zum Anlaß, um auf die notwendige Weiterbildung der Dozenten hinzuweisen. Major Schur leitete aus dem Passus des Befehls, demzufolge die DJV „auf die Güte des Unterrichts zu achten" habe, auch deren Verpflichtung zur Schulung des Lehrpersonals ab und forderte die Übersendung eines Schulungsplanes ${ }^{220}$. Die daraufhin an Karlshorst übermittelte Themenaufstellung enthielt neben besonders für die Volksrichterausbildung relevanten Themen wie die "Lehre vom richtigen Strafmaß" und der "Methodik des Unterrichts, insbesondere der praktischen Übungen“ vor allem aktuelle Rechtsgebiete wie "Gesetzgebung der Okkupationsmächte“, „Bauernrecht" und „landeseigene Betriebe“221. Außerdem schlug die DJV zur Beseitigung von Mängeln in der Methodik des Unterrichts eine Tagung der Lehrgangsleiter in Bad Schandau vor, damit diese dort „dem Unterricht und den Übungen [beiwohnen] und in gegenseitiger Aussprache in die Probleme der Methodik eingeführt" werden könnten ${ }^{222}$. Zwar machte der Besuch des Unterrichts den wesentlichen Teil der vom 10. bis 12. Dezember stattfindenden Konferenz aus; diese wurde freilich auch zu einem allgemeinen Meinungsaustausch der Kursleiter genutzt. Es ging dabei um die Unterbringung, die Lehrgangsleitung - die, so die übereinstimmende Meinung, von einem hauptamtlichen Leiter wahrgenommen werden müsse -, die Betreuung der ehemaligen Absolventen und die Auswahl der Lehrgangsteilnehmer. Der Bericht über die Tagung vermittelt den Eindruck, daß die Lehrgangsleiter, die alle der SED angehörten, nicht an der Vermittlung von Ideologie, sondern an einer wissenschaftlich fundierten, möglichst effektiv zu gestaltenden juristischen Ausbildung interessiert waren. Sie scheuten sich in diesem $\mathrm{Zu}$ sammenhang auch nicht, das brisante Problem der schlechten Schüler anzusprechen: Zwar wollten sie diese nach Kräften fördern, waren aber davon überzeugt, daß einige "hoffnungslose Fälle“ ausgeschlossen werden müßten ${ }^{223}$.

Die Tagung hatte ebenfalls die erheblichen Unterschiede in der Qualität der Ausbildungsstätten verdeutlicht. Bad Schandau war eindeutig die beste Einrichtung dieser Art: Sie war neben Schwerin-Zippendorf das einzige Volksrichterinternat, verfügte über „vorbildliche wirtschaftliche Einrichtungen“, wandte Methoden an, die den anderen Kursen zur Nachahmung empfohlen wurden, und ihr Lehrgangsleiter hatte ein besonderes Betreuungssystem für ehemalige Absolventen entwickelt. Mit dieser Bewertung stimmte auch eine im SED-Parteiapparat entstandene Aufzeichnung vom 9. Januar 1948 überein, die freilich nicht nur die

${ }^{219}$ Hartwig konstatierte in: Die Ausbildung der Volksrichter, S. 158, mit dem neuen Lehrplan könne die Soziologie "eingehend" behandelt werden, verschwieg aber, daß sich an der Stundenzahl nichts geändert hatte.

220 Vermerk Hartwigs, 26. 9. 1947, BAB, DP1 SE Nr. 3561.

221 Diese Themen wurden durch ein Referat zu „Bedeutung und Recht der Wirtschaftsplanung“ ergänzt und auf einer Fortbildungstagung in der DJV am 23./24. 3. 1948 behandelt: siehe DJV an Rechtsabteilung der SMAD, Januar 1948, und 5. 4. 1948, BAB, DP1 SE Nr. 3476.

222 Chef der DJV an Rechtsabteilung der SMAD, 9. 10. 1947, ebenda.

${ }^{223}$ Bericht über die Zusammenkunft der Leiter der Richterlehrgänge in Bad Schandau vom 10.12. 12. 1947, in: Wentker, Volksrichter, Dok. 20, S. 161. 
fachlichen Qualitäten, sondern auch die politische Ausrichtung und das „politische Leben" der einzelnen Volksrichterschulen bewertete224. Auch in dieser Hinsicht nahm die sächsische Richterschule vor allem wegen der rührigen SED-Betriebsgruppe 225 den Spitzenplatz ein. An zweiter Stelle folgte Schwerin-Zippendorf, wo "Ansätze zur Entwicklung eines gleich guten Niveaus" wie in Bad Schandau bestünden. Als „Problemkinder" galten hingegen die Schulen in Sachsen-Anhalt, Thüringen und Brandenburg, wo es nicht gelungen sei, „ein Internat $\mathrm{zu}$ schaffen und einen genügend gefestigten und unter politischen Gesichtspunkten befriedigenden Lehrkörper zu bilden". In dem SED-Papier kam der politischen Ausrichtung somit mindestens die gleiche Bedeutung wie den fachlichen Aspekten zu.

Damit geraten die Einwirkungsmöglichkeiten in den Blick, die von der KPD bzw. der SED in den Jahren 1946 bis 1948 in der Volksrichterausbildung genutzt wurden. Die Kommunisten machten ihren Einfluß vor allem bei der Kandidatenauswahl geltend. Sie konkurrierten hier mit den bürgerlichen Parteien, die - im Unterschied zur SPD 226 - sich aber eher desinteressiert zeigten ${ }^{227}$. Insbesondere auf seiten der CDU bestanden von Anfang an Bedenken im Hinblick auf die Rechtmäßigkeit dieser Form der Juristenausbildung, die durch das wieder in Kraft gesetzte Gerichtsverfassungsgesetz von 1924 nicht gedeckt sei228. Noch 1947 waren weite Kreise in der Union aufgrund der aus ihrer Sicht unzureichenden gesetzlichen Grundlage skeptisch gegenüber der neuen Richterausbildung: Da man in der CDU von einer künftigen, an das GVG angelehnten gesamtdeutschen Regelung ausging und eine Benachteiligung, wenn nicht gar Entlassung der bis dahin tätigen Volksrichter befürchtete, äußerte der Reichsverband der Union noch im Februar 1947 seine Bedenken gegenüber dieser Form juristischer Ausbildung229. Erst später wurde von seiten einzelner CDU-Landesverbände darauf hingewiesen, daß Kandidaten aus der Partei nominiert werden müßten, um „Gesinnungsfreunde[.] " in die Justiz einzubauen ${ }^{230}$. Die LDP hingegen entfaltete - zumindest in Thüringen - größere Aktivitäten bei der Werbung von Kandidaten für die Lehrgänge. Der Landesverband richtete auf seiner Parteischule in Friedrichroda im Juni 1947 einen vierwöchigen Vorkurs für von der Partei vorgeschlagene Bewerber ein. Die Begründung verdeutlicht die pragmatischen Motive der

${ }_{224}$ Ausbildung der Volksrichter, 9. 1. 1948, BAB, DP1 VA Nr. 10, Bl. $107 \mathrm{f}$.

$225 \mathrm{Vgl}$. Schulungsplan der Betriebsgruppe der Volksrichterschule in Bad Schandau in der Zeit vom 1. 11. 1948-28. 2. 1948, ebenda, Bl. 109. Dieser Schulungsplan bestand vornehmlich aus politischjuristischen Vorträgen, die von zum Teil prominenten sächsischen SED-Mitgliedern gehalten wurden.

${ }^{226}$ Der SPD-Zentralausschuß wies bereits am 3.12.1945 alle Bezirksvorstände auf die Bewerbungsmodalitäten für die Volksrichterkurse hin, SAPMO, DY 30 IV 2/13/404. Diese schnelle Reaktion läßt sich wohl vor allem auf Kleikamp zurückführen, der auch sonst versuchte, den SPD-Einfluß etwa durch Vermittlung von Dozenten aus der eigenen Partei - zu sichern: siehe Kleikamp an Hoeniger, 18. 1. 1946, BAB, DP1 SE Nr. 3561.

${ }^{227}$ So Wende in seinem autobiographischen Bericht: vgl. Welsh, Revolutionärer Wandel, S. 153.

${ }^{228}$ Siehe CDU-Bezirksverband Leipzig [Carl Günter Ruland] an Schiffer, 21. 11. 1945, BAB, DP1 SE Nr. 3561.

${ }^{229}$ Die Stellungnahme des Reichsverbandes in: Welsh, Revolutionärer Wandel, S. 154. Vgl. auch die Äußerung von Lentz (CDU) in einer Dienstbesprechung am 16. 5. 1947, BAB, DP1 VA Nr. 7354.

${ }^{230}$ So der CDU-Landesvorsitzende Ernst Zborowski im Mai 1948, zit. nach Pohl, Justiz in Brandenburg (Manuskript), S. 104. 
Thüringer LDP bei diesem Schritt: „Unsere grundsätzliche Zurückhaltung gegenüber der Einrichtung für Volksrichter“, so der Landesvorstand, „darf nicht dazu führen, in der Ausübung des uns zustehenden Vorschlagsrechts nachlässig zu verfahren und uns dadurch gegenüber den Volksrichtern aus den Reihen der anderen Parteien beiseite drängen zu lassen. Überdies bedeutet die Volksrichterlaufbahn in jedem Falle eine Gelegenheit, eine sichere und geachtete Lebensstellung zu erlangen." 231 Den Erfolg dieser Bemühungen bezeugte die Thüringische Landeszeitung mit einer Notiz vom 28. September 1947: Denn von den 128 Vorschlägen für den 3. Volksrichterlehrgang stammten 58 von der LDP (und 70 von der SED), während die Union keine Kandidaten stellte ${ }^{232}$. Insgesamt engagierten sich die bürgerlichen Parteien jedoch in dieser Hinsicht sehr viel weniger als KPD und SED.

Das KPD-Sekretariat betonte bereits im März 1946 die hohe Bedeutung der Richterschulen für die „Demokratisierung der Justiz“ und bat die Bezirksleitungen vor allem um eine sorgfältige Auswahl der Kandidaten. Diese sollten nicht auf Bewerbungen warten, sondern "geeignete Genossen“ ansprechen und für die Richterausbildung gewinnen ${ }^{233}$. Ein Rundschreiben des SED-Zentralsekretariats vom 12. Juli wiederholte diese Aufforderung und wies darüber hinaus darauf hin, daß "nur hochqualifizierte Bewerber" in Frage kämen, die nicht notwendigerweise Parteimitglieder sein müßten ${ }^{234}$. Am 30. Juli 1946 schließlich wurden die Landesvorstände aufgefordert, auf ausreichende Grammatik- und Orthographiekenntnisse zu achten und notfalls bei der Abfassung der Bewerbungsgesuche zu helfen, um zu verhindern, daß die eigenen Kandidaten bei dem Auswahlverfahren der Landesverwaltungen scheiterten. Wichtiger war indes die Anweisung, „doppelt soviel Vorschläge [sic] ein[zu]reichen wie Plätze für den neuen Kursus vorhanden sind, damit bei der endgültigen Auswahl vor den Behörden, wo mit einer Ausschaltung vieler Bewerber zu rechnen ist, von Seiten [sic] unserer Partei unbedingt stets genügend Vorschläge vorhanden sind" 235 .

Wenngleich die DJV ihren Vorschlag, daß jede Partei gleich viele Anwärter nominieren sollte, bei der SMAD-Rechtsabteilung durchsetzen konnte ${ }^{236}$, stellte die SED in den ersten drei Lehrgängen die überwältigende Mehrheit der Hörer. Dazu trug nicht nur die Zurückhaltung der bürgerlichen Parteien bei der Nominierung der Kandidaten bei, sondern auch, daß die SED-Mitglieder aufgrund einer entsprechenden parteipolitischen Zusammensetzung der Auswahlkommissionen oftmals die besseren Chancen besaßen. So befanden sich etwa unter den $220 \mathrm{Kan}$ didaten für den dritten Lehrgang in Sachsen 103 LDP- und nur 86 SED-Mitglieder. Ausgewählt wurden insgesamt 85 Personen, von denen 57 der SED und nur

231 Rundschreiben des LDP-Landesverbands an dic Kreisgruppen, 5. 2. 1947, BAB, DP1 SE Nr. 3145, Bl. 299.

232 Schule der Volksrichter, in: Thüringische Landeszcitung, 28. 9. 1947, BAB, DP1 SE Nr. 3545. Zum LDP-Vorbereitungskurs für Volksrichter siehe auch Weber, Justiz und Diktatur, S. 48.

${ }^{233}$ Rundschreiben vom 28. 3. 1946 in: Dokumente zur Geschichte der kommunistischen Bewegung, Bd. 3, S. $467 \mathrm{f}$.

${ }^{234}$ Rundschreiben des SED-Zentralsekretariats, 12.6. 1946, SAPMO, DY 30 IV 2/13/445. Am 16. 7. 1946 wurde in einem weiteren Rundschreiben u. a. diese Aufforderung wiederholt, ebenda.

235 Rundschreiben des SED-Zentralsekretariats, 30.7. 1946, in: Wentker, Volksrichter, Dok. 15, S. 134. Dieser Satz ist auch zit. bei Pfannkuch, Volksrichterausbildung, S. 43.

236 Vgl. S. 151. 
18 der LDP angehörten ${ }^{237}$. Für den dritten Kurs in Mecklenburg waren 70 Kandidaten nominiert worden, darunter 32 SED- und 20 CDU-Angehörige; von den 43 Teilnehmern, für die sich die Auswahlkommission am 15. August entschieden hatte, besaßen 29 das Parteibuch der SED, aber nur 7 das der CDU238. Insgesamt 74,3 Prozent aller Schüler des ersten Lehrgangs gehörten den beiden Arbeiterparteien bzw. der SED an ${ }^{239}$. Auch im zweiten Lehrgang konnte die SED ihre vorherrschende Stellung sichern, indem sie 150 von insgesamt 193 Teilnehmern (77,7 Prozent) in vier Kursen stellte ${ }^{240}$. Im dritten Lehrgang schließlich gehörten 158 von 220 Schülern (71,8 Prozent) in allen Ländern außer Thüringen der SED an. Diese einem Bericht vom 19. September 1947 beigefügten Zahlen zeigen indes auch, daß der genuine Arbeiteranteil in den vier Kursen insgesamt relativ gering war; die weitaus meisten Schüler waren vorher als Angestellte oder in freien Berufen tätig gewesen (142 von 220, also 64,5 Prozent). Nur wenn man ihre Herkunft, also die schichtenspezifische Zuordnung der Eltern zugrundelegte, konnte geltend gemacht werden, daß die Mehrheit aus dem Arbeiter-, Handwerker- oder Bauernmilieu stammte (141 von 220, also 64,1 Prozent) ${ }^{241}$.

Trotz aller Bemühungen gelang es der SED nicht, genügend politisch und fachlich geeignete Kandidaten vorzuschlagen. Auf den SED-Juristenkonferenzen im August 1946 und im März 1947 wurde zum Teil heftige Kritik an der Auswahl der Volksrichterschüler geübt. Das Versagen der Partei wurde dabei unter anderem von Karl Schultes aus Thüringen zum Teil auf das Desinteresse der Landesparteiorganisation zurückgeführt. Jedenfalls seien, so Benjamin, weder die politische Eignung und Bewährung der vorgeschlagenen Genossen noch deren Bildungsstand ausreichend gewesen; nicht nur von Hans Gerats (Halle) wurden in diesem Zusammenhang mangelnde Orthographiekenntnisse und unzureichende sprachliche Fähigkeiten genannt. Hinzu kamen die Probleme von SED-Mitgliedern mit den Richterkursen. So hatten nach dem Bericht des Leiters des sächsischen Lehrgangs Wilhelm Weiland eine Reihe von Genossen kritisiert, daß ihre Ausbildung viel zu wissenschaftlich und zu unpolitisch sei. Andere hatten Gerats zufolge sich nicht von ihren Vorurteilen im Hinblick auf die Justiz befreien können und betrachteten diese immer noch als Klassenjustiz ${ }^{242}$. Dabei war es insbesondere das Konkurrenzverhältnis zu CDU und LDP, das die Mehrzahl der versammelten SED-Juristen auf eine bessere Qualifizierung der von ihnen vorgeschlagenen

${ }^{237}$ Siehe Pfannkuch, Volksrichterausbildung, S. 63. Insgesamt traten nur 77 Teilnehmer den Lehrgang in Bad Schandau an, von denen 56 der SED und nur noch 7 der LDP angehörten: vgl. ebenda und Bericht über den Beginn des 3. Volksrichter-Lehrgangs, in: Wentker, Volksrichter, Dok. 19, S. 156.

238 Vermerk, 15. 8. 1947, BAB, DP1 SE Nr. 3554. Letztlich traten 44 Personen den Lehrgang an; von diesen waren 36 in der SED und nur 5 in der CDU: siehe Wentker, Volksrichter, Dok. 19, S. 154. Dies hängt wahrscheinlich damit zusammen, daß die laut Vermerk vom 15. 8. 1947 aufgenommenen 2 FDGB- und 4 VVN-Mitglieder ebenfalls der SED angehörten.

239 Berechnet nach Amos, Justizverwaltung, S. 159, sowie (für Brandenburg) nach Referat Benjamins, o.D., in: Wentker, Volksrichter, Dok. 14, S. 129.

${ }^{240}$ Die Zahlenangaben in: DJV an Rechtsabteilung der SMAD, 22. 11. 1946, BAB, DP1 SE Nr. 3478. Zu Sachsen-Anhalt liegen keine Zahlen vor.

241 Bericht über den Beginn des 3. Volksrichter-Lehrgangs, in: Wentker, Volksrichter, Dok. 19, S. 154157.

${ }^{242}$ Stenographische Niederschrift über die Juristen-Konferenz am 3./4. 8. 1946, SAPMO, DY 30 IV 2/1.01/13, Bl. 48 f., 71 und 79; Stenographische Niederschrift über die 1. Juristenkonferenz der SED in Berlin am 1./2. 3. 1947, SAPMO, DY 30 IV 2/1.01/37, Bl. $59 \mathrm{f}$. 
Kandidaten drängen ließ. Vor allem im März 1947 befürchteten die SED-Juristen, daß die bürgerlichen Parteien neue Schüler präsentieren würden: Die SED, so Benjamin, müsse daher mit erstklassigen Kandidaten aufwarten, die es mit diesen aufnehmen könnten ${ }^{243}$. Umgesetzt wurde diese Forderung in einem Beschluß des SED-Zentralsekretariats am 13. März 1947, demzufolge die Landesvorstände anzuweisen waren, „in Zukunft zu den Lehrgängen für Volksrichterschulen nur solche Kräfte vorzuschlagen, die für die Ausbildung als Volksrichter geeignet und befähigt" seien ${ }^{244}$. Das wahrscheinlich von Götz Berger verfaßte SED-Rundschreiben vom 29. März 1947 benannte als Voraussetzungen für die Teilnahme an den Lehrgängen erstens die „klare Erkenntnis der politischen Notwendigkeit der richterlichen und staatsanwaltlichen Tätigkeit“, zweitens „geistige Aufnahmefähigkeit" sowie "die Fähigkeit sich in Wort und Schrift (Beherrschung der Orthographie) gewandt auszudrücken“ und drittens „eine saubere politische und moralische Vergangenheit“. Diese "erhöhten Anforderungen“, so hieß es weiter, „dürfen aber nicht dazu führen, daß das bisher zu stellende Kontingent sich verringert. " ${ }^{245}$ Mit der Anweisung, den höheren Ansprüchen bei der Auswahl der Kandidaten gerecht zu werden, ohne deren Anzahl zu verringern, stellte das Zentralsekretariat die Landesvorstände jedoch vor ein kaum lösbares Problem, das sich zusätzlich verschärfte, als mit Befehl Nr. 193 die Anzahl der auszubildenden Volksrichter drastisch erhöht wurde.

Die Parteiorganisationen wurden ebenfalls angehalten, die Zentrale über die Verhältnisse an den Schulen zu unterrichten und sich, soweit sie dies konnten, um die Lehrgänge zu kümmern. Neben der Gewinnung neuer, geeigneter Lehrkräfte ging es vor allem um die politische Betreuung der Hörer ${ }^{246}$. Aber auch auf diesem Feld, so die führenden SED-Juristen, hatte die Partei versagt. Benjamin unterschied dabei zwischen einem theoretischen und einem organisatorischen Problem. So sei die Partei noch nicht in der Lage, „die Erscheinungen des Rechtslebens [...] restlos einzuordnen und in eine Synthese mit unserem marxistischen Wissen zu bringen“. Dies führe oft dazu, daß beispielsweise Widersprüche zwischen juristischen und marxistischen Definitionen nicht aufgelöst werden könnten und daher bei den Teilnehmern das Gefühl aufkomme, man könne entweder juristisch oder marxistisch argumentieren. Zudem halte die SED keinen persönlichen Kontakt zu den Schülern. Bei manchen Genossen sei „Überradikalismus“ die Folge gewesen, und sie hätten unter Berufung auf das eigene revolutionäre Bewußtsein das juristische Fachwissen als „Rechtsformalismus und Paragraphenreiterei“ abgelehnt. Bei anderen wiederum sei „das politische Grundwissen [...] versackt“, so daß diese sich ausschließlich um ihre juristische Fachausbildung gekümmert hätten ${ }^{247}$.

${ }^{2+3}$ Ebenda, Bl. 46. Schon auf der Konferenz vom August 1946 hatte Weiland ähnliche Befürchtungen geäußert.

244 Protokoll der Zentralsekretariatssitzung 13. 3. 1947, SAPMO, DY 30 IV 2/2.1/71, TOP 19c.

245 Berger hatte auf der SED-Juristenkonferenz vom 1./2.3. 1947 den Inhalt des Rundschreibens teilweise wörtlich vorweggenommen, SAPMO, DY 30 IV 2/1.01/37, Bl. 74 f. Das Rundschreiben in: Wentker, Volksrichter, Dok. 17, S. 147.

${ }^{246} \mathrm{Vgl}$. dazu schon das Rundschreiben vom 28.3. 1946 in: Dokumente zur Geschichte der kommunistischen Bewegung, Bd. 3, S. 468.

${ }_{247}$ Stenographische Niederschrift über die Juristen-Konferenz am 3./4. 8. 1946, SAPMO, DY 30 IV 2/1.01/13, Bl. 50-52. Auch auf der Juristenkonferenz vom März 1947 erwähnte Benjamin Mängel „in der ideologischen Betreuung und Ausrichtung der Schüler“; ein Absolvent aus Sachsen-Anhalt 
Die SED versuchte ebenfalls, auf die Gestaltung der Vorlesung „Rechtssoziologie" Einfluß zu nehmen. Wie Polak im August 1946 darlegte, war diese Vorlesung ursprünglich - wohl im Frühjahr 1946 - in der DJV ausgearbeitet, von der SMAD-Rechtsabteilung aber abgelehnt worden. Die wandte sich daraufhin an das SED-Zentralsekretariat, deren Justizabteilung einen Plan „nach marxistischem Gesichtspunkt" ausarbeitete und nach Karlshorst weiterleitete ${ }^{248}$. Dieser Plan, von dem Wende annahm, er sei in Karlshorst erstellt worden, erreichte am 12. Juni die DJV; die Lehrgangsleiter wurden bei der Besprechung vom 17. August 1946 gebeten, festzustellen, „wieweit die persönlichen Voraussetzungen zur Durchführung dieser Veranstaltung bei den heutigen Lehrgängen gegeben" seien ${ }^{249}$. Da sich keine Dozenten fanden, entschloß sich die SED-Justizabteilung, im zweiten Lehrgang den Kursus in Potsdam von Mitarbeitern des zentralen Parteiapparates lesen und stenographieren zu lassen. Die überarbeiteten Stenogramme sollten nach Bestätigung durch Karlshorst ab Februar 1947 den Richterlehrgängen zur Verfügung stehen ${ }^{250}$.

Zwar lagen die Vorlesungsmanuskripte bis Anfang März 1947 vor ${ }^{251}$, aber das SED-Zentralsekretariat hatte keine Stenotypistin zur Verfügung gestellt, so daß der zweite Teil des Planes vorerst nicht verwirklicht werden konnte ${ }^{252}$. Lediglich den SED-Landesverbänden war jeweils ein Exemplar der Manuskripte zugegangen, so daß die DJV am 15. Juli über die Justizministerien der Länder die Lehrgangsleiter anwies, sich an die Landesvorstände der Partei wegen Überlassung der Texte zu wenden. Aus der Aufzählung der Themen in dem Rundschreiben geht hervor, daß in der rechtssoziologischen Vorlesung, die Götz Berger auf der SEDJuristenkonferenz vom März 1947 unverblümt „einen Kursus über dialektischen Materialismus" genannt hatte, die Geschichte im Geiste des Marxismus-Leninismus gedeutet wurde 253 . Erst am 10. November 1947 konnte die DJV der SMADRechtsabteilung die Ausarbeitungen, die inzwischen auch den Lehrgängen zugegangen waren, zukommen lassen ${ }^{254}$. Die "rechtssoziologische Vorlesung" wurde

führte an, daß von den acht Genossen, die in Halle die Prüfung bestanden hätten, höchstens vier politisch aktiv seien: SAPMO, DY 30 IV 2/1.01/37, Bl. 46, 50.

248 Stenographische Niederschrift über die Juristen-Konferenz am 3./4. 8. 1946, SAPMO, DY 30 IV 2/1.01/13, Bl. 95.

249 Vermerk Wendes vom 31. 7. 1946, SAPMO, DY 30 IV 2/13/445; Niederschrift über die Besprechung vom 17. 8. 1946, BAB, DP1 SE Nr. 3556.

$250 \mathrm{Vgl}$. neben den Äußerungen Polaks auf der SED-Juristenkonferenz auch Benjamin an Wende, 18. 12. 1946, BAB, DP1 SE Nr. 3552.

251 Stenographische Niederschrift über die 1. Juristenkonferenz der SED in Berlin am 1./2.3. 1947, SAPMO, DY 30 IV 2/1.01/37, Bl. $78 \mathrm{f}$. Aus dem Protokoll geht hervor, daß Benjamin nicht informiert worden war.

252 Justizministerium Brandenburg an DJV, 3. 6. 1947, BAB, DP1 SE Nr. 3552.

${ }_{253} \mathrm{DJV}$ an Landes- und Provinzialregierungen/Justizministerien, 25. 6. 1947, ebenda. Darin wurden folgende Themen genannt: „Der antike Sklavenstaat“, „Der Feudalstaat", „Zerfall des Feudalstaates und Entstehung des bürgerlichen Staates“, „Rechts- und Staatslehre in der Epoche der englischen und französischen Revolution", „Die Oktoberrevolution in Rußland und die sowjetischen Verfassungen“, „Die bürgerliche Revolution in Deutschland“, „Die Weimarer Republik“, „Das Hitler-Regime“, "Unser Kampf gegen das Monopol-Kapital“ und „Die jetzige Lage“.

${ }^{254}$ Chef der DJV an Rechtsabteilung der SMAD, 10.11. 1947, ebenda. Zur Verzögerung hatte auch beigetragen, daß der DJV Ende September kein Papier zur Vervielfältigung der Manuskripte zur Verfügung gestanden hatte: Abteilung Justiz an Fechner und Ulbricht, 26. 9. 1947, SAPMO, NY 4182/1120, Bl. 121. 
jedoch, wie etwa der Potsdamer Lehrgangsleiter mitteilte, von den Schülern oft nicht ernst genommen. Auf Benjamins Anregung erteilte die DJV daraufhin im Februar 1948 die Weisung, die soziologische Vorlesung sowohl in Übungen als auch im Rahmen der Abschlußprüfung zu berücksichtigen 255 .

Insgesamt war in den Jahren bis 1948 der SED-Einfluß auf die Volksrichterkurse begrenzt. Es gelang der Partei zwar, die Lehrgänge mit ihren Mitgliedern zahlenmäßig zu dominieren, jedoch handelte es sich dabei oft weder um politisch noch fachlich besonders geeignete Kräfte. Wenngleich die SMAD-Rechtsabteilung die Gestaltung der rechtssoziologischen Vorlesung der SED überließ, konnten aufgrund von Organisationsmängeln die ausgearbeiteten Skripte erst dem dritten Volksrichterlehrgang zur Verfügung gestellt werden. Die Kurse waren folglich bis 1948 noch kaum ideologisiert. Die Abteilung VI der DJV, deren Leiter daran festhielten, daß auch der Unterricht an den Volksrichterschulen wissenschaftlich fundiert sein müsse, nutzte ihren Handlungsspielraum in diesen Jahren zu einer Optimierung der juristischen Ausbildung und wurde darin von den Lehrgangsleitern unterstützt. Dabei war es vor allem die SMAD-Rechtsabteilung, die diesen Bestrebungen Grenzen setzte, etwa indem sie anordnete, keine Schüler aufgrund von fachlichen Mängeln auszuschließen. Auch der Erlaß von Befehl Nr. 193, der zwar deutlich machte, daß die SMAD nunmehr verstärkt auf Volksrichterkurse setzte, um die Frage des juristischen Nachwuchses zu lösen, erlaubte der DJV eine Fortsetzung ihres bisherigen Kurses, der auf eine möglichst hochwertige juristische Qualifikation der Lehrgangsteilnehmer setzte.

\section{Die Weiterbildung der Volksrichter (1946-1948)}

Über die Notwendigkeit, das Justizpersonal und besonders die Volksrichter weiterzubilden, herrschte von Anfang an Einigkeit. Schiffers Zielsetzung, die Kluft zwischen Volk und Justiz zu überwinden, bildete den Hintergrund für eine Anweisung der DJV vom 6. April 1946, der zufolge die rein fachliche Weiterbildung der Richter und Staatsanwälte nicht ausreichte; um die Verbundenheit der Rechtsprechung "mit der politischen, sozialen und wirtschaftlichen Entwicklung des Volkes“ zu erhalten, müßten auf den regelmäßig abzuhaltenden Fortbildungsveranstaltungen am Sitz der einzelnen Landgerichte neben fachwissenschaftlichen Vorträgen auch solche politischen Inhalts gehalten werden. Daß dabei „alle Auffassungen mit gleichem Recht zur Geltung kommen" und keine einseitigen parteipolitischen Einflußnahmen ermöglicht werden sollten, war für die Verantwortlichen in der DJV „selbstverständlich“256. Wenngleich von Karassjow ausdrücklich unterstützt ${ }^{257}$, erwies sich die Umsetzung der Rundverfügung unter den Bedingungen der unmittelbaren Nachkriegszeit als schwierig; trotz einer erneuten Aufforderung gleichen Inhalts im Oktober 1946 ließ „die systematische und politi-

255 Benjamin an Hartwig, 9. 2. 1948; DJV an Landesregierungen/Justizministerium, 17. 2. 1948, BAB, DP1 SE Nr. 3552.

${ }^{256} \mathrm{DJV}$ an Landes- und Provinzialverwaltungen/Abt. Justiz, 6. 4. 1946 BAB, DP1 VA Nr. 6782.

257 Chef der Rechtsabteilung der SMAD an Chef der DJV, 21. 5. 1946, BAB, DP1 SE Nr. 3548. 
sche Fortbildung der Richter und Staatsanwälte“ im Februar 1947 „vielfach noch zu wünschen übrig “258.

Sehr viel wichtiger wurde die fachliche Fortbildung der Volksrichter, da sie mit ihrer kurzen Ausbildung den Anforderungen der Praxis nicht gerecht werden konnten ${ }^{259}$. Eine "weitere systematische Schulung" erschien daher nicht nur Wende und Benjamin, sondern auch den Lehrgangsabsolventen als „unerläßlich“. Die Planung von Fortbildungsveranstaltungen mußte Wende zufolge zentral erfolgen, um zu verhindern, daß die Länder aufgrund anfallender Kosten und anderer damit verbundenen Schwierigkeiten ganz darauf verzichteten ${ }^{260}$. In einer Rundverfügung setzte er für das erste Jahr nach der Abschlußprüfung vier einwöchige Freizeiten zu diesem Zweck fest; wie viele weitere Veranstaltungen im zweiten Jahr folgen sollten, wollte er von den Ergebnissen der ersten Freizeiten und von der praktischen Arbeit der Absolventen abhängig machen. Des weiteren kündigte er für die selbständige Weiterbildung der Absolventen und Richter im Soforteinsatz sogenannte "Schulungsbriefe" der DJV an, in denen besonders wichtige und für Anfänger schwierige Fragen der Praxis knapp behandelt werden sollten ${ }^{261}$. Ab Ende 1946 wurden nachweislich derartige Fortbildungsveranstaltungen für Volksrichter in den Ländern abgehalten; nur waren sie meist kürzer als von Wende vorgesehen und fanden zu selten statt ${ }^{262}$.

In Anbetracht der lückenhaften Ausbildung galt es darüber hinaus, die Weiterbildung der Absolventen zu systematisieren. Die DJV empfahl daher in Anlehnung an die Praxis einiger Länder am 9. Oktober 1946, einem „bestimmten Sachbearbeiter oder auch dem Leiter des Lehrgangs die ständige Betreuung der neuen Richter und Staatsanwälte" zu übertragen. Dieser wiederum hatte monatlich der DJV Bericht zu erstatten, damit, wie es in der Rundverfügung hieß, „aus dem Vergleich der in allen Ländern und Provinzen gemachten Erfahrungen für alle der größtmögliche Nutzen gezogen werden kann“263. Die Landesjustizabteilungen handelten entsprechend: In Sachsen beispielsweise wurde Kurt Ebert mit der Betreuung der Absolventen beauftragt ${ }^{264}$. Dieser forderte seine ehemaligen Schüler auf, ihm monatlich über Art und Umfang der ausgeübten Tätigkeit, über die Anzahl der erledigten Sachen, über die Unterstützung durch die bisherigen Berufsrichter und darüber zu berichten, „was an der Ausbildung auf Grund der jetzigen

258 DJV an die Präsidenten der Landes- und Provinzialverwaltungen, 28. 10. 1946, ebenda; Hartwig an Abt. II, III und IV, 18. 2. 1947, ebenda.

${ }^{259}$ So im Rückblick Wende, Autobiographischer Bericht, BAK, Kl. Erw. Nr. 116, Bl. 23.

260 Vermerk Wendes für Melsheimer, November 1946, BAB, DP1 VA Nr. 6335, Bl. 123 f. Darin stellte Wende fest, daß er mit der Auffassung Hilde Benjamins „zur Sache [...] übereinstimme“.

$261 \mathrm{DJV}$ an die Landes- und Provinzialverwaltungen/Abt. Justiz, November 1946, Konzept, in: Wentker, Volksrichter, Dok. 29, S. 204 f. Daß die Rundverfügung abgeschickt wurde, geht aus einem Schreiben Eberts an den SED-Landesvorstand in Dresden vom 19.2. 1947, BAB, DP1 SE Nr. 3561, hervor.

262 Derartige Veranstaltungen fanden in Bad Schandau vom 28.-30. 12. 1946 und vom 5.-10. 5. 1947; in Halle am 27./28. 4. 1947 und in Schwerin vom 18.-28.8. 1947 statt. Siehe dazu den Bericht Eberts an das sächsische Justizministerium, 6. 1. 1947, BAB, DP1 VA Nr. 1032, Bl. 7-10, sowie die Berichte über die Dienstreisen nach Bad Schandau, 5. 6. 1947, nach Halle, 2. 5. 1947, und nach Schwerin, 28. 8. 1947, alle in: BAB, DP1 SE Nr. 3561.

${ }^{263}$ DJV an Landes- und Provinzialverwaltungen/Abt. Justiz, 9. 10. 1946, BAB, DP1 VA Nr. 6335, Bl. 121.

${ }^{264}$ Vizepräsident der Landesverwaltung Sachsen/Justiz an DJV, 31. 10. 1946, ebenda, Bl. 127. 
Erfahrungen mangelhaft gewesen ist und einer Abänderung bedarf". Zudem plante er ein Treffen der Absolventen, das zum Erfahrungsaustausch und zur Weiterbildung genutzt werden sollte ${ }^{265}$. Im Laufe der Zeit erhielt Ebert auch Durchschriften von deren Entscheidungen, von Anklageschriften und Beschlüssen; er selbst wiederum fand sich bereit, Anfragen ehemaliger Schüler zu beantworten ${ }^{266}$. Während damals der enge Kontakt zwischen Betreuer und Absolventen also dazu dienen sollte, diese weiter zu qualifizieren und die Ausbildung in den Kursen zu optimieren, wurden damit auch Möglichkeiten zur Kontrolle und Überwachung des Justizpersonals geschaffen.

Die Notwendigkeit und allgemeine Akzeptanz der Weiterbildung ermöglichten auch deren Mißbrauch zur ideologischen Beeinflussung und Justizsteuerung. Dies verdeutlichen zwei Vorträge auf einer Tagung zur Fortbildung von 141 Richtern und Staatsanwälten in Schwerin am 21./22. April 1947, an der auch der dortige Richterlehrgang teilnahm. Aus Berlin war Melsheimer angereist, der im Rahmen seiner Ausführungen über „Richtertum und Politik“ eine die „progressive Auffassung" der Richter widerspiegelnde Rechtsprechung forderte und die Gewaltenteilung als „eine überholte Angelegenheit“ bezeichnete ${ }^{267}$. Der Schweriner Oberlandesgerichtspräsident Wolfgang Lange (SED) kritisierte in seinem Vortrag über „Die Fehlerquellen der bisherigen Rechtsprechung der Gerichte in Strafsachen und die Wege zu ihrer Abstellung" vor allem die zu milden Urteile bei Wirtschaftsverbrechen; als Gegenmaßnahmen schlug er unter anderem eine „verstärkte Leitung und Kontrolle der Gerichte" sowie die Angabe der Gründe für Abweichungen zwischen dem vom Staatsanwalt beantragten und dem vom Gericht verhängten Strafmaß vor. Den Volksrichtern riet er, sich bei jeder Strafsache zunächst zu überlegen, „ob eine strafwürdige Handlung vorliegt, und welche Strafe das Volk als Sühne verlangt", und erst dann über das für die Aburteilung in Frage kommende Gesetz nachzudenken und eventuell im Kommentar nachzuschlagen. Lange bezeichnete es zudem als deren Aufgabe, „im Wege der Auslegung des veralteten Gesetzes nach Möglichkeit dem Rechtsbewußtsein des Volkes Rechnung zu tragen“, und scheute sich in diesem Zusammenhang nicht, „vom gesunden Menschenverstand oder dem gesunden Volksempfinden“" zu sprechen ${ }^{268}$. Er wollte damit zwar nicht die im Dritten Reich möglichen, mit Kontrollratsproklamation Nr. 3 vom 20. Oktober 1945 jedoch verbotenen Verurteilungen aufgrund von "Analogie“ und unter Rückgriff auf das "gesunde Volksempfinden“ wieder einführen ${ }^{269}$; der Gebrauch des Begriffs verweist indes darauf, daß sowohl die NSDAP als auch die SED vorgaben, das Recht im Sinne des Volkes zu handhaben, obwohl sie letztlich nur die Indienstnahme des Rechts durch die Politik beabsichtigten.

${ }^{265}$ Zentralstelle der Ausbildungslehrgänge für Richter und Staatsanwälte in Sachsen, Rundschreiben Nr. 1, 4. 11. 1946, ebenda, Bl. 131.

${ }^{266}$ MdJ Sachsen, Ausbildungslehrgang für Richter und Staatsanwälte an DJV, 6. 11. 1947, BAB, DP1 SE Nr. 3549.

${ }^{267} \mathrm{Vgl}$. Bericht Heinrichs an die DJV vom 5. 5. 1947, BAB, DP1 VA Nr. 7355; dort auch das Referat Melsheimers.

268 Referat Langes in: BAB, DP1 SE Nr. 3550.

269 Siehe Kontrollratsproklamation Nr. 3, II, Abs.3, in: Amtsblatt des Kontrollrats, Nr. 1, 29. 10. 1945, S. 22. 
Auch die Militärverwaltung nutzte solche Zusammenküfte zur Einflußnahme auf Richter und Staatsanwälte. So initiierte die SMAD-Rechtsabteilung eine groß angelegte, von 200 Personen besuchte Fortbildungsveranstaltung vom 2. bis 4. August 1947 in Halle. Zur Teilnahme verpflichtet waren die Volksrichter, Volksstaatsanwälte und die Richter im Soforteinsatz; eingeladen wurden alle in Halle beschäftigten Volljuristen und Referendare sowie die Landgerichtspräsidenten und Oberstaatsanwälte des Oberlandesgerichtsbezirks; auch der dortige Volksrichterlehrgang war anwesend 270 . Die Referate befaßten sich zum einen mit Rolle und Aufgaben des Richters, insbesondere des Volksrichters, und zum anderen mit juristischen Fachfragen ${ }^{271}$. Der stellvertretende Leiter der SMAD-Rechtsabteilung, Oberst Bukanow, nutzte die Gelegenheit zu heftiger Gerichtskritik. In deutlichen Worten bemängelte er eine Reihe seiner Meinung nach zu milder Urteile und gab vor diesem Hintergrund zwei allgemeine Anweisungen: Der Richter müsse „sich in die Forderungen der heutigen Zeit hineinfinden“ und dürfe „nicht über dem Volk stehen“, sondern müsse mit diesem zusammengehen. Seine Ausführungen gipfelten in dem Satz: „Er [der Richter] braucht nicht alle Gesetze zu kennen, aber die Forderungen der Zeit muß er kennen." Deutlicher konnte kaum ausgedrückt werden, daß die Richter sich weniger an abstrakte Normen, sondern an die Vorgaben der SMAD zu halten hatten, die festlegte, was unter den Gegenwartsforderungen zu verstehen war. Auf die unsicheren, noch unerfahrenen Lehrgangsabsolventen wie auf die Volksrichterschüler dürften diese Worte aus dem Mund eines der ranghöchsten Offiziere der SMAD-Rechtsabteilung ihre Wirkung nicht verfehlt haben.

Auf Veranlassung Bukanows wies die DJV am 11. September 1947 die Landesjustizministerien an, innerhalb der nächsten zwei Monate ähnlich angelegte Veranstaltungen durchzuführen, zu denen der gleiche Teilnehmerkreis einzuladen war $^{272}$. So sollte sichergestellt werden, daß die Leitlinien der SMAD nicht nur die Volksrichter, sondern auch die berufstätigen Richter und Staatsanwälte sowie die Referendare erreichten. Entsprechende Fortbildungstagungen mit ähnlichen Inhalten und teilweise sogar den gleichen Referenten ${ }^{273}$ wurden daraufhin in allen Ländern außer Sachsen durchgeführt ${ }^{274}$. Der Bericht Hartwigs über die Tagung in Potsdam zeigt, daß neben der SMAD-Rechtsabteilung auch die SED diese Veranstaltung nutzte, um ihre justizpolitischen Vorstellungen zu verbreiten. Oberstleutnant Jakupow beanstandete in Potsdam nicht nur die nachsichtige Urteilspraxis bei Wirtschaftsstrafverbrechen, insbesondere bei Nichterfüllung des Abgabe-

$270 \mathrm{Als}$ Indiz für die sowjetische Initiative können die Anwesenheit von Vertretern der SMADRechtsabteilung und der Sowjetischen Militäradministration in Sachsen-Anhalt sowie die Unterstützung der Sowjetischen Militärverwaltung bei der Beschaffung der Verpflegung angesehen werden: Vermerk über Fortbildungsveranstaltung in Halle, 8. 9. 1947, BAB, DP1 SE Nr. 3548.

271 Tagesordnung der Fortbildungstagung, ebenda.

272 Chef der DJV an Landesregierungen/Justizministerium, 11. 9. 1947, ebenda.

273 Auffällig ist die Anwesenheit Jakupows und Schäfermeyers sowohl auf der Tagung in Kühlungsborn am 1./2.11. 1947 (Bericht Rosenthal-Pelldrams vom 8.1. 1948, BAB, DP1 VA Nr. 987, Bl. 51-55) als auch auf der Tagung in Potsdam am 22. 11.1947 (Bericht Hartwigs vom 24. 11. 1947, in: Wentker, Volksrichter, Dok. 30, S. 205-207).

${ }^{274}$ DJV an Rechtsabteilung der SMAD, 20. 10. 1947, 12.11. 1947, BAB, DP1 SE Nr. 3476. Aus dem ersten Schreiben geht auch hervor, daß Bukanow die Anregung zur Rundverfügung vom 11.9. 1947 gegeben hatte. 
solls bei Bauern, sondern wandte sich, im Gegensatz zu Hoeniger, dagegen, „den Strafvollzug allzu human zu gestalten" ${ }^{275}$. Einem anderen Bericht zufolge kritisierte er auch die zu liberale Revisionspraxis der Landgerichte, die damit zusammenhänge, daß „die qualifizierten Richter des Landgerichts mit den Gesetzen mehr jonglier[ $t]$ en und sich nicht von den öffentlichen Interessen leiten ließen (wie die Volksrichter) und zu lebensfremd seien"276. Fraglich bleibt, welchen Wirkungsgrad diese Ausführungen besaßen. Denn von den zu Beginn der auf zwei Tage angesetzten Veranstaltung anwesenden 60 Teilnehmern war nach der Mittagspause des ersten Tages bereits die Hälfte verschwunden - ein Umstand, der sich zum Teil auf Defizite bei der Vorbereitung, aber auch darauf zurückführen läßt, daß für viele ein freies Wochenende wichtiger als eine Fortbildungstagung war277.

Bei der seit Herbst 1947 intensivierten Weiterbildung der Volksrichter wird erstmals die Tendenz erkennbar, Qualifizierungsmaßnahmen zur Justizsteuerung zu nutzen. Dies entsprach nicht dem Kurs der DJV, die mit ihren Anweisungen vor allem die fachliche Unterrichtung der Absolventen im Auge hatte. Es war somit auch hier die SMAD, die diese Akzentverschiebung vornahm. Die SED spielte demgegenüber eine untergeordnete Rolle: Abgesehen von Vorträgen prominenter Einzelpersönlichkeiten wie Melsheimer oder Wolfgang Lange trat sie bei diesen Tagungen weniger hervor. Erst als auf sowjetische Anweisungen hin Großveranstaltungen organisiert wurden, nutzte auch die SED-Parteiorganisation diese Gelegenheit, um ihren Einfluß geltend zu machen.

\section{Der Einsatz der Volksrichter (1946-1948)}

Wie die Personalpolitik im Justizwesen insgesamt, fiel der Einsatz der Volksrichter in die Kompetenz der Länder. Aufgrund ihres Auftrags, „neue Kräfte aus den demokratischen Volksschichten zum Justizdienst" heranzuziehen, und ihres Dienstaufsichtsrechts über den Personalbestand der Gerichte und Staatsanwaltschaften ${ }^{278}$ sah sich die DJV jedoch befugt, allgemeine Anweisungen zur Verwendung der Lehrgangsabsolventen zu erteilen und entsprechende Berichte von den Ländern anzufordern. Hinzu kam, daß innerhalb der DJV die Zuständigkeit nicht bei der Ausbildungs-, sondern bei der Personalabteilung lag. Dort war die von Anfang an intensiv mit der Volksrichterfrage befaßte Hilde Benjamin tätig, die somit die Möglichkeit erhielt, auf den Einsatz der Lehrgangsabsolventen maßgeblichen Einfluß zu nehmen ${ }^{279}$.

Nachdem Schiffers Vorhaben gescheitert war, Richter je nach ihren Vorkenntnissen auf den unterschiedlichen Stufen des Justizdiensts einzusetzen, bestand

275 Bericht über die Sonderveranstaltung zur Fortbildung der Absolventen der Richterlehrgänge, der Referendare und Assessoren in Potsdam am 22.11. 1947, in: Wentker, Volksrichter, Dok. 30, S. $206 \mathrm{f}$.

276 Götz Berger, Bericht über die Juristentagung in Potsdam am 22. 11. 1947, BAB, DP1 VA Nr. 13, Bl. 12-17, hier 15.

277 Vgl. Wentker, Volksrichter, Dok. 30, S. 206.

278 Vgl. Vorläufiges Statut der DJV, abgedruckt in: Amos, Justizverwaltung, S. 218-220, hier $218 \mathrm{f}$.

279 Benjamin hatte ihrem eigenen Bericht zufolge „stets eine Kartei auf [ihrem] Schreibtisch, die den Werdegang jedes Absolventen auswies": Benjamin, Volksrichter, S. 736. 
keine Alternative mehr zur Gleichbehandlung von Volksrichtern und Volljuristen. "Der Volksrichter", so Benjamin, „wird Vollrichter und soll voll berechtigt neben dem akademischen Richter stehen." Der Absolvent der Richterlehrgänge könne somit „grundsätzlich jede Stellung einnehmen [...] und sei es die eines Senatspräsidenten beim Oberlandesgericht oder die eines Generalstaatsanwalts"280. Diese Perspektiven waren 1946 noch Zukunftsmusik für die kommunistischen Justizpolitiker; zunächst einmal kam es darauf an, die Absolventen des ersten Richterlehrgangs möglichst sinnvoll einzusetzen. Das Grundproblem bestand darin, daß sie sofort als Richter oder Staatsanwälte zu fungieren hatten, gleichzeitig aber nicht überfordert werden durften. Zudem war die DJV darauf bedacht, nicht durch den Einsatz unerfahrener Kräfte an den falschen Stellen die Funktionsfähigkeit der Justiz insgesamt zu beeinträchtigen. Auch die SMAD-Rechtsabteilung war sich des Problems bewußt. Auf ihre Weisung hin ${ }^{281}$ ging in dieser Angelegenheit am 18. Juli eine von Abteilungsleiter Winkelmann formulierte Rundverfügung an die Justizabteilungen. Darin griff er ausdrücklich auf die Erfahrungen mit den Richtern im Soforteinsatz zurück und empfahl, die Lehrgangsabsolventen auf Staatsanwalts- und Amtsanwaltsstellen sowie als Beisitzer in Strafkammern und Zivilkammern erster Instanz, keinesfalls aber an kleinen Amtsgerichten einzusetzen, wo sie auf allen Rechtsgebieten tätig sein mußten und keine Gelegenheit hatten, sich beraten zu lassen. Gegebenenfalls sollten sogar Volljuristen auf Stellen versetzt werden, für die die Volksrichter sich noch nicht eigneten ${ }^{282}$. Insgesamt ging es darum, den Lehrgangsabsolventen die ersten Schritte in der Praxis zu erleichtern und ihnen nicht zu viel zuzumuten. Die Justizabteilungen der Landesverwaltungen teilten im wesentlichen die Auffassung der DJV und sagten einen entsprechenden Einsatz der Absolventen des ersten Richterlehrgangs zu²83.

$\mathrm{Daß}$ die noch völlig unerfahrenen Abgänger der Volksrichterkurse nach bestandener Prüfung nicht uneingeschränkt als Richter oder Staatsanwälte tätig sein konnten, wußte auch die SMAD-Rechtsabteilung. Im August 1946 wies Major Solotajew an, die Absolventen zu Beginn ihrer praktischen Tätigkeit eine dreimonatige Probezeit absolvieren zu lassen, von denen zwei Monate bei einem Amtsgericht oder einer Staatsanwaltschaft und die restliche Zeit bei einem Landgericht oder einer Amtsanwaltschaft verbracht werden mußten. Die Kandidaten sollten dabei unter Aufsicht „die volle Arbeit eines Richters oder Staatsanwalts ausführen" und auch ein entsprechendes Gehalt beziehen; am Ende der drei Monate hatte der vorgesetzte Richter oder Staatsanwalt ein Gutachten abzugeben, auf dessen Grundlage über „die endgültige Einsetzung“ des Absolventen in eine selb-

${ }^{280}$ Referat Benjamins, in: Wentker, Volksrichter, Dok. 14, S. 130. Vgl. auch Benjamin, Volksrichter in der Sowjetzone, S. 13.

281 Vgl. Aktenvermerk v. Stackelbergs, 14. 6. 1946, BAB, DP1 VA Nr. 2, Bl. 256; Vermerk Winkelmanns, 17. 7. 1946, BAB, DP1 VA Nr. 6335, Bl. 111.

${ }^{282} \mathrm{DJV}$ an Landes- und Provinzialverwaltungen/Abt. Justiz, 18. 7. 1946, in: Wentker, Volksrichter, Dok. 36, S. 219 f.

${ }^{283}$ Vgl. Landesverwaltung Mecklenburg-Vorpommern, Abt. Justiz an DJV, 30. 7. 1946, BAB, DP1 VA Nr. 6335, Bl. 115; Landesverwaltung Sachsen, Abt. Justiz an DJV, 8. 8. 1946, ebenda, Bl. 117; Provinzialverwaltung Mark Brandenburg, Abt. Justiz an DJV, 9. 8. 1946, ebenda, Bl. 118. Das Landesamt für Justiz in Thüringen hatte die Rundverfügung der DJV an den Oberlandesgerichtspräsidenten in Gera weitergeleitet (ebenda, Bl. 116), von dem jedoch ebensowenig eine Antwort vorliegt wie aus Sachsen-Anhalt. 
ständige Stellung entschieden werden sollte ${ }^{284}$. Diese Anordnung wurde am 10. September in einer Rundverfügung weitergeleitet ${ }^{285}$, so daß bereits die Absolventen der ersten Lehrgänge vor ihrem endgültigen Einsatz eine dreimonatige Probezeit absolvieren mußten.

Die Justizabteilungen sahen die Aufteilung der Einarbeitungsphase in einen Abschnitt bei einem Amtsgericht und einen weiteren bei einem Landgericht als unzweckmäßig an. Während der Leiter des sächsischen Lehrgangs Ebert aus Gesprächen mit ehemaligen Schülern den Eindruck gewann, daß die kurze Zeit an einem Landgericht nicht ausreichte, um „das notwendige Bild über Aufgaben und Verhandlungstechnik des Landgerichts “ zu vermitteln ${ }^{286}$, führte das Justizministerium in Halle an, daß die Volksrichter bei den Amtsgerichten dringend benötigt würden und ein Wechsel für diese ohne gründliche Einarbeitung unvorteilhaft sei $^{287}$. Das brandenburgische Justizministerium schließlich hatte die Absolventen zunächst überwiegend den Landgerichten zugeteilt und nur in Ausnahmefällen an Amtsgerichte überwiesen ${ }^{288}$. Alle Lehrgangsleiter sprachen sich daher bei ihrer Zusammenkunft in Bad Schandau gegen eine Trennung der Probezeit aus und empfahlen, „die Absolventen entweder einem Landgericht als Beisitzer oder einem größeren Amtsgericht zuzuteilen, bei dem sie den juristischen Rat eines Volljuristen in Anspruch nehmen können"289. Da dies communis opinio aller auf deutscher Seite Verantwortlichen war und keine Einsprüche von seiten der SMAD-Rechtsabteilung bekannt sind, ist anzunehmen, daß in der Zeit danach die Probezeit ungeteilt absolviert wurde.

Inwieweit sich die Abgänger des ersten Kurses in ihren neuen Funktionen bewährten, läßt sich letztlich nur anhand von Gerichts- und Prozeßakten beurteilen, mit denen ihre Tätigkeit an den Gerichten und Staatsanwaltschaften rekonstruiert werden kann. Da eine derartige Analyse den Rahmen dieser Darlegungen sprengen würde, soll hier ein kurzer Blick auf die Berichte über die Tätigkeit der Volksrichter genügen. Den Absolventen attestierte man insgesamt regen Eifer und großes Interesse; auf ihren neuen Stellen waren sie indes von Anfang an stark überlastet, was nicht nur auf ihre mangelnde Erfahrung, sondern auch auf den großen Arbeitsanfall bei den Gerichten zurückgeführt wurde. Probleme hatten sie vor allem in der Prozeßführung, die in ihrer Ausbildung vernachlässigt worden war. Ein Bericht aus Sachsen-Anhalt kritisierte zudem, „daß die Volksrichter fast ausschließlich in der Strafrechtspflege" unterwiesen worden seien, was ihre Einsatzmöglichkeiten stark einschränke ${ }^{290}$. Trotz aller Lücken schienen sich die Volksrichter zumindest in Sachsen nach einem halben Jahr gut eingearbeitet zu haben.

${ }^{284}$ Niederschrift über die Besprechung vom 17. 8. 1946, BAB, DP1 SE Nr. 3556.

${ }_{285} \mathrm{DJV}$ an Landes- und Provinzialverwaltungen/Abt. Justiz, 10.9. 1946, BAB, DP1 VA Nr. 6335,

Bl. 119.

286 Ebert an DJV, 15. 1. 1947, BAB, DP1 VA Nr. 1032, Bl. 6.

${ }_{287}$ Provinzialregierung Sachsen-Anhalt/Justizminister an DJV, 25.1. 1947, BAB, DP1 SE Nr. 3561.

288 DJV, Abt. II an Abt. VI, 18. 2. 1947, BAB, DP1 VA Nr. 1032, Bl. 5.

289 Vermerk Hartwigs für Benjamin, 16. 12. 1947, BAB, DP1 VA Nr. 6526.

290 Zentralstelle der Ausbildungslehrgänge für Richter und Staatsanwälte in Sachsen an DJV, 9. 11.

1946, BAB, DP1 VA Nr. 6335, Bl. 130; Provinzialverwaltung Mark Brandenburg/Abt. Justiz an

DJV, 23. 11. 1946, ebenda, Bl. 135; Landesverwaltung Mecklenburg-Vorpommern/Abt. Justiz an

DJV, 11. 11. 1946, BAB, DP1 SE Nr. 3561; Provinzialregierung Sachsen-Anhalt/Justizminister an

DJV, 25. 1. 1947, ebenda (daraus das Zitat). 
Zwar kritisierte Ebert, daß einige von ihnen zur Weiterbildung juristische Vorlesungen an den Universitäten und Repetitorien besuchten; alles in allem hätten sie aber „aus der Praxis inzwischen erhebliche Erfahrungen und Kenntnisse gesammelt, die sie von den bisherigen Berufsrichtern kaum noch unterscheiden " 291 . Zurückhaltender war die Berichterstattung aus Thüringen, wo man die Volksrichter lediglich bei den Staatsanwaltschaften als „volle Arbeitskräfte“ betrachtete; den höheren Ansprüchen, die die Arbeit an den Gerichten stellte, waren die Volksrichter einem thüringischen Landgerichtspräsidenten zufolge noch nicht gewach$\operatorname{sen}^{292}$. Ganz anders Benjamin, die geradezu euphorisch bereits im Februar 1947 darauf verwies, „daß die Klagen über den Mangel an prozessualer und praktischer Vorbildung nach den ersten 10 Wochen der Beschäftigung in erheblichem Umfang bereits behoben" seien ${ }^{293}$. Wenn sich einige Volksrichter nicht so bewährt hätten, so Benjamin einen Monat später, liege das „wohl daran, daß man sie nicht an der richtigen Stelle eingesetzt habe "294. Die unterschiedlichen Beurteilungen verdeutlichen die Problematik der vorliegenden Berichte, die eben nicht immer um ein angemessenes Urteil bemüht waren, sondern auch eine negative oder positive Voreingenommenheit gegenüber den Volksrichtern erkennen lassen.

Sowohl die grundsätzliche Einstellung zur Volksrichterfrage als auch die Leistungen der neuen Richter und Staatsanwälte führten zu einer von Land zu Land unterschiedlichen Beförderungspraxis. Am schnellsten ging das sächsische Justizministerium vor, das auf Vorschlag Eberts ${ }^{295}$ bereits zum 1. März 1947 die neun besten Absolventen des ersten Lehrgangs zu Amtsgerichtsräten ernannte ${ }^{296}$. Gegenüber der DJV bezeichnete er diese ehemaligen Schüler „als Kräfte, die in der Praxis sich außerordentlich gut bewährt haben und heute bereits als vollwertige Richter auf ihrem Gebiet angesehen werden können" 297 . Während das Potsdamer Justizressort entsprechende Ernennungen von sieben Absolventen für die nächste Zukunft in Aussicht stellte, teilte das thüringische Justizministerium lapidar mit, $\mathrm{da} ß$ die im Justizdienst befindlichen neun Absolventen noch nicht in Planstellen eingewiesen seien, und gab nicht zu erkennen, daß sich an deren Status in absehbarer Zeit etwas ändern würde ${ }^{298}$.

Ein beim Einsatz der Lehrgangsabsolventen in den ersten Jahren immer wieder auftretendes Problem betraf ihr Verhältnis zu den akademischen Richtern, auf deren Unterstützung sie angewiesen waren. Zwar gab es durchaus Beispiele für eine umfassende Hilfsbereitschaft und eine nachhaltige Förderung der Volksrich-

291 Ebert an SED-Landesvorstand Sachsen, 19. 2. 1947, ebenda. Vgl. auch seine positive Einschätzung der Absolventen des ersten Lehrgangs in seinem Bericht vom 15. 4. 1947, in: Wentker, Volksrichter, Dok. 37, S. 220 f.

292 Landesamt für Justiz, Thüringen, an DJV, 11. 4. 1947, BAB, DP1 SE Nr. 3561.

${ }^{293}$ DJV, Abt. II an Abt. VI, 18. 2. 1947, BAB, DP1 VA Nr. 1032, Bl. 5.

294 Vermerk über die Dienstbesprechung vom 13. 3. 1947, BAB, DP1 VA Nr. 7354. Vgl. auch Benjamin, Die neuen Volksrichter, S. 117.

${ }_{295}$ Ebert an SED-Landesvorstand Sachsen, 19. 2. 1947, BAB, DP1 SE Nr. 3561.

296 Vgl. Wentker, Volksrichter, Dok. 37, S. 220 f.

297 Zentralstelle der Ausbildungslehrgänge für Richter und Staatsanwälte im Land Sachsen an DJV, 16. 4. 1947, BAB, DP1 SE Nr. 6335, B1. 149.

298 Die Schreiben des thüringischen und brandenburgischen Justizministeriums vom 18. bzw. 17.4. 1947, die, ebenso wie das Schreiben Eberts vom 16.4., Antworten auf eine Anfrage der DJV vom 1. 4. 1947 darstellen, ebenda, Bl. $146 \mathrm{f}$. 
ter durch die Volljuristen; andere Absolventen klagten jedoch darüber, daß man sie sich selbst überlassen und ihnen entweder untergeordnete Tätigkeiten zugewiesen oder zu viel zugemutet habe ${ }^{299}$. Die traditionell ausgebildeten Justizjuristen brachten ihren neuen Kollegen folglich nicht immer das nötige Verständnis entgegen, was Benjamin darauf zurückführte, daß die bereits tätigen Volljuristen nicht hinreichend auf ihre Aufgaben bei der Einarbeitung der Volksrichter vorbereitet worden waren ${ }^{300}$. Daher versandte die DJV rechtzeitig vor dem Eintritt der Absolventen des zweiten Richterlehrgangs in die Praxis ein Rundschreiben, in dem sie auf die besonderen Aufgaben verwies, „die den akademisch vorgebildeten Richtern bei der Einführung der neuen Volksrichter in die Praxis" oblagen. Bei den Landgerichten wurden besonders die Kammervorsitzenden und bei den Amtsgerichten die Amtsgerichtsdirektoren und Aufsichtsrichter ermahnt, ,in taktvoller und kollegialer Weise den neuen Richter zu beraten, die von ihm abgesetzten Urteile zumindest in Stichproben zu überprüfen und auf diese Weise etwaige Fehler aufzuzeigen und Zweifelsfragen schnell zu klären"301. Inwieweit diese Anweisung befolgt wurde, läßt sich schwer nachprüfen. Die Kritik an der verständnislosen Aufnahme von Absolventen des dritten Lehrgangs an einigen sächsischen Gerichten Ende $1948^{302}$ verweist jedoch darauf, daß das Verhältnis zwischen Volksrichtern und akademischen Richtern nie ganz spannungsfrei blieb.

Da die Volksrichter ohne ein Äquivalent des Referendariats in den Justizdienst eintraten, mußten sie durch die Praxis geschult werden. Wie unterschiedlich die Länder dabei mit den Abgängern des ersten Lehrgangs verfuhren, zeigt die Auswertung einer Befragung unter den Volksrichtern im Januar 1948. Dabei hatten diese anzugeben, wie oft sie in welchen Gebieten der Justiz tätig gewesen waren. In der von Benjamin gezogenen Bilanz schnitten Sachsen und Mecklenburg am besten $\mathrm{ab}$, da man hier die Volksrichter zwar vielseitig eingesetzt (auf durchschnittlich 3,5 bzw. 2,9 Rechtsgebieten), sie aber nicht, wie in Brandenburg (Durchschnittsbeschäftigung auf 6,6 Rechtsgebieten) zu oft mit einer neuen Tätigkeit konfrontiert hatte. Sachsen-Anhalt und Thüringen hingegen hätten „die Möglichkeiten des Einsatzes der Volksrichter nicht ausgenutzt": In Thüringen hatte sich an der bereits 1947 festgestellten Haupttätigkeit der Absolventen bei den Staatsanwaltschaften nicht viel geändert. Dabei war für Benjamin eine möglichst umfassende Schulung der Volksrichter kein Selbstzweck. Indem sie zwischen der Vielfalt des Einsatzes und der Beförderung der Absolventen zu Behördenleitern und Kammervorsitzenden einen Zusammenhang herstellte, verdeut-

299 Siehe dazu den Bericht Eberts über die Tagung der Teilnehmer am 1. Ausbildungslehrgang für Richter und Staatsanwälte in der Zeit vom 28.-30. 12. 1946, BAB, DP1 VA Nr. 1032, Bl. 7-10; und die Äußerungen der Volksrichter Zielinski, Wensierski, Junius und Rehse auf der SED-Volksrichtertagung in Potsdam am 7. 9. 1947, BAB, DP1 VA Nr. 20, Bl. 5, 8, 12,17. Vgl. auch Benjamin, Von nun an, S. 121.

300 Abt. II an Abt. VI, 18. 2. 1947, BAB, DP1 VA Nr. 1032, Bl. 5.

301 Chef der DJV an Landesregierungen/Justizministerium, 2.7. 1947, BAB, DP1 VA Nr. 6335, Bl. 156.

302 Siehe Bericht über den Verlauf der 1. Fortschulungstagung der Absolventen des 3. Ausbildungslehrganges vom 20.-23.4. 1949, BAB, DP1 VA Nr. 1046, Bl. 139, und die scharfe Reaktion der DJV in einem Schreiben an das sächsische Justizministerium, 27. 5. 1949, ebenda, Bl. 143. 
lichte sie, daß es ihr vor allem darum ging, die Volksrichter möglichst rasch zu befähigen, leitende Stellungen im Justizwesen zu übernehmen ${ }^{303}$.

Die Volksrichterausbildung diente zunächst primär der Behebung des Personalmangels unter den Justizjuristen. Sie war anfangs kaum politisiert und entsprach in den Jahren von 1945 bis 1948 nicht der Vorstellung der kommunistischen Justizpolitiker in DJV und SED. Dies war auf das Zusammenwirken von drei Faktoren zurückzuführen: Erstens gab die SMAD-Rechtsabteilung 1945 zwar die allgemeine Anweisung, "Richter aus dem Volke“ in Kurzkursen auszubilden; ihr Verhalten in den ersten Jahren zeigt jedoch, daß sie nicht über ein geschlossenes Konzept zur Volksrichterausbildung verfügte. Zweitens waren die Kommunisten in der DJV und in den Landesjustizverwaltungen in der Minderheit, so daß sie ihre weitgehenden Vorstellungen gegenüber der zwar reformwilligen, aber keineswegs revolutionär gesinnten Mehrheit in den mit der Volksrichterausbildung betrauten Institutionen nicht durchsetzen konnten. Denn für diese Mehrheit der Juristen stand nicht die ideologisch-politische Schulung, sondern die fachliche Qualifizierung der angehenden Volksrichter im Vordergrund. Drittens trug eine Reihe von Sachzwängen, wie etwa der Mangel an kommunistischen Dozenten für die Volksrichterschulen, dazu bei, daß der Einfluß der SED auf die Gestaltung der Lehrgänge begrenzt blieb. Ein Wandel zeichnete sich erst $1947 \mathrm{ab}$, als die SMAD-Rechtsabteilung durch erste Eingriffe verdeutlichte, daß die Besatzungsmacht - unabhängig von der DJV - entschieden hatte, Richter und Staatsanwälte vor allem aus den Volksrichterkursen zu rekrutieren und deren Weiterbildung für Justizsteuerungszwecke zu benutzen. Damit wurde zwar der Handlungsspielraum der nicht-kommunistischen Mitarbeiter der DJV eingeengt, jedoch konnte noch bis 1948 eine Ideologisierung der Ausbildung verhindert werden.

Daneben bestand auch weiterhin die Möglichkeit, über ein juristisches Studium mit anschließendem Referendariat in den Justizdienst zu gelangen. Deren Inhalte waren aufgrund von Initiativen aus der DJV in reformerischer Absicht ergänzt, aber keineswegs revolutioniert worden. Reibungsverluste ergaben sich dabei vor allem durch Rivalitäten mit der für die Hochschulen zuständigen DVV, während sich die SMAD-Rechtsabteilung - noch stärker als bei der Volksrichterausbildung - mit Eingriffen und Empfehlungen in den Ausbildungsgang weitgehend zurückhielt. Gegenüber der Volksrichterausbildung fristete die akademische juristische Ausbildung jedoch ein Schattendasein. Abgesehen davon, daß diese weitaus länger dauerte, konnten die Universitäten aufgrund der entnazifizierten und daher stark ausgedünnten akademischen Lehrkörper nur eine begrenzte Anzahl von Studenten aufnehmen. Entscheidend war jedoch, daß viele von diesen das Referendariat nicht antraten und in andere Berufe abwanderten. Da die Anzahl der bis 1948 geprüften Assessoren verschwindend gering und „belasteten“ Referendaren seit September 1947 durch eine sowjetische Anordnung zudem der Weg in den Justizdienst versperrt war, erhielten die Kommunisten in der DJV zusätzliche Argumente für die Stärkung der Volksrichterausbildung.

${ }^{303}$ Hilde Benjamin, Tätigkeit der Absolventen des 1. Lehrganges im ersten Jahr ihrer Tätigkeit, 13. 1. 1948, BAB, DP1 SE Nr. 3561. 